Portland State University

PDXScholar

Winter 4-1-2019

\title{
A Study of Thermal Energy Storage of Phase Change Materials: Thermophysical Properties and Numerical Simulations
}

Kyung-Eun Min

Portland State University

Follow this and additional works at: https://pdxscholar.library.pdx.edu/open_access_etds

Part of the Heat Transfer, Combustion Commons

Let us know how access to this document benefits you.

\section{Recommended Citation}

Min, Kyung-Eun, "A Study of Thermal Energy Storage of Phase Change Materials: Thermophysical Properties and Numerical Simulations" (2019). Dissertations and Theses. Paper 4835.

https://doi.org/10.15760/etd.6711

This Dissertation is brought to you for free and open access. It has been accepted for inclusion in Dissertations and Theses by an authorized administrator of PDXScholar. Please contact us if we can make this document more accessible: pdxscholar@pdx.edu. 
A Study of Thermal Energy Storage of Phase Change Materials: Thermophysical Properties and Numerical Simulations

by

Kyung-Eun Min

A dissertation submitted in partial fulfillment of the requirements for the degree of

Doctor of Philosophy

in

Mechanical Engineering

Dissertation Committee:

Sung Yi, Chair

Chien Wern

Faryar Etesami

Raj Solanki

Portland State University

2019 
(c) 2019 Kyung-Eun Min 


\begin{abstract}
A Thermal Energy Storage (TES) system is meant for holding thermal energy in the form of hot or cold materials for later utilization. A TES system is an important technological system in providing energy savings as well as efficient and optimum energy use. The main types of a TES system are sensible heat and latent heat. A latent heat storage is a very efficient method for storing or releasing thermal energy due to its high energy storage density at constant temperatures, and a latent heat storage material can store 5-14 times more heat per unit volume than a sensible heat storage material can. Phase Change Materials (PCMs) are called latent heat storage materials. PCMs can save thermal energy, and use energy efficiently because PCMs can absorb thermal energy in the solid state, and the thermal energy can be released in the liquid state. Therefore, PCMs as new materials for saving energy can be applied into building applications.

PCMs have widely researched, but the current issues are lack of accurate and detailed information about thermophysical properties of PCMs to apply into buildings and inaccurate materials properties measured by existing methodology. The objective of this study is to develop a methodology and procedure to accurately determine the thermophysical properties of PCMs based on salt hydrates. TES systems of PCMs are measured and analyzed by various methods, such as DSC method and heat flow method. In addition, this study demonstrates to design a building roof with PCMs
\end{abstract}


to save energy using Finite Element Analysis (FEA).

The developed methodology is designed based on ASTM C1784-14 for measuring the thermal energy storage properties of PCMs. The thermophysical properties and thermal stabilities are evaluated by using a Differential Scanning Calorimetry (DSC), which is made with DSC Q 200 equipment from TA Instruments and DSC STA 8000 equipment from Perkin Elmer Company. The thermal conductivities are assessed by heat flow meter, which is FOX 314 equipment from TA Instruments, and the enthalpy changes of the PCMs are determined by DSC method and heat flow method. Numerical FEA to evaluate potential energy savings is conducted using ABAQUS software

Four kinds of Phase Change Materials (PCMs), which have phase changes at $21^{\circ} \mathrm{C}, 23^{\circ} \mathrm{C}, 26^{\circ} \mathrm{C}$, and $30^{\circ} \mathrm{C}$, respectively, are used for measuring the thermophysical properties. The onset/peak temperatures, the enthalpy, the heat flow, and the heat capacity of the PCMs are measured to assess the thermal energy storage system under the dynamic DSC mode. The results obtained using DSC equipment have a higher melting temperature than their own temperatures, which are known theoretically. The freezing temperatures of the PCMs are decreased by about $30^{\sim} 40^{\circ} \mathrm{C}$ compare to their theoretical freezing temperatures. It is speculated that supercooling happens during the solidification. The enthalpy change curves as a function of temperature, which are determined by DSC method and heat flow method, are indicated to assess thermal energy storage system of the PCMs. During the phase change, the energy is 
increased. This is the reason why the energy is utilized to loosen or break apart the molecular or atomic bond structures of the PCMs by the latent heat. Moreover, the enthalpy change curves determined by heat flow method show more precise results than the curves by DSC method, because various factors lead to a temperature gradient in the PCM and the heat flux signal peak being shifted toward high temperatures. Regarding the thermal conductivities results of the PCMs, the thermal conductivities of the PCMs in the solid state are higher than those of the PCMs in the liquid state. This phenomenon happens due to the effect of the microstructure changing from the orderly solid structure in the solid state to the disorderly liquid structure in the liquid state. The numerical Finite Element Analysis (FEA) is conducted to evaluate potential energy savings of a roof. The results, such as the temperature variations from the outdoor to indoor measured under step 1 (the daytime) condition, show that the outdoor temperatures are higher than the indoor temperatures. This is due to the low thermal conductivity of the PCM in the liquid state. The low thermal conductivity of the PCM reduces the heat transmission to the indoor that in turn increases the outdoor temperature.

This study shows the developed methodology and procedure, the accurate material information for the newly developed PCM, and the numerical FEA to analyze the TES systems with much more precision in the area of the PCMs. 
Dedication

To my parents Choon-Gyu Min and Eun-Ja Kim 


\section{Acknowledgements}

First and foremost, I would like to express the deepest appreciation to my advisor, Professor Sung Yi, who has always been a tremendous mentor. Without his guidance and support, I would not have completed my doctoral degree. I am grateful for his wonderful support, very encouraging words, and intensive scrutiny throughout many years to make my dissertation presentable. He has given me unforgettable memories of his patience, intelligence, and erudition. In addition, I would like to thank my other committee members, Professor Chien Wern, Professor Faryar Etesami, and Professor Raj Solanki for their deeply insightful comments, suggestions, and valuable feedback.

I would also like to thank previous advisors, Chang-Woo Lee and Jun-Ki Kim at KITECH. Without their teaching, this degree would not have been possible. Also, I would like to thank my friends, S.B. Jung, H.Y. Kim, W.J. Choi, S.Y. Cho, H.J. Lee, S.H. Lee, Chinh Vu, Tricia Hutchins, Crystal Snelson, and Sarah Santucci. In addition, I would like to express gratitude to my fiancé, Jae-Won Jang. I would have had a hard time studying without his advice.

Last but not least, I would like to thank my family: my father, Choon-Gyu Min, my mother, Eun-Ja Kim, my brother, Kyung-Su Min, and my sister, Kyung-Nan Min for their infinite encouragement and support. Words cannot express how thankful I am for their sacrifices. My doctoral degree could not have been completed successfully without their devotion and encouragement. I dedicate my dissertation to my family. 


\section{Table of Contents}

Abstract $\quad$ i

Dedication $\quad$ iv

Acknowledgements $\quad$ V

List of Tables $\quad$ X

List of Figures $\quad$ xii

Chapter 1 Introduction 1

1.1 Objectives ............................ 1

1.2 Literature review . . . . . . . . . . . . . . . . . 4

1.2.1 Thermal Energy Storage . . . . . . . . . . . . . . . . 4

1.2.1.1 Sensible Heat . . . . . . . . . . . . . . . 5

1.2.1.2 Latent Heat . . . . . . . . . . . . . . . . 5

1.2.1.3 Thermochemical Energy . . . . . . . . . . . 6

1.2.2 Classification of Phase Change Materials . . . . . . . . . . . 7

1.2.2.1 Organic PCM . . . . . . . . . . . . . . . 9

1.2.2.2 Inorganic PCM . . . . . . . . . . . . . . . . 10 
1.2.2.3 Eutectic PCM ............... . . 11

1.2.3 Applications . . . . . . . . . . . . . . . . 13

1.2.3.1 Thermal Energy Storage for Buildings . . . . . . . 13

1.2.3.2 PCM Integrated Wall . . . . . . . . . . . . . . . 14

1.2.3.3 PCM Assisted Under-Floor Heating System . . . . . 19

1.2.3.4 PCM Assisted Ceiling Boards . . . . . . . . . . . 21

1.2.3.5 PCM Integrated Roof . . . . . . . . . . . 25

1.2.3.6 Solar Water Heating Systems . . . . . . . . . . 29

1.2.3.7 Solar Air Heating Systems . . . . . . . . . . . 31

1.2.3.8 Conservation and Transport of Temperature Sensitive Materials ................. 34

1.2.3.9 Smart Textiles . . . . . . . . . . . . . . 36

1.2.3.10 Biomaterials and Biomedical Applications . . . . . 38

1.2.3.11 Electronics . . . . . . . . . . . . . . . 40

1.2.3.12 Automotive Industry . . . . . . . . . . . . 43

1.2.3.13 Space Applications . . . . . . . . . . . 44

$\begin{array}{lll}\text { Chapter } 2 & \text { Experiments } & 47\end{array}$

2.1 Phase Change Materials $(\mathrm{PCMs}) \ldots \ldots . \ldots 47$

2.2 Experimental Methods . . . . . . . . . . . . . . . 49

2.2.1 Experimental Methodology . . . . . . . . . . . . . 49 
2.2.1.1 Data Analysis . . . . . . . . . . . . . . . . . 49

2.2.2 Differential Scanning Calorimetry . . . . . . . . . . . . 58

2.2.2.1 Enthalpy Curves . . . . . . . . . . . . . . . 64

2.2.2.2 Specific Heat Capacity Calculations . . . . . . . . . . 65

2.2.3 Heat Flow Meter . . . . . . . . . . . . . . . . . . . 67

2.2.3.1 Thermal Conductivity . . . . . . . . . . . 67

2.2.3.2 Volumetric Heat Capacity . . . . . . . . . . . 69

2.2.3.3 Enthalpy Curves .............. . . 71

2.2.4 Thermal Diffusivity Calculations . . . . . . . . . . . . . . 74

2.3 Numerical Simulation . . . . . . . . . . . . . . . . . . 75

2.3.1 Verification Study . . . . . . . . . . . . . . . 75

2.3.2 Mathematical Model . . . . . . . . . . . . . . . . 77

2.3.3 Case Study: Simulation Conditions . . . . . . . . . . . . . . . 80

$\begin{array}{lll}\text { Chapter } 3 & \text { Results and Discussion } & 84\end{array}$

3.1 DSC Analysis . . . . . . . . . . . . . . . . . . . . . . 84

3.1.1 Dynamic DSC Curves . . . . . . . . . . . . . . 84

3.1.1.1 Original Phase Change Materials . . . . . . . . . . 84

3.1.1.2 Phase Change Materials Melted . . . . . . . . . . 98

3.1.1.3 Phase Change Material in Liquid State . . . . . . . . 106

3.1.2 Isothermal DSC Curves . . . . . . . . . . . . . . . . . 109 
3.1.2.1 Original Phase Change Materials . . . . . . . . . . 109

3.1.2.2 Phase Change Materials Melted . . . . . . . . . . . 113

3.1.2.3 Phase Change Material in Liquid State . . . . . . . . 115

3.1.3 Enthalpy Curves . . . . . . . . . . . . . . . . . . . 118

3.1.4 Specific Heat Capacity . . . . . . . . . . . . . . . . . . . . 130

3.2 Heat Flow Meter Analysis . . . . . . . . . . . . . . . . . 133

3.2.1 Thermal Conductivity . . . . . . . . . . . . . . 133

3.2 .2 Volumetric Heat Capacity . . . . . . . . . . . . . . . 135

3.2.3 Enthalpy Curves . . . . . . . . . . . . . . . . . . . 137

3.3 Thermal Diffusivity . . . . . . . . . . . . . . . . . . . . . 140

3.4 Numerical Simulation . . . . . . . . . . . . . . . . . . . . . 142

3.4.1 Verification Study . . . . . . . . . . . . . . . . . . . 142

3.4 .2 Case Study . . . . . . . . . . . . . . . . . . . . . . . . 148

$\begin{array}{lll}\text { Chapter } 4 & \text { Conclusions } & 153\end{array}$

$\begin{array}{ll}\text { Bibliography } & 161\end{array}$ 


\section{List of Tables}

1.1 Advantages and disadvantages of organic PCMs . . . . . . . . . . . . 10

1.2 Advantages and disadvantages of inorganic PCMs . . . . . . . . . . 11

1.3 Advantages and disadvantages of eutectic PCMs . . . . . . . . . . . . . . 12

2.1 Properties of PCMs(Infinity R Corporation [2017a]) . . . . . . . . . 48

2.2 Measurement condition of DSC analysis with the first cooling system . . 63

2.3 Measurement condition of DSC analysis with the second cooling system . 63

2.4 Temperature conditions for measuring thermal conductivities . . . . . . . 69

2.5 Temperature conditions for measuring volumetric specific heat capacity

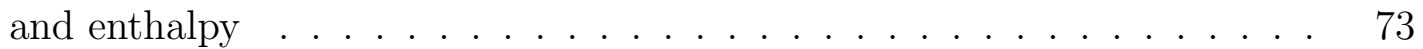

2.6 Test conditions for verification studies . . . . . . . . . . . . . 77

2.7 Internal temperature variation related to various parameters . . . . . . . 81

3.1 Thermal properties of PCMs by measuring dynamic DSC using Q 200 . . 92

3.2 Thermal properties of PCMs by measuring dynamic DSC using STA $8000 \quad 93$

3.3 The specific heat capacities, enthalpies, and total energy storage of PCMs for endothermic reaction . . . . . . . . . . . . . . . . . . . 132 
3.4 The specific heat capacities, enthalpies, and total energy storage of PCMs

for exothermic reaction . . . . . . . . . . . . . . . . . . . 132

3.5 The specific heat capacities, enthalpies, and total energy storage of PCMs for endothermic reaction . . . . . . . . . . . . . . . . . . 132

3.6 Thermal diffusivity of PCMs under endothermic reaction . . . . . . . . . 141

3.7 Thermal diffusivity of PCMs under exothermic reaction . . . . . . . . . . 141

3.8 Thermal diffusivity of PCMs under endothermic reaction . . . . . . . . . 141

3.9 Test conditions and results for verification studies . . . . . . . . . . . . . 144

3.10 Time and temperature until steady-state conditions are achieved . . . . . 152 


\section{List of Figures}

1.1 Classification of $\mathrm{PCMs} \ldots \ldots \ldots$

1.2 The micro encapsulated PCM from Microtec Lab, Inc. (Archtecture and Design Powered by Infolink $[2015]) \ldots \ldots \ldots \ldots$

1.3 A PCM integrated panel from DuPont Company (Dupont [2012]) . . . 16

1.4 Schematic of the heating system (Lin et al. [2007]) _ . . . . . . . 20

1.5 Schematic of commercial product of under-floor heating system made by NetGreen Solar Ltd. (NetGreen Solar Ltd. [2017]) . . . . . . . . . . . 21

1.6 Schematic diagram of cooled ceiling system with MPCM slurry storage tank (Wang and Niu $[2009]) \ldots \ldots \ldots \ldots \ldots$

1.7 Schematic of heat pipe and PCM applications (Turnpenny et al. [2000]) .

1.8 Schematic of TES heat pump system during the charging mode. 1) Heat pump (A. Evaporator, B. Condenser), 2) cold tank, 3) hot tank, 4) AHU, 5) outlet water-to-air heat exchanger, 6) inlet water-to-air-heat exchanger, 7) fan heater $($ Moreno et al. [2014]) . . . . . . . . . . . . 25

1.9 Schematic of the solar heating system (Socaciu $[2012 \mathrm{a}]$ ) . . . . . . . 26

1.10 The PCM integrated building roof (Pasupathy et al. [2008]) _ . . . . . 27

1.11 Schematics of test roofs (Biswas et al. [2013]) $\ldots \ldots \ldots \ldots$ 
1.12 Schematic diagram of solar water heating system (Prakash et al. [1985]) . 30

1.13 A cylindrical storage vessel with PCM storage (Ghoneim [1989]) . . . . . 30

1.14 Schematic of the air based solar heating system with Phase Change Energy Storage (PCES) (Jurinak and Abdel-Khalik [1979]) . . . . . . . . . . . . 32

1.15 Schematic of the simulation room with SSPCM (Zhou et al. [2007]) . . . 33

1.16 Schematic of the LNG refrigerated vehicle (Tan et al. [2010]) . . . . . . . 36

1.17 PCM microcapsules coated on the surface of fabric (a) and embedded in fiber (b) (Mondal [2008]) . . . . . . . . . . . . . . . . . . . 37

1.18 Schematic of PCM applied heat sink under QFP package (Kandasamy et al. [2008]) . . . . . . . . . . . . . . . . . . . . . 41

1.19 Heat receiver (Cui et al. [2003]) . . . . . . . . . . . . . . 46

2.1 Typical DSC curve for heat flux (Reading and Craig [2006]) . . . . . . . 59

2.2 Dynamic DSC temperature profile with the first cooling system . . . . . 62

2.3 Dynamic DSC temperature profile with the second cooling system . . . . 62

2.4 A comparison of stored heat in latent material and sensible material (Günther

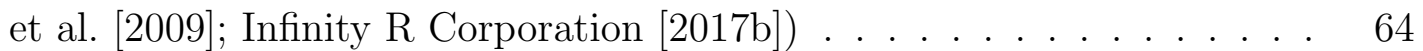

2.5 The enthalpy as a function of temperature curve of an ideal PCM . . . . 72

2.6 Al structure for verification study . . . . . . . . . . . . . . 76

2.7 A building roof . . . . . . . . . . . . . . . . . . . . 78

2.8 Geometry of a roof with the PCM . . . . . . . . . . . . . . 81 
3.1 Dynamic DSC curve of the PCM melted at $21^{\circ} \mathrm{C} \ldots \ldots$. . . . . . . 86

3.2 Dynamic DSC curve of the PCM melted at $23^{\circ} \mathrm{C} \ldots \ldots$. . . . . . 86

3.3 Dynamic DSC curve of the PCM melted at $26^{\circ} \mathrm{C} \ldots \ldots$. . . . . . . 87

3.4 Dynamic DSC curve of the PCM melted at $30^{\circ} \mathrm{C} \ldots \ldots$. . . . . . 87

3.5 Dynamic DSC curve of the PCM melted at $21^{\circ} \mathrm{C} \ldots \ldots$. . . . . . . . . 90

3.6 Dynamic DSC curve of the PCM melted at $23^{\circ} \mathrm{C} \ldots$. . . . . . . . . 90

3.7 Dynamic DSC curve of the PCM melted at $26^{\circ} \mathrm{C} \ldots \ldots$. . . . . . . 91

3.8 Dynamic DSC curve of the PCM melted at $30^{\circ} \mathrm{C} \ldots \ldots$. . . . . . . 91

3.9 Temperature properties of PCMs under endothermic reaction . . . . . . 94

3.10 Temperature properties of PCMs under exothermic reaction . . . . . . . 94

3.11 Temperature properties of PCMs under endothermic reaction . . . . . . 95

3.12 Enthalpy of PCMs under endothermic reaction . . . . . . . . . . 95

3.13 Enthalpy of PCMs under exothermic reaction . . . . . . . . . . 96

3.14 Enthalpy of PCMs under endothermic reaction . . . . . . . . . . . 96

3.15 Dynamic DSC curve of the PCM melted at $21^{\circ} \mathrm{C}$ and made into the liquid state at above room temperature . . . . . . . . . . . . 100

3.16 Dynamic DSC curve of the PCM melted at $23^{\circ} \mathrm{C}$ and made into the liquid state at above room temperature . . . . . . . . . . . . . 100

3.17 Dynamic DSC curve of the PCM melted at $21^{\circ} \mathrm{C}$ and made into the liquid state at above room temperature . . . . . . . . . . . . . . 101 
3.18 Dynamic DSC curve of the PCM melted at $23^{\circ} \mathrm{C}$ and made into the liquid state at above room temperature . . . . . . . . . . . . . . 101

3.19 Temperature properties of original PCMs and PCMs made into the liquid state measured using DSC Q 200 equipment under endothermic reaction

3.20 Temperature properties of original PCMs and PCMs made into the liquid state measured using DSC Q 200 equipment under exothermic reaction . 103

3.21 Temperature properties of original PCMs and PCMs made into the liquid state measured using DSC STA 8000 equipment under endothermic reaction 104

3.22 Enthalpy of original PCMs and PCMs made into the liquid state measured using DSC Q 200 equipment under endothermic reaction . . . . . . . . 104

3.23 Enthalpy of original PCMs and PCMs made into the liquid state measured using DSC Q 200 equipment under exothermic reaction . . . . . . . . 105

3.24 Enthalpy of original PCMs and PCMs made into the liquid state measured using DSC STA 8000 equipment under endothermic reaction . . . . . . 105

3.25 Dynamic DSC curve of the PCM in the liquid state . . . . . . . . . . 107

3.26 Temperature properties of PCMs . . . . . . . . . . . . . 108

3.27 Enthalpies of PCMs . . . . . . . . . . . . . . . . . 108

3.28 Isothermal DSC curve of the PCM melted at $21^{\circ} \mathrm{C} \ldots \ldots . . . . . . \quad 110$

3.29 Isothermal DSC curve of the PCM melted at $23^{\circ} \mathrm{C} \ldots \ldots . . . . . . .111$

3.30 The first isothermal DSC curve of the PCM melted at $26^{\circ} \mathrm{C} \ldots \ldots . . .111$

3.31 The second isothermal DSC curve of the PCM melted at $26^{\circ} \mathrm{C}$. . . . . 112 


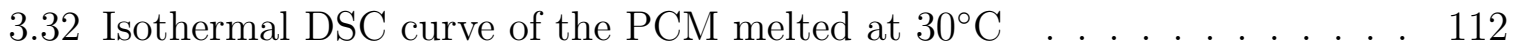

3.33 Isothermal DSC curve of the PCM melted at $21^{\circ} \mathrm{C}$ and made into the liquid state ........................ . . . . 114

3.34 Isothermal DSC curve of the $\mathrm{PCM}$ melted at $23^{\circ} \mathrm{C}$ and made into the liquid state . . . . . . . . . . . . . . . . 115

3.35 Isothermal DSC curve of the PCM in the liquid state . . . . . . . . . 116

3.36 Enthalpy curve of the $\mathrm{PCM}$ melted at $21^{\circ} \mathrm{C} \ldots \ldots \ldots$

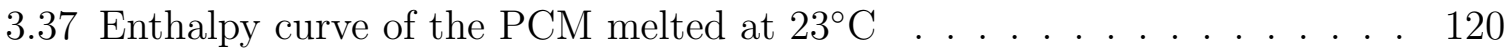

3.38 Enthalpy curve of the PCM melted at $26^{\circ} \mathrm{C} \ldots \ldots$. . . . . . . . . . 121

3.39 Enthalpy curve of the $\mathrm{PCM}$ melted at $30^{\circ} \mathrm{C} \ldots \ldots$. . . . . . . . . . 121

3.40 Enthalpy curve of the PCM made into the liquid state and melted at $21^{\circ} \mathrm{C} 122$

3.41 Enthalpy curve of the PCM made into the liquid state and melted at $23^{\circ} \mathrm{C} 122$

3.42 Enthalpy curve of the PCM melted at $21^{\circ} \mathrm{C} \ldots \ldots$. . . . . . . . . 123

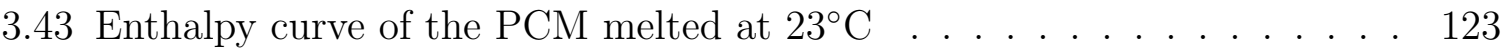

3.44 Enthalpy curve of the PCM melted at $26^{\circ} \mathrm{C} \ldots \ldots$. . . . . . . . . . . 124

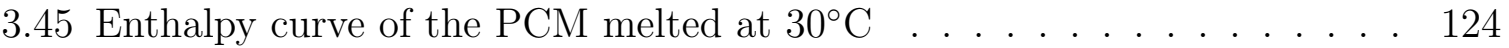

3.46 Enthalpy curve of the PCM made into the liquid state and melted at $21^{\circ} \mathrm{C} 125$

3.47 Enthalpy curve of the PCM made into the liquid state and melted at $23^{\circ} \mathrm{C} 125$

3.48 Enthalpy curve of the PCM in the liquid state at room temperature . . . 126

3.49 The thermal conductivities of the PCMs . . . . . . . . . . . . . . 134 
xvii

3.50 Volumetric heat capacities of PCMs measured using heat flow meter FOX 314 equipment ............................. 135

3.51 Enthalpy curves of PCMs measured using heat flow meter FOX 314 equipment . . . . . . . . . . . . . . . . . . 137

3.52 FEA result of the first verification . . . . . . . . . . . . . . . . 145

3.53 Temperature curves as a function of time from FEA results of the first verification study . . . . . . . . . . . . . . . . . 145

3.54 FEA result of the second verification . . . . . . . . . . . . . 146

3.55 Temperature curves as a function of time from FEA results of the second verification study . . . . . . . . . . . . . . . . . . . . 146

3.56 FEA result of the third verification . . . . . . . . . . . . . 147

3.57 Temperature curves as a function of time from FEA results of the third verification study . . . . . . . . . . . . . . . . . . 147

3.58 FEA results for the building roof incorporating PCM melted at $21^{\circ} \mathrm{C}$. 149

3.59 FEA results for the building roof incorporating $\mathrm{PCM}$ melted at $23^{\circ} \mathrm{C}$. 150

3.60 FEA results for the building roof incorporating $\mathrm{PCM}$ melted at $26^{\circ} \mathrm{C}$. 150

3.61 FEA results for the building roof incorporating $\mathrm{PCM}$ melted at $30^{\circ} \mathrm{C} \ldots 151$

3.62 Temperature variations as a function of time graphs of the building roofs incorporating $\mathrm{PCMs}$. . . . . . . . . . . . . . 152 


\section{Chapter 1}

\section{Introduction}

\subsection{Objectives}

According to the report from the U.S. Energy Information Administration in 2016, $41 \%$ of worldwide energy was consumed for residential buildings, especially, $60 \%$ of that value was consumed for heating and cooling applications (The U.S. Energy Information Administration [2016]). The United Kingdom's Government Department for Business, Energy \& Industrial Strategy reported the energy use in the United Kingdom from 1970 to 2015 in 2016 . The report released about $30 \%$ of energy was consumed by residential sector. Heating system consumed $56 \%$ of such value (The United Kingdom's Government Department [2016]). From the results, the biggest potential for energy saving in residential sector was in heating or cooling applications.

In order to save energy, a Thermal Energy Storage (TES) system is considered as an ideal solution when Phase Change Materials (PCMs) having a TES system are incorporated into the building application. Moreover, potential cost savings by

decrease in energy consumption and by delay of peak load for the daytime can be 
obtained by incorporating PCMs in the residential and building sector.

A Thermal Energy Storage (TES) system is an important technological system to provide energy savings as well as the efficient and optimum energy use because a TES can hold thermal energy of materials in the solid state or in the liquid state. Therefore, a TES is an efficient energy storage, which can improve the performance of energy systems, and a TES can correct the gap between the demand and supply of energy. The main types of a TES are a sensible heat storage and a latent heat storage. The latent heat storage is a very efficient method to store and release thermal energy because it has a high-energy storage density at constant temperatures. A latent heat storage material can store 5-14 times more heat per unit volume than a sensible heat storage material can.

Phase Change Materials (PCMs) are well known as latent heat storage materials. PCMs can save thermal energy, and use energy efficiently, because PCMs can absorb thermal energy in the solid state, and the thermal energy can be released in the liquid state at a constant temperature. Therfore, PCMs as new materials for saving energy can be applied into building applications.

The objective of this study is to develop a methodology and procedure to accurately determine material properties of PCMs based on salt hydrates because inaccurate materials properties are measured by existing methodology. The materials properties of the PCMs are presented by various methods, such as DSC method and heat flow method, because information about the properties of the PCMs is not ac- 
curate and detailed. In order to determine and assess the TES systems of the PCMs over a variety temperature range, the results, such as the dynamic/isothermal results, the thermal conductivities, and the enthalpy changes of the PCMs were compared and analyzed. In addition, this study demonstrates how to design building roofs incorporating PCMs to save energy using FEA. Therefore, this study propose the developed methodology to analyze accurately the material properties of the PCMs. The developed methodology can be used to analyze accurately the TES systems of PCMs. The results obtained by the methodology can then be used to form a database, which can offer important and valuable information for a wide range of TES applications.

In the following parts of the thesis, Section 1.2 shows a thermal energy storage, classification of Phase Change Materials (PCMs), and applications of applying PCMs. Section 2 introduces experimental methods and materials selected in order to determine the thermophysical properties from the experimental analysis. Section 3.1 shows dynamic Differential Scanning Calorimetry (DSC) results and isothermal DSC results. In this thesis, two types of DSC equipment are used to measure the thermophysical properties accurately using various PCMs. In order to analyze TES systems of PCMs, enthalpy change curves as a function of temperature are consisted of results of dynamic DSC. In Section 3.2, the thermal conductivities, the volumetric heat capacities, and the enthalpy change curves as a function of temperature obtained using heat flow meter are indicated to assess the effects of the presence of PCMs, especially, enthalpy change curves by heat flow method results are compared 
with enthalpy change curves by dynamic DSC method. Section 3.3 shows the thermal diffusivity to indicate ability of PCMs to transfer thermal energy as the diffusion is happened. Section 3.4 shows numerical simulation, such as verification study and case study, to check accuracy of the result obtained using ABAQUS and to investigate potential for energy savings with incoporating PCMs in a building.

\subsection{Literature review}

\subsubsection{Thermal Energy Storage}

Thermal Energy Storage (TES) is defined as the temporary holding of thermal energy in the form of hot or cold substances for later utilization (Abedin and Rosen [2011]). A Thermal Energy Storage (TES) system is an important technology to provide energy savings and the efficient and optimum energy use in very specific areas such as security energy supply or thermal inertia and thermal protection (Abedin and Rosen [2011]; Zalba et al. [2003]). Also, a TES system is an efficient energy storage, which can improve the performance of energy systems, and the TES can reduce the mismatch between the supply and demand of energy. A TES system is classified as a sensible heat thermal energy storage, a latent heat thermal energy storage, and a chemical energy storage. 


\subsubsection{Sensible Heat}

A sensible heat storage involves storing or releasing thermal energy by increasing or decreasing the temperature of a solid or liquid storage material through a heat transfer interaction. Also, in a sensible heat storage, thermal energy, which is stored or released, happens over a range of temperature without a change in phase of a material during the process of charging and discharging. The amount of heat stored is based on the mass of storage material, specific heat capacity, and the temperature change (Abedin and Rosen [2011]; Zalba et al. [2003]; Pielichowska and Pielichowski [2014]). Therfore, equation of a sensible heat storage can be written as

$$
Q=\int_{T_{1}}^{T_{2}} m C_{p} d t=m C_{p}\left(T_{2}-T_{1}\right)
$$

where $Q$ is the sensible heat stored, $m$ is the mass of storage material, $C_{p}$ is the specific heat capacity at constant pressure, and $T_{1}$ and $T_{2}$ are the temperature range.

\subsubsection{Latent Heat}

A Latent heat storage is a very efficient method for storing or releasing thermal energy due to its high storage density at a constant temperature (Pielichowska and Pielichowski [2014]). A latent heat storage depends on the storage material absorbing or releasing heat at a constant temperature during the phase change. Unlike a sensible heat storage, a latent heat storage offers a higher storage density at a more narrow 
temperature range. In addition, latent heat storage materials such as Phase Change Materials (PCMs) can store 5-14 times more heat per unit volume than sensible heat storage materials such as water, masonry, or rock can (Sharma et al. [2009]).

For understanding the storage density of a latent heat storage system, a sensible heat storage over the entire temperature range should be considered with a latent heat storage at a narrow temperature range during the phase transition. Thus, the total stored energy for TES system with a PCM can be expressed as, (Pielichowska and Pielichowski [2014]; Tao et al. [2015])

$$
Q=m \int_{T_{i}}^{T_{m}} C_{p, \text { solid }} d T+m \Delta h+m \int_{T_{m}}^{T_{f}} C_{p, \text { liquid }} d T
$$

where the first term and last term are sensible heat of the solid and liquid phases, and the second term is latent heat during the phase transition, $m$ is the mass of a PCM, $T_{i}$ is an initial temperature, $T_{m}$ is a melting temperature, $T_{f}$ is a finish temperature, and $\Delta h$ is a latent heat of fusion.

\subsubsection{Thermochemical Energy}

In a thermochemical energy storage, a thermochemical energy storage involves sorption and thermochemical reactions. Thermal energy is stored and released by dissociation reaction and chemically reverse reaction. The total stored energy for TES system with a PCM is given by 


$$
Q=a_{r} m \Delta h
$$

where $a_{r}$ is the extent of conversion, $m$ is the mass of storage material and $\Delta h$ is the heat of the reaction.

Even though a thermochemical energy storage has a higher storage capacity than other storage systems, this method is limited due to the high cost for using this method (Abedin and Rosen [2011]; Sharma et al. [2009]).

\subsubsection{Classification of Phase Change Materials}

Phase Change Materials (PCM) are called latent heat storage materials, and the thermal energy transition happens as a material is changed from liquid to solid or from solid to liquid (Sharma et al. [2009]).

The ideal PCMs in a thermal energy storage system should fulfill desirable criteria related to thermal, physical, kinetic, chemical properties, and economics (Zalba et al. [2003]; Sharma et al. [2009]; Hawer et al. [1993]; Khudhair and Farid [2004]; Tyagi and Buddhi [2007a]):

Thermal properties are: 1) proper temperature range for phase change; 2) high phase change latent heat of fusion per unit volume; 3) high specific heat to provide additional sensible heat storage; 4) high thermal conductivity of both liquid and solid phases. 
Physical properties are: 1) favorable phase equilibrium; 2) small volume change in phase transition; 3) low vapor pressure over temperature range; 4) high density.

Kinetic properties are: 1) no supercooling during the freezing process; 2) high nucleation rate; to avoid supercooling of liquid phase during solidification; 3) adequate crystallization rate.

Chemical properties are: 1) long term chemical stability; 2) compatibility with the construction materials; 3) no corrosion influence on materials of construction; 4) non-toxic, non-flammable, and non-explosive materials.

Economics are: 1) abundant; 2) available; 3) cost effective; 4) easy recycling and treatment.

PCMs can be classified by three parts depending on the temperature range (melting temperature): 1) low temperature PCMs: phase change temperature is below $15^{\circ} \mathrm{C}$, and their applications are air conditioning and the food industry; 2) mid temperature PCMs: phase change temperature range is $15^{\sim} 90^{\circ} \mathrm{C}$, and applications are solar, medical, textile, electronic, and building material; 3) high temperature PCMs: temperature is above $90^{\circ} \mathrm{C}$, and the PCMs are used for industrial and aerospace applications (Pielichowska and Pielichowski [2014]; Kenisarin [2010]). As shown in Figure 1.1, PCMs can be divided into three groups: organic, inorganic, and eutectic. 


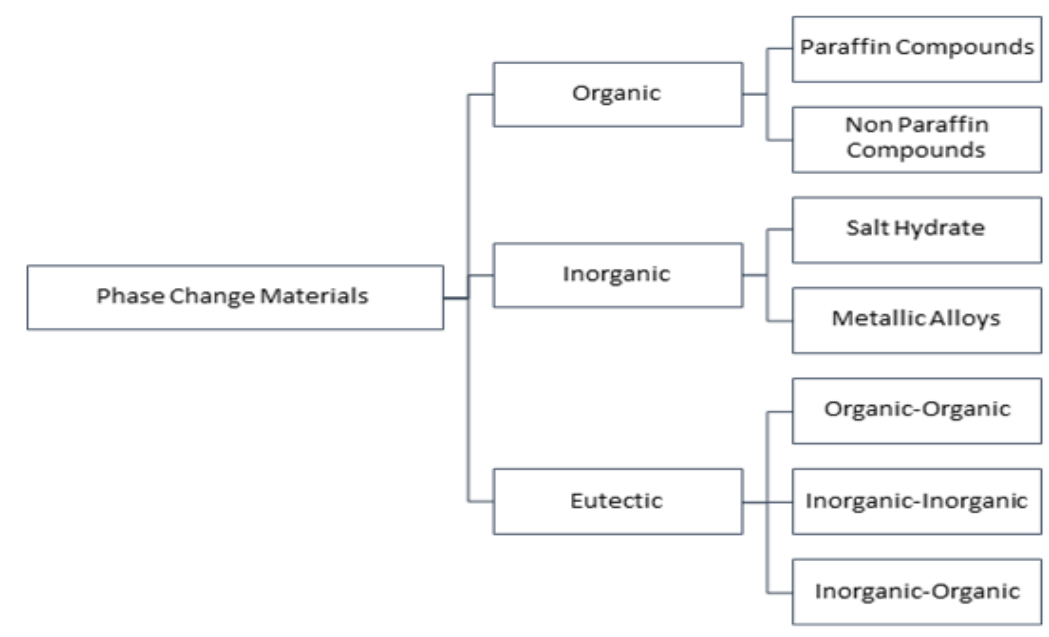

Figure 1.1: Classification of PCMs

\subsubsection{Organic PCM}

Organic Phase Change Materials are classified as Paraffin compounds and NonParaffin compounds. Organic PCMs involve congruent melting and freezing without phase segregation or degradation of latent heat. Also, organic PCMs are selfnucleating, which means accelerated solidification or crystallization. Organic materials have small temperature range from $-5^{\circ} \mathrm{C}$ to $150^{\circ} \mathrm{C}$, small density below $1 \mathrm{~g} / \mathrm{cm}^{3}$, and high heat of fusion range from 45 to $250 \mathrm{~kJ} / \mathrm{kg}$ (Sharma et al. [2009]; Subramanian [2011]; Banu et al. [1998]).

Paraffin consists of a mixture straight chain of $\mathrm{CH}_{3}-\left(\mathrm{CH}_{2}\right)-\mathrm{CH}_{3}$. This chain is directly related to a large amount of latent heat of fusion so the melting temperature and latent heat can be increased with the chain length increase. The general formula of Non-paraffin as fatty acids is a chain of $\mathrm{CH}_{3}\left(\mathrm{CH}_{2}\right)_{2 n} \mathrm{COOH}$, and fatty acids have 
Table 1.1: Advantages and disadvantages of organic PCMs

\begin{tabular}{|c|c|}
\hline Advantages & Disadvantages \\
\hline No supercooling & Flammable \\
No phase segregation & Low thermal conductivity \\
Low vapor pressure & High volume change for phase \\
Chemically stable & transition \\
Recyclable & Non-compatible with the \\
& plastic container \\
& Instability at high \\
& temperatures \\
\hline
\end{tabular}

a higher latent heat of fusion than paraffin PCMs (Pielichowska and Pielichowski [2014]). Advantages and disadvantages of orgainc PCMs are shown in Table 1.1.

\subsubsection{Inorganic PCM}

Inorganic PCMs are classified as salt hydrates and metallic alloys. Inorganic PCMs have a higher latent heat of fusion than other PCMs. Salt hydrates are made of inorganic salt and water in a crystal matrix and have general formula of $\mathrm{AB} \cdot \mathrm{nH}_{2} \mathrm{O}$. Salt hydrates have a high latent heat, a high melting temperature range from $15^{\circ} \mathrm{C}$ to $117^{\circ} \mathrm{C}$, a high thermal conductivity of 0.4 to $1 \mathrm{~W} / \mathrm{mK}$, and density of over 1 $\mathrm{g} / \mathrm{cm}^{3}$. In the case of molten salts, a melting temperature range is from $250^{\circ} \mathrm{C}$ to $1680^{\circ} \mathrm{C}$ (Pielichowska and Pielichowski [2014]; Kenisarin [2010]; Subramanian [2011]). Inorganic PCMs, especially salt hydrate are widely used for commercial PCMs with a low cost such as $\mathrm{CaCl}_{2} \cdot 6 \mathrm{H}_{2} \mathrm{O}, \mathrm{MgCl}_{2} \cdot 6 \mathrm{H}_{2} \mathrm{O}, \mathrm{MgNO}_{3} \cdot 6 \mathrm{H}_{2} \mathrm{O}$, and $\mathrm{Na}_{2} \mathrm{SO}_{4} \cdot 10 \mathrm{H}_{2} \mathrm{O}$. Table 1.2 is listed advantages and disadvantages of inorganic PCMs. In order to solve 
Table 1.2: Advantages and disadvantages of inorganic PCMs

\begin{tabular}{|c|c|}
\hline Advantages & Disadvantages \\
\hline High latent heat of fusion & Supercooling \\
High thermal conductivity & Phase segregation \\
Small volume change during & Corrosive to metals \\
melting & \\
Sharp phase change & \\
Low cost & \\
Non-flammable & \\
Non-toxic & \\
\hline
\end{tabular}

drawback of segregation and supercooling, a rolling cylinder heat storage system is suggested (Furbo [1983]).

Metallic alloys are used as a high temperature PCMs with high thermal reliability and repeatability. Even though metallic alloys have a high thermal conductivity and a high latent heat of fusion, metallic alloys PCMs are not used for commercial application due to the weight (Sharma et al. [2009]).

\subsubsection{Eutectic PCM}

Eutectic PCMs are defined as a minimum-melting composition of two or more components for improving properties. Eutectic PCMs consist of organic compounds, or inorganic compounds, or organic-inorganic compounds. Two or more PCMs are mixed to make a new eutectic PCMs, which have melted at the same temperature. Eutectic PCMs can melt and freeze without segregation because a mixture of the component crystals can combine congruently during the solidification (Sharma et al. 
[2009]). Advantages and disadvantages of eutectic PCMs are listed in Table 1.3.

Table 1.3: Advantages and disadvantages of eutectic PCMs

\begin{tabular}{|c|c|}
\hline Advantages & Disadvantages \\
\hline Sharp melting point & High cost \\
Properties can be tailored to & Limited data on \\
match specific requirements. & thermophysical properties for \\
& many cominations \\
\hline
\end{tabular}




\subsubsection{Applications}

Phase Change Materials (PCMs) can be applied in the building industry, solar energy systems, conservation/transport of temperature sensitive materials, smart textiles, and so on. In recent years, biomedical applications and electronics applied PCMs have emerged in the industry. The applications of thermal energy storage systems applied PCMs are considered in the following sections.

\subsubsection{Thermal Energy Storage for Buildings}

PCMs can often be used in the building industry to improve the effect of a thermal energy storage and stabilize temperature. PCMs depended on the building systems are categorized as passive, assisted passive, and active storage systems. In terms of passive storage systems, PCMs incorporated directly into the building are used for heating/cooling systems without active mechanical devices. PCMs are continuingly being investigated for passive storage systems, including PCM wall, PCM shutter, PCM building block and air based heating system, etc. (Pielichowska and Pielichowski [2014]; Chan et al. [2010]). In the case of assisted passive systems, PCMs are incorporated into the building for heating or cooling as passive systems. Moreover, the system of convection is also used for air flow in order to pass through the material surface. Active storage systems can be used for off peak storages of thermal energy storages in buildings, and PCMs in active systems are involved in auxiliary heating 
or cooling units. PCMs have studied for active storage systems with floor heating, ceiling boards, and photovoltaic applications (Tyagi and Buddhi [2007b]).

Some representative applications of thermal energy storage with PCMs for high performance building are introduced in this section. Generally, PCMs can be integrated with various kinds and elements for buildings, but each applications has its intrinsic characteristics. This section consists of generally used building applications, including PCM integrated wall, PCM assisted under floor heating system, PCM assisted ceiling board, and PCM integrated roof.

\subsubsection{PCM Integrated Wall}

PCM integrated wall is widely used and studied for high performance buildings due to the effective heat transfer and convenient use. In order to integrate PCMs with building walls, there are two ways, classified as immersion and attachment. First of all, the method of immersion is to integrate PCMs into many different construction materials for building envelope, such as wallboard, plaster, concrete, and bricks. Generally, immersion PCMs are classified as direct immersion, macro-encapsulated, and micro-encapsulated PCMs. Micro-encapsulated PCMs are used successfully for high performance building industry, but applications of direct immersion and macro encapsulated PCMs are not applied with the building structure materials.

Micro encapsulated PCM is a PCM is encapsulated inside the acrylic polymer/membrane with the dimension of few micrometers. Advantage of using of micro encapsu- 


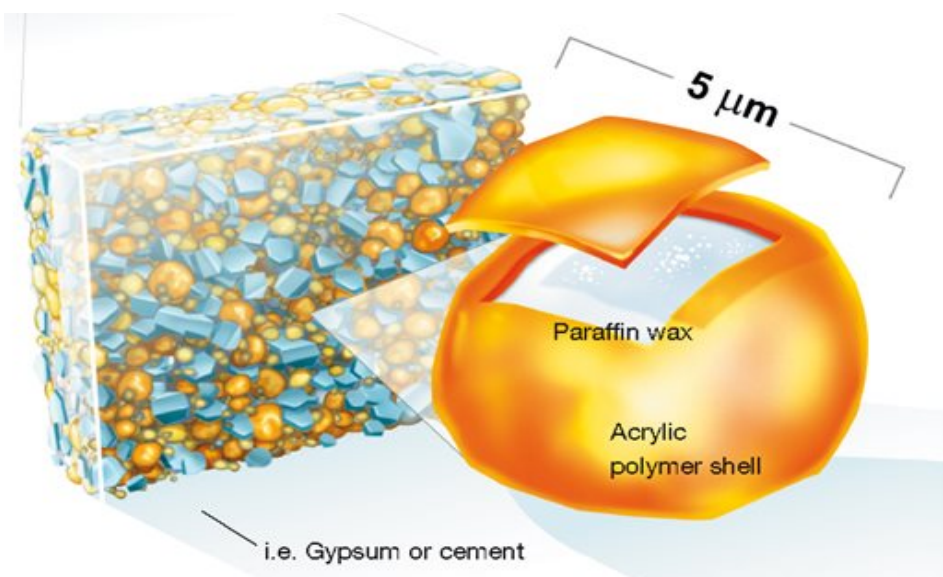

Figure 1.2: The micro encapsulated PCM from Microtec Lab, Inc. (Archtecture and Design Powered by Infolink [2015])

lated PCMs is to avoid the shortages, rather than using direct immersed or macroencapsulated PCMs. Nowadays, there are many commercial products of micro encapsulated PCMs as Micro PCM (MPCM) produced by Microtek Lab, Inc (Microtek [2017]). General properties of the micro PCM product are that temperature range is $-30^{\circ} \mathrm{C}$ to $65^{\circ} \mathrm{C}, \mathrm{PCM}$ content in capsule is $85-90 \mathrm{wt} . \%$, and particle size is $14-24$ micron for dry powder or wet cake forms and 2-5 micron for slurry form (Microtek [2017]). Figure 1.2 shows the brief schematic of the micro encapsulated PCM produced by Microtek Lab, Inc (Archtecture and Design Powered by Infolink [2015]).

The solution of attachments is to attach one or more PCM integrated wall layers to the wall. PCMs can be integrated with attached layers (wallboard) and considered as the interior decoration work. Since the PCM integrated a board or a panel accepts a separate mass production of the board or the panel layer, it has advantages of high efficiency and low overall cost. Thus, this method is widely used in real applications 


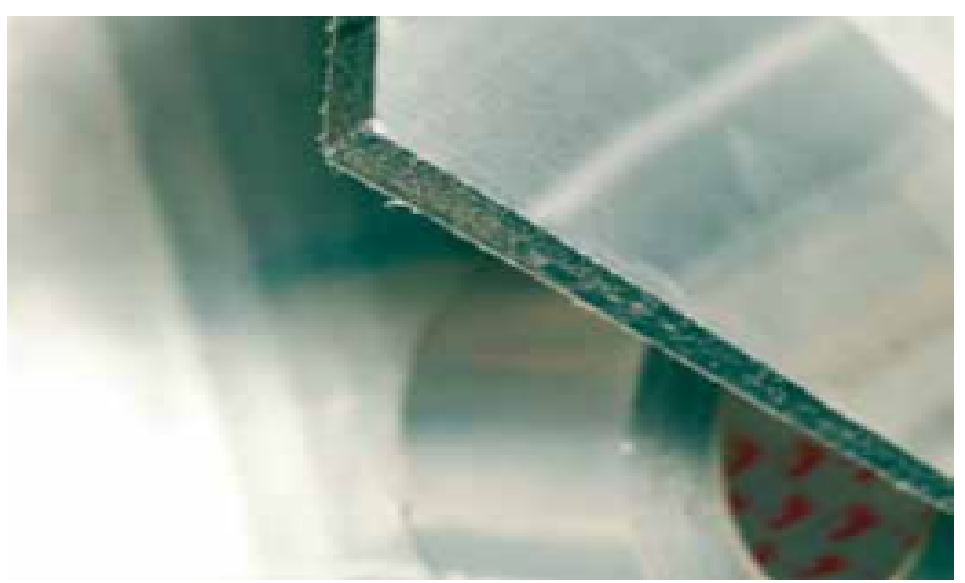

Figure 1.3: A PCM integrated panel from DuPont Company (Dupont [2012])

(Tyagi and Buddhi [2007b]; Cao [2010]). The typical commercial product is a PCM panel made by DuPont Company. Technical properties of the panel are paraffin loading of $60 \%$, melt point of $21.7^{\circ} \mathrm{C}$, latent heat storage capacity of $>70 \mathrm{~kJ} / \mathrm{Kg}$, conductivity in the solid state of $0.18 \mathrm{~W} / \mathrm{mK}$, and conductivity in the liquid state of $0.14 \mathrm{~W} / \mathrm{mK}$ (Dupont [2017]). Figure1.3 shows the typical PCM integrated panel produced by DuPont Company (Dupont [2012]).

Many researchers have investigated applications and studies of the PCM integrated wall. Typically, several studies and applications with the PCM integrated wall can be classified into two types. The first type is study and applications for the wall between indoor and outdoor. The second type is research and application for the wall between indoor and room (Cao [2010]).

A typical application of the first type is a Trombe wall. To get better thermal storage mass than the conventional masonry wall, PCMs are used in the application 
of collector storage building wall as the Trombe Wall. Many studies have focused on investigating the reliability of PCMs in the Trombe Wall (Ghoneim et al. [1991]). Phase change material units need less space and weight rather than water walls so these are very suitable materials to make and use in retrofit applications for high performance buildings. Salt hydrates and hydrocarbons under PCMs are mainly used in building construction, and metallic compounds are sometimes added for increasing thermal conductivity and efficiency.

In the end of 1970s, Benard et al. [1985] studied to make a series of experiments to compare sensible and latent materials for the Trombe wall. They measured the behavior of three different thermal walls by using same test cell.The PCMs in the three different thermal walls were respectively a hard paraffin (Acro-wax 45-48) for wall A, a soft paraffin (Total SW2) for wall B, and concrete for wall C. Even though the wall including paraffin wax was $1 / 5$ the thickness and $1 / 12$ the weight of wall $\mathrm{C}$ including concrete, the results indicated similar thermal energy storage effects (Benard et al. [1985]).In order to investigate the reliability of PCM applied into the Trombe wall, many researchers studied experimental, theoretical, and simulation tests of the collector-storage building walls using Phase Change Materials such as sodium sulphate decahydrate, medicinal paraffin, P116-wax, and concrete (Ghoneim et al. [1991]; Swet [1980]; Chandra et al. [1985]). These results indicated the Trombe wall applied sodium sulphate decahydrate had a better thermal energy storage system due to its high latent heat and thermal conductivity, and the PCM, which has less thick- 
ness, was a suitable material in comparison to a conventional masonry wall in order to provide desirable thermal energy storage systems. Until now, many researchers have studied applications of PCMs integrated Trombe walls.

This part is for research and application for the wall between indoor and rooms. Most residential buildings such as apartments or attached houses have walls shared between rooms. A typical application of the integrated wall shared between two adjacent rooms is a PCM wallboard. The PCM wallboards are attached to the interior wall in order to share a wall between two rooms. The PCM wallboards including encapsulated-PCMs are widely used and cheap in building applications. These PCM wallboards as shared wall should be considered to control the fluctuation of temperature for thermal stability (Kuznik and Virgone [2009]). Many researchers have examined how to stabilize temperature of adjacent rooms by using PCM wallboards applied into the building or into numerical simulation over several years (Salyer and Sircar [1990]; Feldman et al. [1991]; Neeper [2000]; Kalousck and Hirs [2002]; Ahmad et al. [2006]). Ahmad et al. [2006] and Liu and Awbi [2009] investigated the effects of a PCM wallboard on heat flux, surface temperature and heat conductivity loss. Their results showed that the use of PCM wallboards reduced temperature fluctuations of about $4 \sim 5{ }^{\circ} \mathrm{C}$ on wall surfaces (Ahmad et al. [2006]; Liu and Awbi [2009]).

Macro encapsulated PCM and direct immersion method are not widely used in commercial product due to the several drawbacks such as heat transfer rate is decreased and these methods are protected against destruction. The alternative method 
is to use micro encapsulated PCM accessible for the building industry in order to overcome the drawbacks (Schossig et al. [2005]).

\subsubsection{PCM Assisted Under-Floor Heating System}

An under-floor heating system is also the important part for heating or cooling of buildings. Especially under-floor electrical heating systems are widely used in building industry for heating of the indoors. Since the electricity tariffs of peak hours are more expansive than those of off peak hours, the electrical heating load should be shifted from high electricity tariffs to low electricity tariffs so the thermal storage system has to considered with an under-floor heating system.

First of all, Athienitis and Chen [2000] suggested the sensible heat storage solutions as the transient heat transfer (the storage medium) in under-floor heating systems. They focused on the effect of the cover later and solar radiation on dynamic thermal performance of floor heating systems. The thermal storage was composed of hardwood cover layers over concrete or gypcrete (gypsum-concrete composite) thermal storage. The results were that solar radiation stored in the floor thermal storage can be decreased heating energy consumption $30 \%$ or more, and increase in thermal storage thickness did not affect energy saving with conventional proportional-integral control. Lin et al. [2007] carried out the experimental study of an electrical heating system with a ductless air supply and a shape-stabilized PCM for a thermal storage. Schematics of the heating system are shown in Figure 1.4. The under-floor heating 


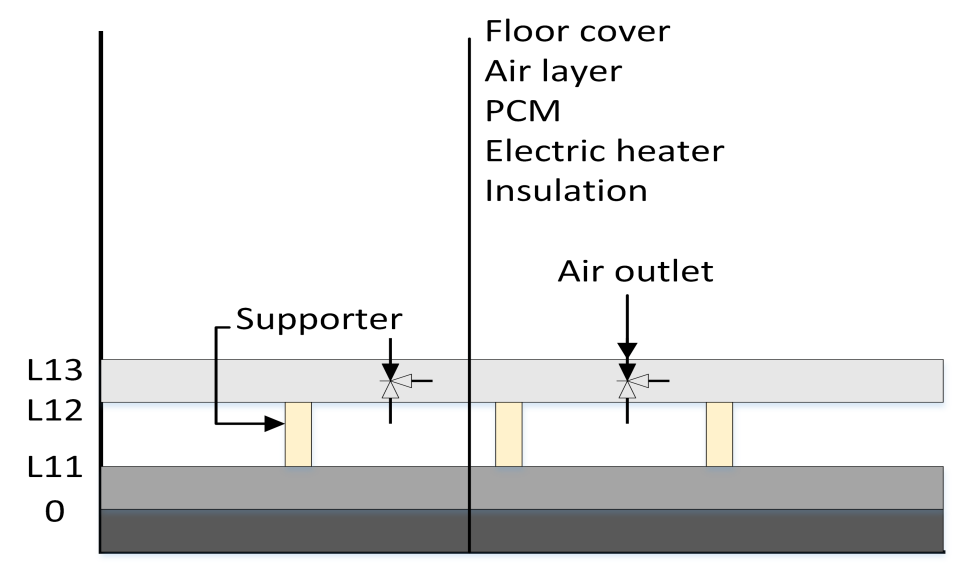

Figure 1.4: Schematic of the heating system (Lin et al. [2007])

system was made of $120 \mathrm{~mm}$ thick polystyrene insulation, electric heating system, $15 \mathrm{~mm}$ thick PCM including $75 \mathrm{wt} \%$ paraffin and $25 \mathrm{wt} \%$ polyethylene, $50 \mathrm{~mm}$ thick air layer, 40mm thick floor cover, cylindrical supporters, and air inlets/outlets. The electric heater melted the PCM layer by using nighttime electricity since the electricity tariff at night was cheaper about $1 / 3-1 / 5$ than at the day and then this heating system absorbed and stored heat (Lin et al. [2004]). The result indicated that the total electricity consumption was shifted from the peak to the off peak period with economic benefit by applying a ductless air supply. In addition, the electricity consumption period shifted showed that thermal comfort can be kept comfortable.

There are many commercial products for PCM assisted under-floor heating systems. NetGreen Solar Ltd. (NetGreen Solar Ltd. [2017]) has produced commercial merchandise such as PCM floor panels. As shown in Figure 1.5, an under-floor heating system consists of floor covering, concrete, PCM thermal storage panel, and insula- 


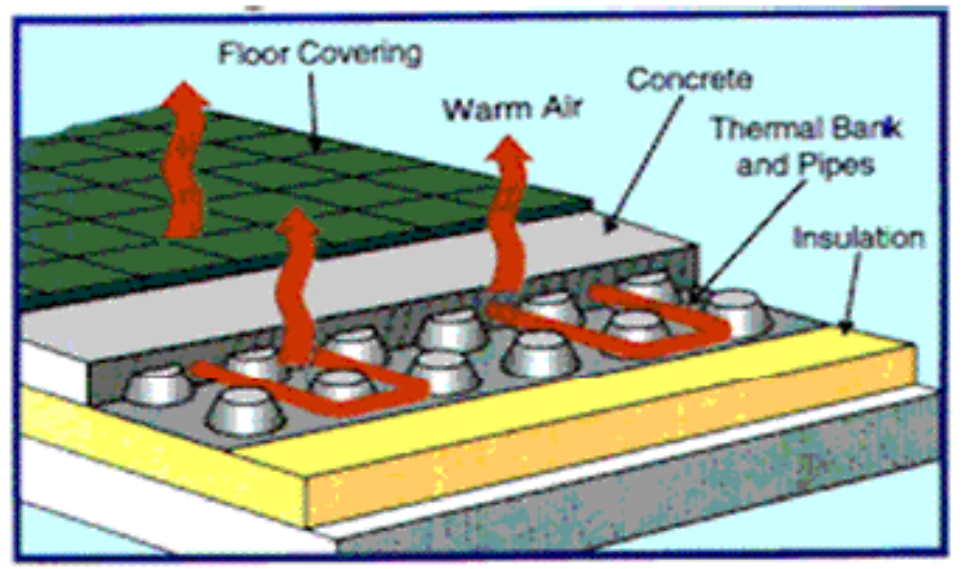

Figure 1.5: Schematic of commercial product of under-floor heating system made by NetGreen Solar Ltd. (NetGreen Solar Ltd. [2017])

tion. The principle of an under-floor electrical heating system with a PCM panel is that the heat from a solar generator during the day circulates through a PCM thermal storage panel of the under-floor electrical heating system. The PCM panel uses latent heat in order to store the heat during the night.

\subsubsection{PCM Assisted Ceiling Boards}

PCM assisted ceiling boards also play an important part, utilized for the heating or cooling in building applications. This method is widely used in building due to ease of installation and implementation. Currently, PCM assisted ceiling boards are classified into three types: a PCM slurry assisted ceiling system; a PCM integrated ceiling system; a separate PCM storage unit assisted ceiling system/air conditioning system (Socaciu [2012a]). The first type, a PCM slurry assisted ceiling system, is an extension of the traditional ceiling system, which is integrated an air conditioning system. The 
difference is heat transfer, which flows via the ceiling board and is switched into PCM slurry. The second type, a PCM integrated ceiling system, integrates PCMs into the ceiling board and this method can cause further development for the building fabric thermal storage. Moreover, the advantage of this kind of ceiling system is to have a PCM as thermal mass, which has a high density of thermal storage. The third type is the separate PCM storage unit assisted ceiling system/air conditioning system. A feature of this third type is that the PCM applied into this type is not directly connected with ceiling. In addition, the third type is applied into a traditional air conditioning system with the chilled water, which flow via the ceiling but there is a separate PCM storage between the air conditioning system and the distribution system of the chilled water, and the PCM storage directly affect the temperature variation of the chilled water. In the commercial industry, the third type is widely used. This is the reason why this method has easy compatibility of PCM storage units with the traditional air conditioning system.

A typical application of the first type is that Turnpenny et al. [2000] showed performance of cooled ceiling operating with Microencapsulated Phase Change Material (MPCM) slurry. Schematics diagram of cooled ceiling system with MPCM slurry storage tank is shown in Figure 1.6.

They proposed a new design of an air conditioning system including a cooled ceiling and a MPCM slurry storage. The MPCM slurry consisted of microencapsulating PCM particles and hexadecane, covered by a thin film shell. During the working 


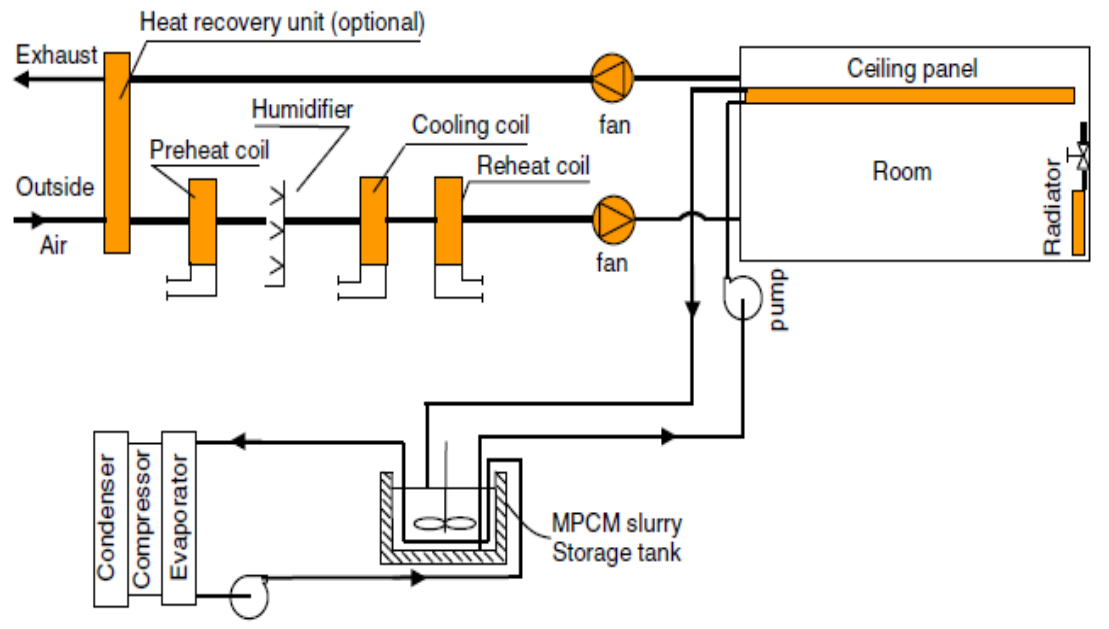

Figure 1.6: Schematic diagram of cooled ceiling system with MPCM slurry storage tank (Wang and Niu [2009])

time, the PCM slurry was directly pumped from the MPCM storage to the ceiling panels and its PCM was melted from a solid state to a liquid state and stored the latent/sensible heats. After that, the MPCM slurry in the liquid state returned to the MPCM storage tank and mixed with another MPCM slurry. Moreover, the researchers conducted a simulation study for comparing three different systems, which are cooled-ceiling with MPCM slurry, with an ice storage and without a thermal storage. The result was that the MPCM slurry storage could shift the cooling part from the daytime to the nighttime, so this system was economically favorable with low day/night electricity tariff rations (Wang and Niu [2009]).

An example of the second type is Turnpenny et al. [2000] designed a novel ventilation cooling system for reducing air conditioning in the buildings with a latent heat storage involving heat pipes embedded in a Phase Change Material (PCM) as 


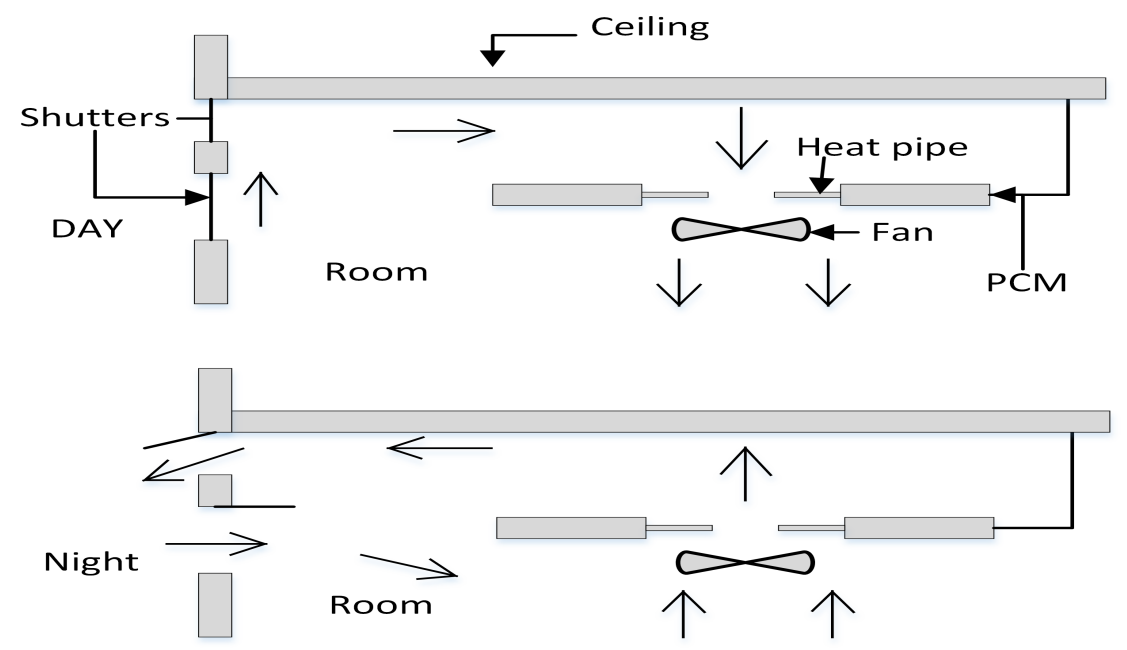

Figure 1.7: Schematic of heat pipe and PCM applications (Turnpenny et al. [2000])

shown in Figure 1.7. Researchers conducted a one-dimensional mathematical modeling of the heat transfer between air and the PCM to determine a test unit. They then studied a theoretical model of heat transfer from air to the PCM through the heat pipe. The results showed this system could melt and freeze all PCMs at low temperature with flow rates. The flow rates could increase the heat transfer rate and reduced the number of storages in order to maintain coolness in a room. Therefore, this system stored coolness in nighttime and released the coolness stored during the day (Turnpenny et al. [2000]).

An application example of the third type is that Moreno et al. [2014] have studied PCM tanks in a heat pump system for space cooling as shown in Figure 1.8. Researchers have shown the real experimental study and numerical simulation, applied summer condition, for a heat pump coupled with thermal energy storage (TES) 


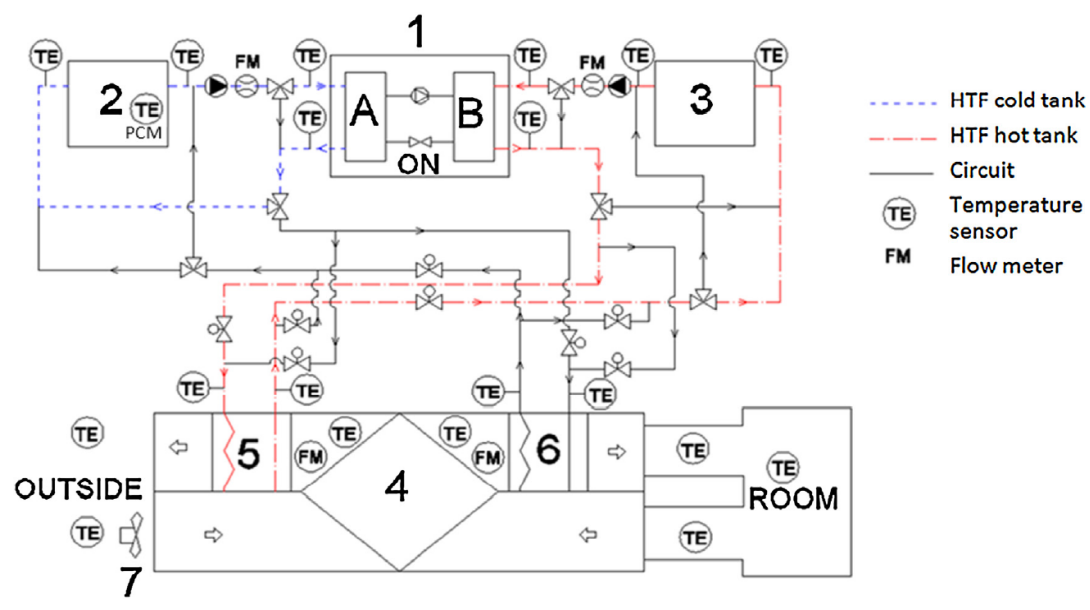

Figure 1.8: Schematic of TES heat pump system during the charging mode. 1) Heat pump (A. Evaporator, B. Condenser), 2) cold tank, 3) hot tank, 4) AHU, 5) outlet water-to-air heat exchanger, 6) inlet water-to-air-heat exchanger, 7) fan heater (Moreno et al. [2014])

tanks. They estimated the thermal behavior of the TES tank for a cold storage and the application of the system for cooling. In order to analyze the results, two different tanks, a water tank and a PCM tank, were compared in this study. In this study, the PCM consisted of a salt hydrate, phase change temperature was about $10^{\circ} \mathrm{C}$, and the macro-encapsulated form in plastic flab slabs. The result was that the PCM tank could provide $14.5 \%$ more energy (cold) and maintain temperature of inside by $20.65 \%$ longer time than the water tank.

\subsubsection{PCM Integrated Roof}

Among all the PCM applications for high performance buildings, a roof is a very important thermal buffer as a PCM integrated wall between the indoors and the 


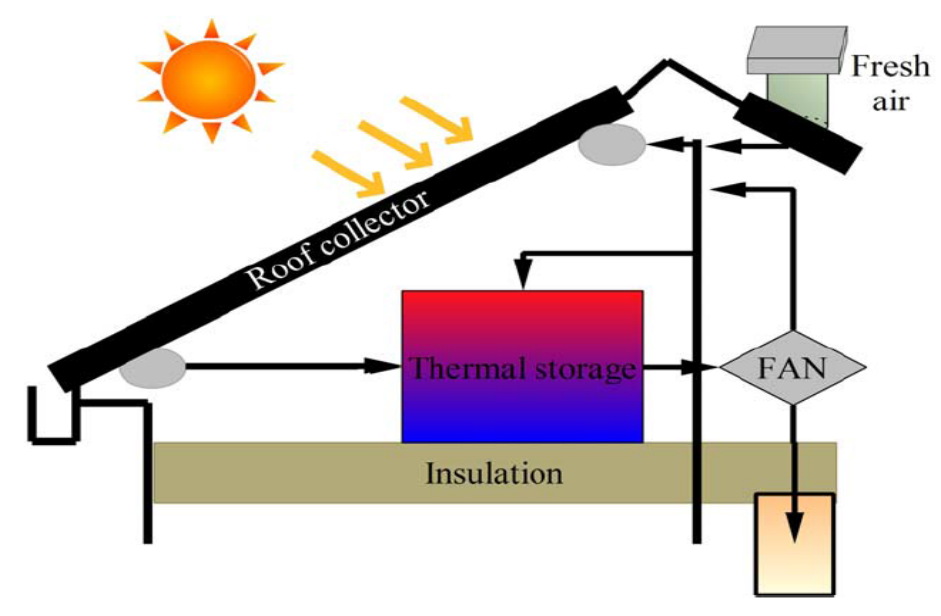

Figure 1.9: Schematic of the solar heating system (Socaciu [2012a])

environment. Moreover, a PCM integrated roof can store heat or energy during the daytime. Then, during the nighttime, the heat stored is released indoors. PCM integrated roof systems can be classified into three types. The first type is a PCM integrated roof system with heating. During the day and when heat is needed, air is flowed via a roof collector and it moves into indoors. The second type is without heating. Air is moved into the thermal storage. The third type is without sunshine. Room air is moved via the thermal storage. After that, the air can be heated and entered into the room. The solar heating system is shown to deliver heat into the house as shown in Figure 1.9 (Socaciu [2012a]).

A typical application was demonstrated by Pasupathy et al. [2008]. They carried out experiments and numerical simulations for the thermal performance of a building roof with a PCM for thermal management. A building roof system incorporating a PCM was made of a roof top slab (brick mixture and mortar), a PCM panel, and 


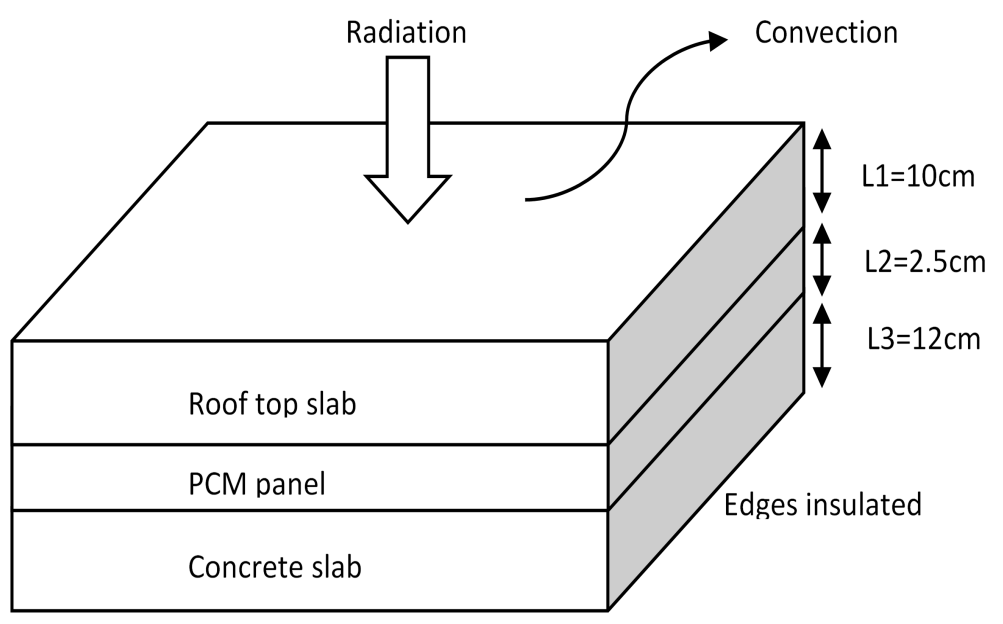

Figure 1.10: The PCM integrated building roof (Pasupathy et al. [2008])

a concrete slab, as shown in Figure 1.10. Also, water pipes were included into the PCM panel to provide a cooling system. In this study, two different rooms have been constructed to compare thermal performance. One room was the building roof system without the PCM panel, and the other room was the building roof system with the PCM panel. The PCM used in the experiment was the salt hydrate. The results from experiments and simulations showed the effect of variation in the indoor room during the year with the PCM panel thickness. A single PCM integrated roof is suitable from December to April, but it is not easily available from May to November because the roof system did not maintain a constant temperature (Pasupathy et al. [2008]).

Biswas et al. [2013] conducted a study of the energy-saving potential of various metal roofs incorporating dynamic insulation systems. The various metal roofs tested in their study were made of a Phase Change Material, a rigid insulation, a low emit- 


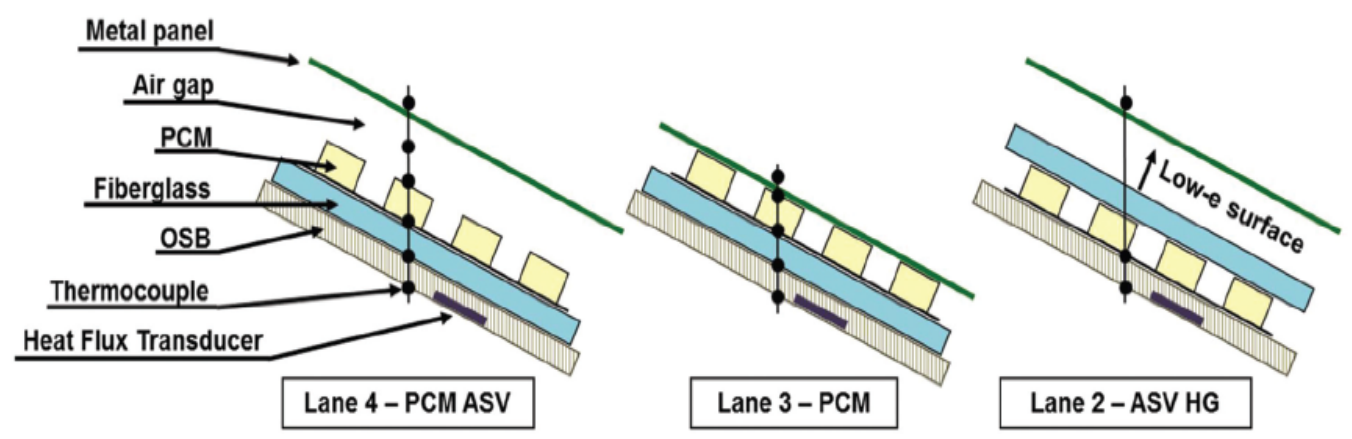

Figure 1.11: Schematics of test roofs (Biswas et al. [2013])

tance surface, and an above-sheathing ventilation (ASV) with standing-seam metal panels on top as shown in Figure 1.11. Selected PCMs were from Infinite R Company. In their study, four different test roofs were used to measure potential for reducing the attic-generated space-conditioning loads. The first type was an asphalt shingle roof, used as a control for comparison. The second type (lane 2) was with air gap and low e surface, and the PCM was under the rigid insulation board. In the third type (lane 3), there was no air gap, and the PCM was over the rigid insulation. In the fourth type (lane 4), there was air gap, and the PCM was also over the rigid insulation. According to Biswas et al. [2013]'s analysis, all of the tested roofs indicated potential in reducing the heat flows via the roof and ceiling, and in reducing temperature fluctuations, especially in the case of lane 2 , since the roof has low ambient temperature and low heat flux, the use of lane 2 is better in summer. Since the roof, which has high temperature and high heat flux, is suitable during the winter, the use of lane 4 is better during the winter (Biswas et al. [2013]). 


\subsubsection{Solar Water Heating Systems}

The solar water heating system is a popular because the system is inexpensive and easy to install and maintain. Prakash et al. [1985] showed a new built-in storage type water heater including a PCM layer at the bottom. During the daytime, the stored water was heated up and the water transfered heat as latent heat to the PCM. During the nighttime, the heat in the PCM was released to water by the cold water, which was substituted by the hot water. Researchers analyzed the new system for various PCM thickness and different flow rates for hot water requirements, and they compared the systems with the PCM and without the PCM. As shown in Figure 1.12, the solar water heater with the PCM storage was designed. The heater system was made of a rectangular galvanized iron thank of $9 \mathrm{~cm}$ depth and $1 \mathrm{~m}^{2}$ exposed surface area with a glass cover of $3 \mathrm{~mm}$ thick on the top and an insulation of $5 \mathrm{~cm}$ thick at the bottom and the sides of heater. The PCM, which was capsulated, was applied over the insulation and the PCM selected in the study was paraffin wax. The results were that water heater incorporating the PCM storage was more effective for hot water requirements during the nighttime, but disadvantage of this system was poor heat transfer between the PCM and water (Prakash et al. [1985]).

Ghoneim [1989] investigated to develop a model of Phase Change Energy Storage (PCES) system. Figure 1.13 showed a cylindrical storage unit in the closed loop pipes with a solar plate collector used in the study. The storage vessel was made of several 


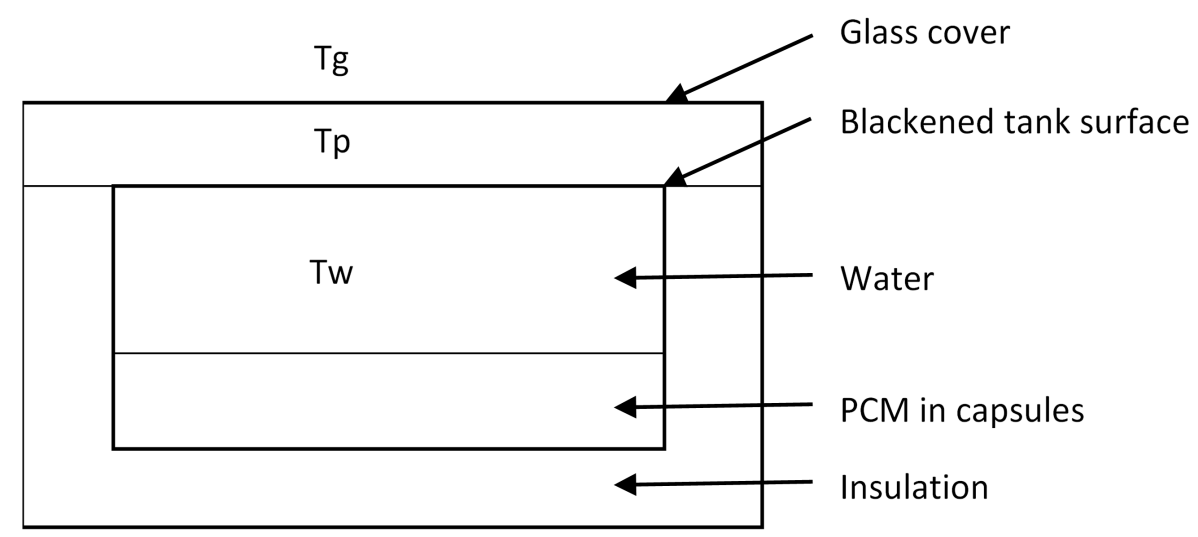

Figure 1.12: Schematic diagram of solar water heating system (Prakash et al. [1985])
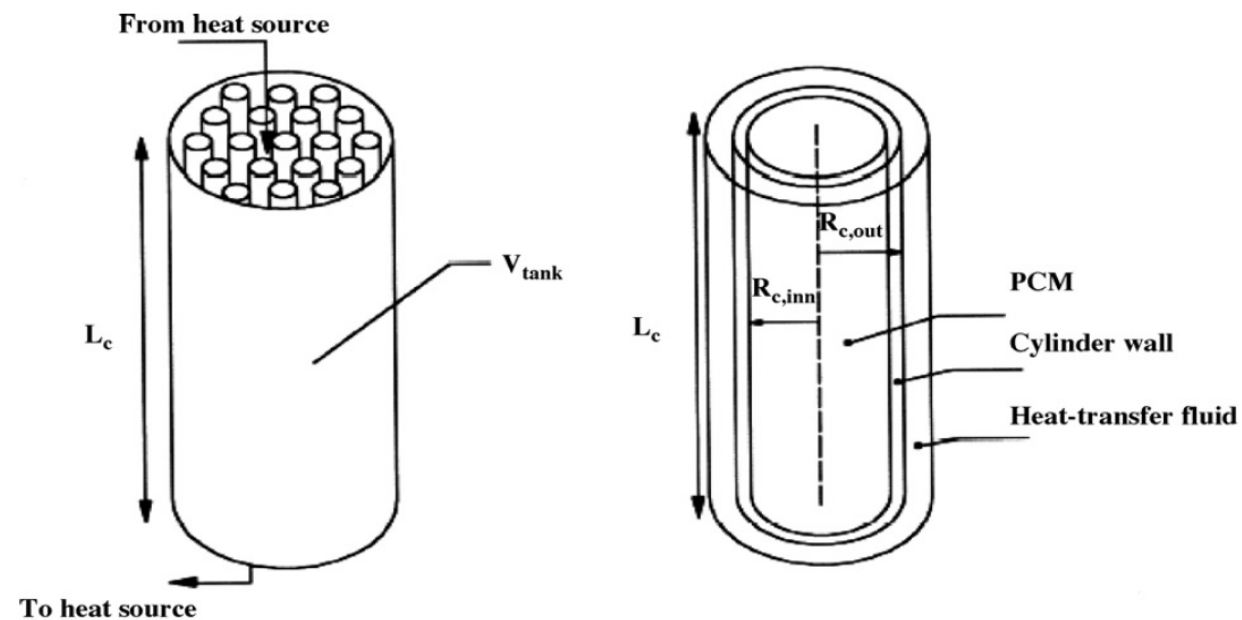

Figure 1.13: A cylindrical storage vessel with PCM storage (Ghoneim [1989])

closed cylindrical pipes containing the phase change medium and the heat transfer fluid flowed parallel to the storage vessel. This system was an efficient storage system for improving the heat transfer between water and the PCM and reserved the heat for a long period of 4 times more (Ghoneim [1989]).

Many researchers have conducted comparative studies of different sized storage 
vessels including a PCM with latent and sensible heat storages (Bansal and Buddhi [1992]; Bajnǿczy et al. [1999]; Kaygusuz [1995]; Rabin et al. [1995]; Mettawee and Assassa [2006]).

\subsubsection{Solar Air Heating Systems}

Jurinak and Abdel-Khalik [1979] carried out a simulation study to investigate the performance of air based solar heating systems utilizing a Phase Change Energy Storage (PCES) as shown in Figure 1.14. Researchers studied the effects of storage size, melting temperature, and latent heat on the thermal performance of air based solar heating systems. Not only the development of empirical method for PCES unit, but also the assessment of PCES economics were indicated in their study. The PCM used in this study was paraffin wax. The result in the study, which showed the thermal performance of an air based solar heating system, was more sensitive to variation under melting temperature of the PCMs. Therefore, melting temperature rather than latent heat of the PCM are considered to select the PCM. An empirical method developed for PCES unit was able to be used to investigate the effective thermal capacitance of PCES unit on air based solar heating system with sensible heat. Assessment of PCES economics with volume reductions showed that PCES was more economical than rock bed storage (Jurinak and Abdel-Khalik [1979]).

Many researchers have investigated the effect of Phase Change Energy Storage (PCES) on the performance of solar air based heating systems utilizing various PCMs. 


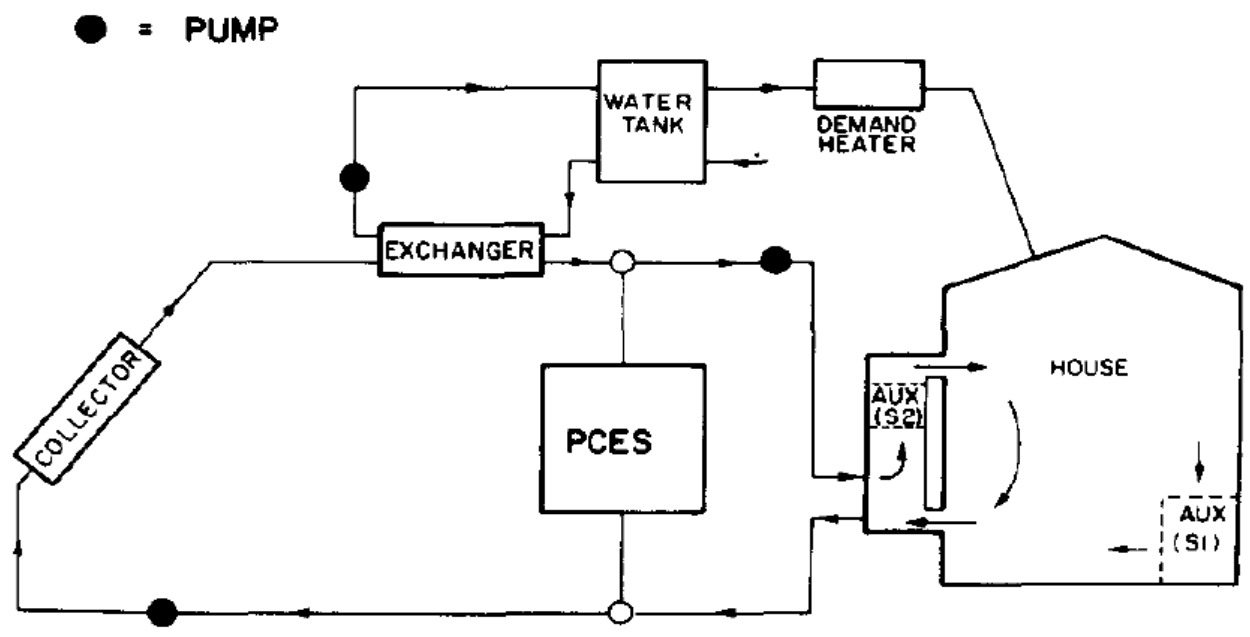

Figure 1.14: Schematic of the air based solar heating system with Phase Change Energy Storage (PCES) (Jurinak and Abdel-Khalik [1979])

In addition, they have carried out comparative analyses between air-based systems and liquid-based systems (Morrison and Abdel-Khalik [1978]; Ghoneim and Klein [1989]).

Enibe [2002] examined the performance of a natural circulation solar air heating system with a Phase Change Energy Storage (PCES). Enibe [2002] conducted the design, construction, and performance evaluation of a passive solar powered air heating system. The air heating system used in this study was made of a single glazed flat plate solar collector involving a PCES. During the day, the solar air heating system was performed under no-load conditions in the ambient temperature range and a daily global irradiation range of $19-41^{\circ} \mathrm{C}$ and $4.9-19.9 \mathrm{MJ} / \mathrm{m}^{2}$, respectively. The peak temperature of the heated air was increased until $15 \mathrm{~K}$ with airflow rate of 0.058 $\mathrm{kg} / \mathrm{s}$ and peak cumulative efficiency of $50 \%$. The results showed valuable and suitable 


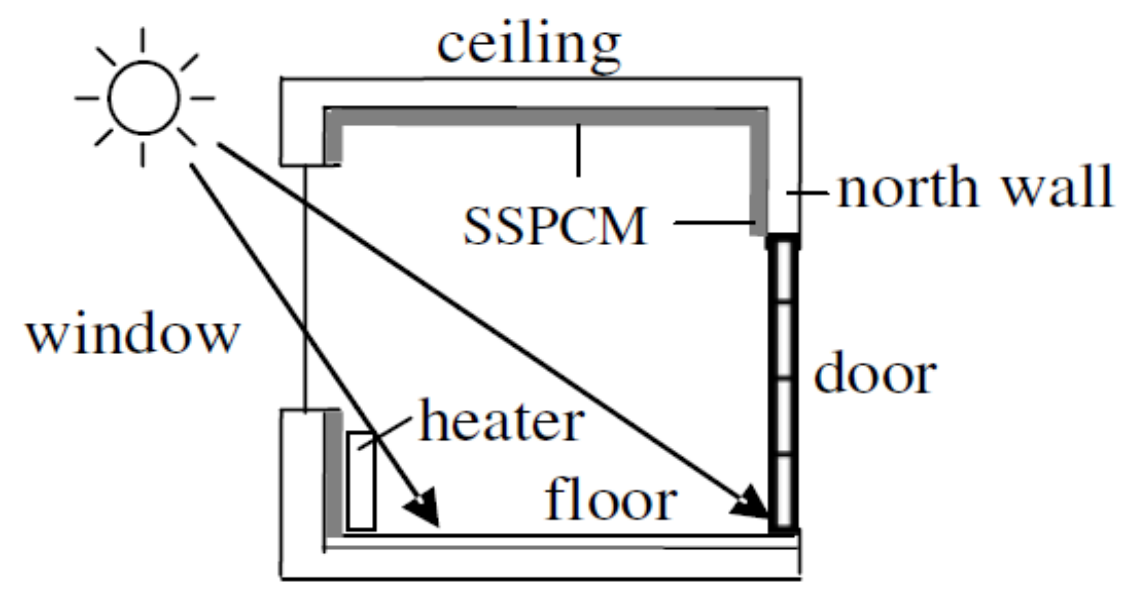

Figure 1.15: Schematic of the simulation room with SSPCM (Zhou et al. [2007])

solar air heating systems for use as crop drying applications without direct exposure to sunlight (Enibe [2002]). Zhou et al. [2007] investigated numerical performance of a hybrid heating system with the thermal storage using shape-stabilized phase change material (SSPCM) plates as shown in Figure 1.15. This study was based on a direct gain passive solar house in Beijing, China. SSPCM plates were applied such as inner lining of walls and the ceiling. Researchers accomplished a simulation study with various enthalpy models during winter heating time and load hours at late night/early morning as well as daytime in order to maintain indoor temperature at over $18^{\circ} \mathrm{C}$. The results showed that the thermal storage effect of SSPCM plates improved the indoor thermal comfort level. In addition, the thermal storage effect indicated to save normal/peak-hour energy use and total energy consumption of $47 \%$ and $12 \%$, respectively (Zhou et al. [2007]). 


\subsubsection{Conservation and Transport of Temperature Sensitive Materials}

In this section, the use of a PCM in different applications is introduced. The most frequently used commercial applications are the conservation and transport of temperature sensitive materials. A PCM provides thermal protection by using its high thermal inertia. Applications for a cold storage are divided into four types: 1) cooling: using of off peak rates and decreasing of installed power; 2) thermal protection: conservation and transport of food such as ice cream or beverages, hotel trade, catering, and so on; 3) medical applications: transport of blood or organs, operating tables, cold therapies; 4) industrial cooling system: regasification terminal (Orǿ et al. [2012]). These applications are already manufactured in the market by many companies (Sofrigam [2017]; PCM Thermal Solution [2017]; PCM Products [2017]; Rubitherm [2017]).

In order to maintain and transport sensitive food, a cold storage such as a container should be needed. Melone et al. [2012] proposed the development of PCM composites with a different latent heat range of $4-10{ }^{\circ} \mathrm{C}$ for a cold storage. Researchers provided an easy way to make a design of a micro encapsulated PCM composite for sold storage packaging by using experimental and computational results (Melone et al. [2012]). Azzouz et al. [2008]; Azzouz et al. [2009] examined the performance of a household refrigerator with a PCM modified for providing a latent heat storage capacity, which allows some operating hours of a refrigerator without a power supply. This system 
was measured under various operating conditions such as PCM thickness, ambient temperature, and thermal load. The experimental tests and numerical simulation results showed that the use of the PCM indicated 10-30\% efficiency of the coefficient of performance, depended on the thermal load and allowed continuous working time of 5-9h without power supply (Azzouz et al. [2008]; Azzouz et al. [2009]). Gin et al. [2010] investigated the effect of door openings and deforest cycles on a freezer with phase change panels to maintain stable temperature. Temperature fluctuation was measured during power loss. The experimental results showed that the use of PCMs in a freezer decreased the temperature variation. Energy consumption was also reduced by $8 \%$ and $7 \%$ during a defrost cycle and door opening, respectively (Gin et al. [2010]).

Transport of temperature sensitive products is also important and efficient work. Tan et al. [2010]carried out an experimental study on liquid/solid phase change for a cold energy storage of liquefied Natural Gas (LNG) refrigerated vehicle as shown in Figure 1.16. They studied to offer valuable design and optimization of the cold energy storage of LNG refrigerated vehicle. The PCM selected in their study had the temperature range of $-30-10{ }^{\circ} \mathrm{C}$, and the $\mathrm{PCM}$ was solidified outside the heat transfer tubes cooled by cryogenic nitrogen gas. The results from the thermal resistance analysis were to be happened the primary thermal resistance in the gaseous heat transfer fluid (HTF) inner the tube, and in order to improve the inner heat transfer and solidification performance, internal fins were applied to the tube. The ice layer was increased in radial direction with time and the ice thickness was distributed along 


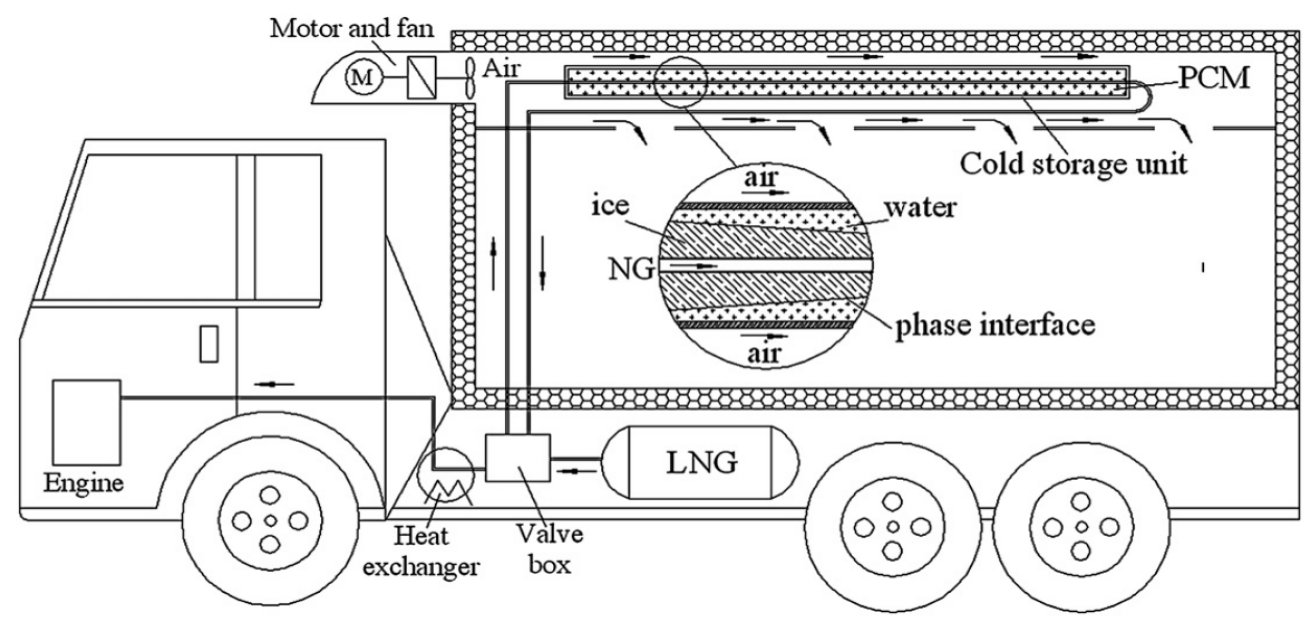

Figure 1.16: Schematic of the LNG refrigerated vehicle (Tan et al. [2010])

the axial direction in parabolic shape (Tan et al. [2010]).

\subsubsection{Smart Textiles}

In the early 1980s, the study for involving micro-encapsulated PCMs into textiles was developed by NASA in order to improve the thermal performance of textile structures, and this new technology was applied to the astronauts' space suits (Pielichowska and Pielichowski [2014]; Mondal [2008]). Vigo and Frost [1982] investigated some types of thermo-regulating fibers under ambient temperature ranges. They studied temperature sensitive hollow fibers into a PCM solution. Based on this study, many studies were developed to improve the role of thermos-regulating fibers (Vigo and Frost [1983]; Vigo [1997]). Nowadays, encapsulated PCMs in textiles are widely used for thermos-regulated textile fibers and fabric coatings as indicated in Figure 1.17. PCMs incorporated textiles are applied to space suits/gloves, sportswear, bedding 

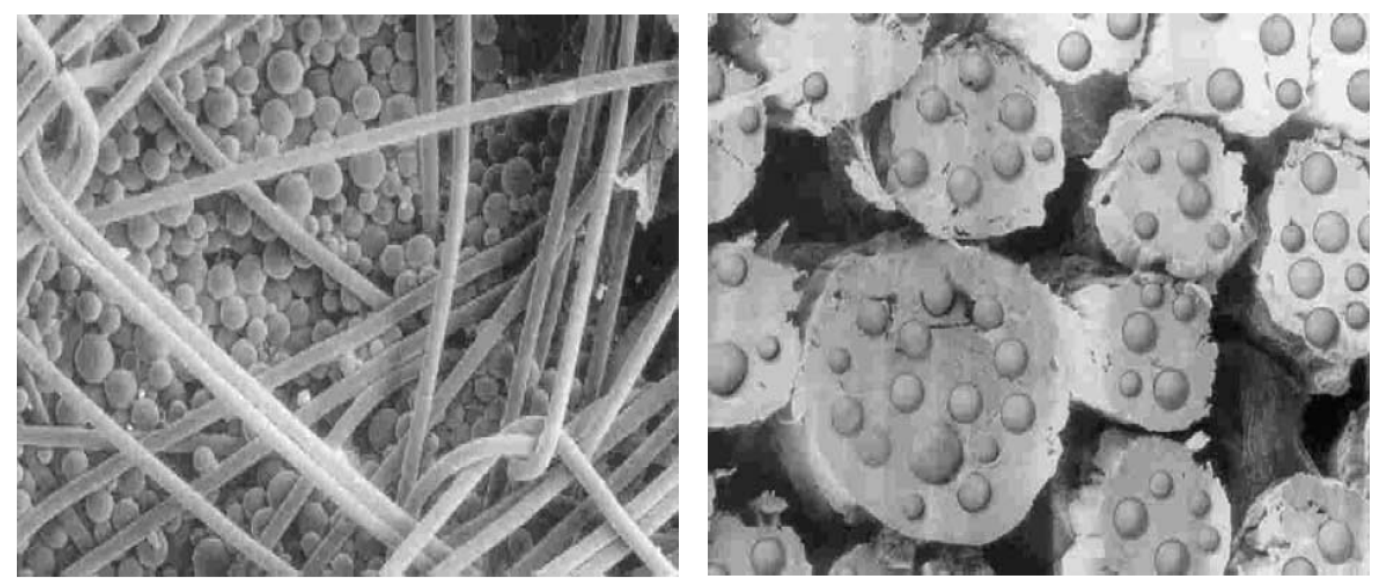

Figure 1.17: PCM microcapsules coated on the surface of fabric (a) and embedded in fiber (b) (Mondal [2008])

accessories, medical applications such as surgical apparel, bandages, ski shoes, ski accessories, mountaineering boots, racecar drivers' boots, and so on. In addition, many applications containing PCMs can be protected from drastic changes of temperature such as overheating or bitter cold, so this effect is defined as thermoregulation (Mondal [2008]).

Shin et al. [2005a]; Shin et al. [2005b] developed the thermoregulation of textile materials with microencapsulated PCMs, which are melamine-formaldehyde microcapsules, including eicosane by in situ polymerization. After that, microencapsulated PCMs were added to polyester knit fabrics by a conventional pad-dry-cure process in order to improve thermoregulation of textile materials. Researchers investigated the characterization of the microencapsulated PCMs on the particle size, size distribution, morphology, thermal properties, and stability. The conclusions showed an increase of 
heat storage capacity with an increase in the concentration of the microcapsules and the thermoregulation fabrics with microencapsulated PCMs was retained about the heat storage capacity of $40 \%$ after launderings of five times (Shin et al. [2005a]; Shin et al. [2005b]).

Koo et al. [2008] measured the thermal and physical properties of waterproof nylon fabric incorporating temperature stabilizing microencapsulated PCM with a dual coating process. Water vapor transmission rate, the thermal release capacity, and thermal insulation of the dual coated fabrics were increased with increments of contents of PCMs microencapsulated. From the results, this study showed better performance of the dual coated fabrics for thermal regulation than using dry/wet coating method. This is the reason why the results of water entry pressure, water vapor transmission rate, and thermal performance were improved (Koo et al. [2008]).

Many researchers reported on the electrospinning of ultrafine fibers thermo-regulated, producing a new method with in situ polymerization and complex coacervation and investigating the effect of thermal protective clothing with various encapsulated PCMs (Chen et al. [2007]; Onder et al. [2008]; Rothmaier et al. [2008]; Wang et al. [2006]).

\subsubsection{Biomaterials and Biomedical Applications}

Phase Change Materials (PCMs) should be also considered important materials for biomaterials and biomedical applications for thermal protection. Recently, there have been many commercial products such as special bandages, thermal regulated textiles 
in order to maintain comfortable skin temperature for burns and heating/cooling therapies (Zhang [2001]). Moreover, merchandise as hot/cold PCM pads for treatment of a local pain can be easily gotten in the market.

Mondieig et al. [2003] presented temperature-sensitive biomedical products that were made of molecular alloys for thermal protection. The biomedical device as the storage for the thermal protection of blood element consisted of a double walled pouch including molecular alloys phase change material. The molecular alloys phase change materials pouches were in a freezer to make a solid state and then after complete solidification, the pouch was contained into the carrier bag. When the blood was moved with the device at room temperature, external calories were discontinued by the molecular alloys phase change materials. The result showed that the pouch with the molecular alloys phase change materials could be maintained at a lower temperature than $10^{\circ} \mathrm{C}$ over 6 hours (Mondieig et al. [2003]).

Lv et al. [2011] proposed a valuable study for thermal protection by using microencapsulated phase change micro/nanoparticles during cryosurgery. They studied to protect the healthy tissue near the cancerous from thermal injury with the use of microencapsulated PCM particles. The PCMs were delivered to the healthy tissue by various injections. From the theoretical results, this new method indicated the destruction of cancer tissues within a proved spatial domain during cryosurgery around healthy tissue. Also, the PCMs, which were not embedded and directly adjacent to the tumor, could develop protection efficacy (Lv et al. [2011]). 
Wang et al. [2010a] proposed a new thermal bio-sensing technique for the highly sensitive thermal detection of thrombin by using RNA aptamer-functionalized phase change nanoparticles as thermal probes. The phase change nanoparticles as thermal probes absorb heat energy and indicate sharp thermal peak during temperature range. Moreover, the presence and amount of thrombin can be assumed from the positions and areas of thermal peaks. Silicon nanopillars including high aspect ratio and thermal conductivity can improve the detection sensitivity by four times under condition of thrombin concentration of 55nM. In addition, the detection could be carried out in serum due to thermal readout, which is immune to colored species (Wang et al. [2010a]).

\subsubsection{Electronics}

The technological developments of electronic devices have shown high density, miniaturization, high performance, and more power into small packages. Thermal management by using a PCM based on cooling system has had critical potential for using electronic devices such as cellular phone, digital cameras, and laptops, etc. Since such devices are not run continuously for a long time, PCM based heat sinks should maintain the working temperature of electronics and prevent overheating. Generally, the allowable maximum temperatures of devices to avoid overheating and damage to such devices are from $85^{\circ} \mathrm{C}$ to $120^{\circ} \mathrm{C}$ (Kandasamy et al. [2008]; Alrashdan et al. [2010]). 


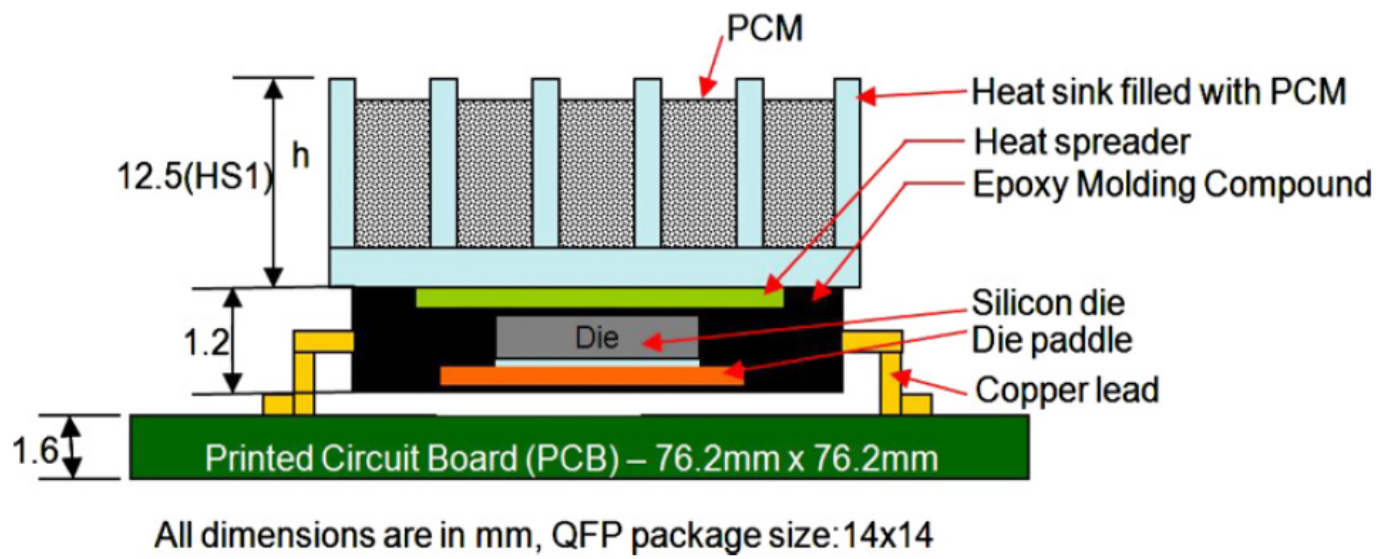

Figure 1.18: Schematic of PCM applied heat sink under QFP package (Kandasamy et al. [2008])

Kandasamy et al. [2007] experimentally presented applications of a new PCM package for thermal management of portable electronic devices under various parameters as power input, orientation of package, and melting/ freezing times. The results showed that as power inputs were increased, the melting rates were increased. The importance of the thermal resistance of the device and the power level used in the PCM packages were also indicated for design of a passive thermal control system, cost, and size (Kandasamy et al. [2007]). In another study with similar results by Kandasamy et al. [2008], transient cooling of plastic quad flat package (QFP) electronic devices using a PCM based on heat sinks was evaluated as indicated in Figure 1.18 (Kandasamy et al. [2008]).

Yin et al. [2008] investigated thermal management as heat transfer of a heat sink with composite PCMs. A composite PCM used in their study was made of paraffin 
into expanded graphite for good absorbability, and the composite PCM was applied into the heat sink of the electronic device as a passive electronic cooling system. The system showed good reliability for resisting the shock of high heat flux and operating stability of devices. The heat transfer coefficient of the heat sink system with the PCM was up to 3 times higher than without the PCM (Yin et al. [2008]). In another study by Yin et al. [2010], a PCM, which was consisted of paraffin and porous expanded graphite composites, was applied in electronic cooling systems. The apparent heat transfer coefficients of the systems were 1.25-1.30 times greater than the traditional cooling systems (Yin et al. [2010]).

Krishnan et al. [2005] presented a new hybrid heat sink, which is combined an active plate fin heat sink with the tip immersed in a passive PCM, for transient thermal management of electronics under conditions of the location, amount/type of PCM, and the fin thickness. In this study, two kinds of PCMs were used such as an organic PCM and a metallic PCM. Thermal diffusivity with the metallic PCM showed better performance than the organic PCM, but the high density with the metallic PCM was unsuitable for a low weight heat sink. As the heat transfer rate of fin was increased, fin thickness and amount of PCMs were also increased, but melting temperatures of PCMs were decreased (Krishnan et al. [2005]).

An experimental study on the cooling of mobile electronic devices such as personal digital assistants (PDAs) and wearable computers using a heat storage unit with a PCM was carried out by Tan and Tso [2004]. The PCM used in their study was n- 
eicosane PCM and was filled in the cavities of the internally fitted heat storage unit. The high latent heat of n-eicosane PCM based on the system absorbed the heat from the chips and maintained the temperature of chips within the allowable temperature of $50^{\circ} \mathrm{C}$ for 2 hours of transient operations of the device. Researchers showed that the temperature of a mobile electronic device could be stable with increasing the amount of PCMs. In addition, they predicted the configuration of heaters in IC package with high power dissipation could operate a higher temperature (Tan and Tso [2004]).

\subsubsection{Automotive Industry}

Phase Change Materials (PCMs) are also widely used for thermal management of catalytic converters (Burch et al. [1996]; Burch et al. [1995]), internal combustion engines (Kim et al. [2010]), and engine cooling systems in automotive industry (Burch et al. [1995]).

Kim et al. [2010] proposed a new cooling method using a PCM in an automotive engine. A new cooling technique was applied in a heat accumulator in order to downsize the automotive cooling system. The cooling system was affected to reduce harmful emissions and improve fuel economy. In order to verify the new system utilizing the heat load averaging capabilities of a PCM, three types of samples simulated are a full size sample of an engine, a down-sized sample of an engine, and a downsized sample of an engine with a heat accumulator including the PCM inside. The results showed that as the full size of the system was decreased by $30 \%$, the smaller 
design indicated to fail dissipation of the peak heat load, to increase in the coolant temperature of $25^{\circ} \mathrm{C}$ rather than full size system, and to decrease the cooling warm up time during a cold start. On the other hand, the peak heat load was averaged in the down size system with heat accumulator with the PCM (Kim et al. [2010]).

Burch et al. [1995] studied to reducing cold start emissions by catalytic converter thermal management. They established variable-conductance vacuum-insulated automotive catalytic converters with a PCM. Thermal analysis was conducted to maintain the converter temperature of $350^{\circ} \mathrm{C}$ for 17 hours. In order to perform the emission test, carbon monoxide and hydrocarbon compounds emissions were measured. In the case of including a palladium catalyst, carbon monoxide and hydrocarbon compounds emissions were reduced by $52 \%$ and $29 \%$ by Federal Test Procedure (FTP) cycle, respectively. According to FTP cycle test, the emission reduction method demonstrated the potential for simplicity, lower cost, and reduced thermal strains (Burch et al. [1995]).

\subsubsection{Space Applications}

Space applications are needed a crucial requirement. Yimer and Adami [1997] improved an analytical model for studying of thermal storage systems based on Lithium hydride $(\mathrm{LiH})$ for space applications. They researched the effect of several geometric and thermal parameters of the thermal storage system with two dimensional shell and tube configurations. The result indicated that energy stored was increased with 
an increase of inner tube and outshell diameters because energy for saving depended on heat or energy store capacity of a material or an object. In addition, charging rates and heat were increased with a decrease of the initial system temperature and an increase of effective thermal conductivity caused by acceleration forces (Yimer and Adami [1997]).

Cui et al. [2003] investigated thermal performance of a heat receiver for the NASA 2KW solar dynamic power system with thermal storage module, which was made of a triple PCM unit. As shown in Figure 1.19, the heat receiver with multiple PCM was measured under the conditions of maximal temperature for heat transfer, working fluid exit temperature and liquid PCM fraction of the total heat transfer tube. The results indicated using multiple PCMs rather than a single PCM could improve the energy rate with a decreasing the fluctuation of the gas exit temperature. Therefore, ability of the heat receiver was enhanced, and weight of the receiver was decreased (Cui et al. [2003]).

Cui et al. [2008] conducted numerical simulations and experiment investigation for a solar heat reciever. A $\mathrm{LiF}-\mathrm{CaF}_{2}$ eutectic mixture PCM and dry air as the working fluid were used in this study. In order to evaluate the thermal performance of the solar heat receiver, the effects of inlet/outlet temperatures and flow rates were investigated in their study. Resutls showed that both of input power and flow rate affected outlet temperature and temperature increase of inlet/outlet. Input power was useful during the daytime because outlet temperature reached until $834 \mathrm{~K}$ at the 


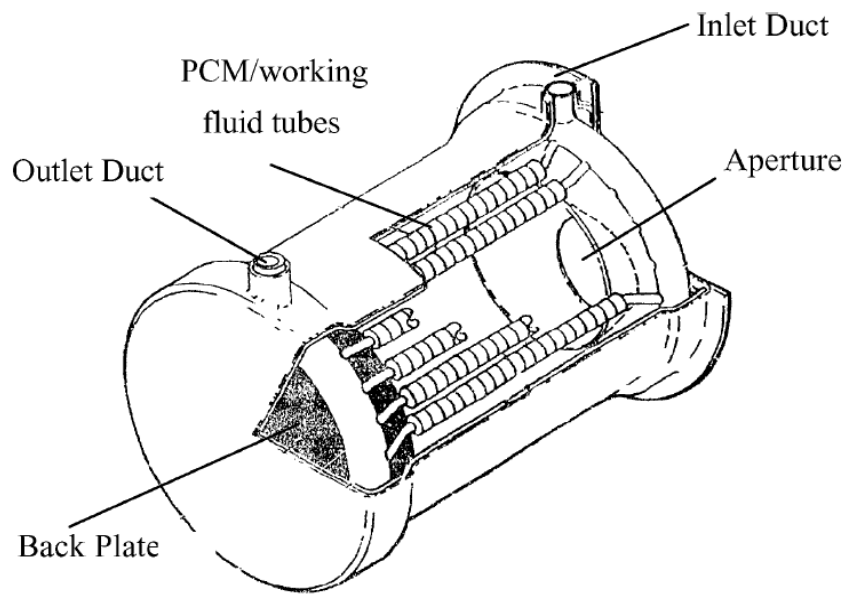

Figure 1.19: Heat receiver (Cui et al. [2003])

end of sunlight period, and flow rate was also useful during the daytime and nighttime because outlet temperature reached 820K at the end of night period (Cui et al. [2008]).

Wu et al. [2013] investigated the influence of shape-stabilized phase change materials (SSPCMs) on spacecraft thermal control under an extreme thermal environment condition. In order to verify the valuable use of SSPCM on spacecraft under the harsh condition, the thermal reaction of SSPCM in short-term high heat flux was assessed in their study. The result showed that SSPCM was indicated efficient absorption of heat to prevent faults of the thermal control system during the change of outer heat flux for the spacecraft (Wu et al. [2013]). 


\section{Chapter 2}

\section{Experiments}

\subsection{Phase Change Materials (PCMs)}

Four types of Phase Change Materials (PCMs), which are based on minerals, have been investigated in this study each with macro-encapsulated PCM. The phase change temperatures of those materials are at $21^{\circ} \mathrm{C}, 23^{\circ} \mathrm{C}, 26^{\circ} \mathrm{C}$, and $30^{\circ} \mathrm{C}$, respectively. Also, the dimensions of the specimens of macro-encapsulated PCMs are $0.047 \mathrm{~m} \mathrm{x} 0.095 \mathrm{~m}$ $\mathrm{x} 0.005 \mathrm{~m}$. The mass of the specimens is $0.0336 \mathrm{~kg}$. This study was conducted based on ASTM C1784-14. The properties of the PCMs are shown in Table 2.1. 
Table 2.1: Properties of PCMs(Infinity R Corporation [2017a])

\begin{tabular}{|c|c|c|c|}
\hline Name & Type & Form & $\begin{array}{c}\text { Melting Temp. } \\
\left({ }^{\circ} \mathrm{C}\right)\end{array}$ \\
\hline Sample 1 & Mineral & $\begin{array}{c}\text { Macro- } \\
\text { encapsulated }\end{array}$ & $21^{\circ} \mathrm{C}$ \\
\hline Sample 2 & Mineral & $\begin{array}{c}\text { Macro- } \\
\text { encapsulated }\end{array}$ & $23^{\circ} \mathrm{C}$ \\
\hline Sample 3 & Mineral & $\begin{array}{c}\text { Macro- } \\
\text { encapsulated }\end{array}$ & $26^{\circ} \mathrm{C}$ \\
\hline Sample 4 & Mineral & $\begin{array}{c}\text { Macro- } \\
\text { encapsulated }\end{array}$ & $30^{\circ} \mathrm{C}$ \\
\hline
\end{tabular}




\subsection{Experimental Methods}

\subsubsection{Experimental Methodology}

\subsubsection{Data Analysis}

The thermal conductivity of PCM can be calculated by using Fourier's law given by:

$$
\rho c_{p} \frac{\partial T}{\partial t}=k \frac{\partial^{2} T}{\partial x^{2}}
$$

The boundary conditions:

$$
\begin{aligned}
& T(0, t)=T_{1} \\
& T(L, t)=T_{2}
\end{aligned}
$$

The initial condition:

$$
T(x, 0)=f(x)
$$

Where $\rho$ is the mass density of the sample $\left(\mathrm{kg} / \mathrm{m}^{3}\right), C_{p}$ is the specific heat $(\mathrm{J} / \mathrm{kgK})$, $k$ is the thermal conductivity $(\mathrm{W} / \mathrm{mK}), T$ is the temperature $\left({ }^{\circ} \mathrm{C}\right), x$ is the thickness $(\mathrm{m})$, and $t$ is the time (sec). 
In order to find out the equilibrium, $\frac{\partial T}{\partial t}$ should be zero with $\frac{\partial^{2} T}{\partial x^{2}}=0$

When $T=C_{1} x+C_{2}$ at $T(0)=T_{1}$, we can obtain $C_{2}=T_{1}$. At $T(L)=T_{2}$, we can also obtain $T_{2}=C_{1} L+C_{2}$. This equation can be changed as $T_{2}=C_{1} L+T_{1}$, and we can then find out $C_{1}=\frac{T_{2}-T_{1}}{L}$.

This leads to

$$
T(x)=\frac{T_{2}-T_{1}}{L} x+T_{1}
$$


Consider 1-D heat conduction with homogeneous BCs in the different form, the Fourier law can be written as:

$$
\frac{1}{\alpha} \frac{\partial T}{\partial t}=\frac{\partial^{2} T}{\partial x^{2}} \quad\left(\alpha=\frac{k}{\rho c_{p}}\right)
$$

The boundary conditions:

$$
\begin{aligned}
& T(0, t)=0 \\
& T(L, t)=0
\end{aligned}
$$

The initial condition:

$$
T(x, 0)=f(x)
$$

We assume

$$
T(x, t)=\varphi(x) G(t)
$$

and substitute 2.8 into 2.5.

$$
\begin{gathered}
\frac{\partial T}{\partial t}=\varphi(x) \frac{\partial G(t)}{\partial t} \\
\frac{\partial^{2} T}{\partial x^{2}}=\frac{\partial^{2} \varphi(x)}{\partial x^{2}} G(t) \\
\varphi(x) \frac{\partial G(t)}{\partial t} \frac{1}{\alpha}=\frac{\partial^{2} \varphi(x)}{\partial x^{2}} G(t)
\end{gathered}
$$




$$
\frac{1}{\alpha} \frac{1}{G(t)} \frac{\partial G(t)}{\partial t}=\frac{\partial^{2} \varphi(x)}{\partial x^{2}} \frac{1}{\varphi(x)}
$$

$$
\frac{1}{\alpha G} \frac{d G}{d t}=\frac{1}{\varphi} \frac{d^{2} \varphi}{d x^{2}}=-\lambda
$$

$$
\frac{d^{2} \varphi}{d x^{2}}=-\lambda \varphi
$$

$$
\frac{d G}{d t}=-\lambda \alpha G
$$

$$
\begin{aligned}
& \frac{d G}{d t}+\lambda \alpha G=0 \\
& G(t)=C e^{-\lambda \alpha G}
\end{aligned}
$$


For $\frac{d^{2} \varphi}{d x^{2}}+\lambda \varphi=0$ with boundary conditions $\varphi(0)=0$ and $\varphi(L)=0$

The solution from BCs is

$$
\begin{gathered}
\varphi(x)=C_{1} \cos (\sqrt{\lambda} x)+C_{2} \sin (\sqrt{\lambda} x) \\
\varphi(0)=C_{1} \cos (\sqrt{\lambda} x)=0 \quad C_{1}=0 \\
\varphi(L)=C_{2} \sin (\sqrt{\lambda} L)=0 \quad \sin \sqrt{\lambda} L=0 \\
\sqrt{\lambda} L=n \pi \quad(n=1,2,3 \ldots), \quad \lambda=\left(\frac{n \pi}{L}\right)^{2} \\
\varphi_{n}(x)=\sin \left(\frac{n \pi x}{L}\right)
\end{gathered}
$$

Since we have assumed equation 2, We can obtain

$$
T(x, t)=\sum_{n=1}^{\infty} B_{n} \sin \left(\frac{n \pi x}{L}\right) e^{-\lambda \alpha t}
$$

For initial condition, $T(x, 0)=f(x)$

$$
T(x, 0)=f(x)=\sum_{n=1}^{\infty} B_{n} \sin \frac{n \pi x}{L}
$$




$$
\begin{array}{r}
B_{n}=\frac{\int_{0}^{L} f(x) \sin \left(\frac{n \pi x}{L}\right) d x}{\int_{0}^{L} \sin ^{2}\left(\frac{n \pi x}{L}\right) d x} \\
=\frac{2}{L} \int_{0}^{L} f(x) \sin \left(\frac{n \pi x}{L}\right) d x \\
\int_{0}^{L} \sin \frac{m \pi x}{L} \sin \frac{n \pi x}{L} d x=\left\{\begin{array}{cc}
0 & (m \neq n) \\
\frac{L}{2} & (m=n)
\end{array}\right.
\end{array}
$$


Consider 1-D heat conduction with non-homogeneous BCs.

Fourier law that can be calculated thermal conductivity, thermal diffusivity, equilibrium time or temperature can be written as:

$$
\frac{1}{\alpha} \frac{\partial T}{\partial t}=\frac{\partial^{2} T}{\partial x^{2}}
$$

The boundary conditions:

$$
\begin{aligned}
& T(0)=T_{1} \\
& T(L)=T_{2}
\end{aligned}
$$

The initial condition:

$$
T(x, 0)=f(x)
$$

The equilibrium solution is

$$
\begin{gathered}
\frac{d^{2} T_{e}}{d x^{2}}=0 \\
T_{e}(x)=\frac{T_{2}-T_{1}}{L} x+T_{1}
\end{gathered}
$$

We assume that

$$
\nu(x, t)=T(x, t)-T_{e}(x)
$$


This equation can be rearranged below:

$$
\begin{gathered}
\frac{\partial^{2} T}{\partial x^{2}}=\frac{\partial^{2} \nu}{\partial x^{2}} \\
\frac{\partial T}{\partial t}=\frac{\partial \nu}{\partial t} \\
\frac{1}{\alpha} \frac{\partial \nu}{\partial t}=\frac{\partial^{2} \nu}{\partial x^{2}}
\end{gathered}
$$

The boundary conditions:

$$
\begin{aligned}
& \nu(0, t)=T(0, t)-T_{e}(0)=0 \\
& \nu(x, t)=T(x, t)-T_{e}(x)=0
\end{aligned}
$$

The initial condition:

$$
\nu(x, 0)=f(x)-T_{e}(x)
$$


When the boundary conditions are applied, we can get that

$$
\begin{gathered}
\nu(x, t)=\sum_{n=1}^{\infty} B_{n} \sin \left(\frac{n \pi x}{L}\right) e^{-\alpha \lambda t} \\
f(x)-T_{e}(x)=\sum_{n=1}^{\infty} B_{n} \sin \left(\frac{n \pi x}{L}\right) \\
B_{n}=\frac{2}{L} \int_{0}^{L}\left[f(x)-T_{e}(x)\right] \sin \left(\frac{n \pi x}{L}\right) d x \\
T(x, t)=\frac{T_{2}-T_{1}}{L} x+T_{1}+\sum_{n=1}^{\infty} B_{n} \sin \left(\frac{n \pi x}{L}\right) e^{-\alpha \lambda t}
\end{gathered}
$$




\subsubsection{Differential Scanning Calorimetry}

The Differential Scanning Calorimeter (DSC) technique is a widely used method for determining the thermal characterizations and properties of Phase Change Materials (PCMs). The basic theory of the DSC is to expose a specimen to a heat signal and to identify the estimated response associated with the energy and temperature under the thermal conditions, which occur for the temperature spectrum or time interval (Craig and Reading [2006]). The DSC technique is effective for the determination of thermal properties and behaviors of materials, including melting temperature, freezing temperature, enthalpy, specific heat capacity, crystallization, glass transitions, and kinetic reactions (Craig and Reading [2006]; Jin et al. [2014]).

In DSC analysis, the heat from a furnace in the DSC machine flows toward a sample pan and the reference pan, which are placed with thermocouples, and the system measures the heat flow difference between the sample pan and a reference pan as a function of temperature.

Because the pressure is constant in DSC equipment, the equation of heat flow is comparable to enthalpy change shown by:

$$
\left(\frac{d q}{d t}\right)_{p}=\frac{d H}{d t}
$$

Where $d q$ is heat flow $(\mathrm{mW}), d t$ is time internal (sec), $d H$ is enthalpy $(\mathrm{J} / \mathrm{g})$. 


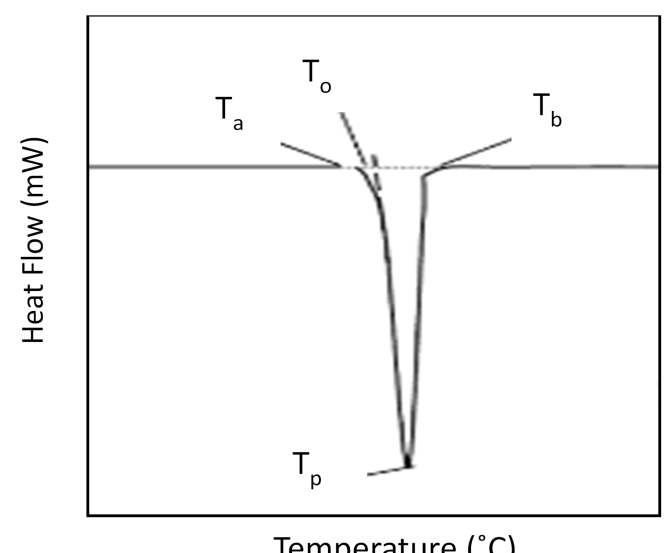

Figure 2.1: Typical DSC curve for heat flux (Reading and Craig [2006])

Also, the equation of the difference in heat flow to the sample pan and the reference pan can be written as:

$$
\frac{\Delta d H}{d t}=\left(\frac{d H}{d t}\right)_{\text {sample }}-\left(\frac{d H}{d t}\right)_{\text {reference }}
$$

When heat flow for the sample pan is higher than heat flow for the reference pan, an endothermic process is occurs in a positive form of $\frac{\Delta d H}{d t}$. When heat flow for the reference pan is higher than heat flow for the sample pan, an exothermic process occurrs in a negative form of $\frac{\Delta d H}{d t}$ (Reading and Craig [2006]; Particle Analytical [2017]). DSC measurement indicates the result of heat flow from a sample pan as a function of temperature, and its result shows a curve of heat flux vs. temperature as shown in Figure 2.1.

In Figure 2.1, $\mathrm{T}_{a}$ and $\mathrm{T}_{b}$ are the temperature range during the phase change of 
$\mathrm{PCM}$, and $\mathrm{T}_{o}$ is the onset temperature, and $\mathrm{T}_{p}$ is the peak temperature (the melting temperature) of a PCM.

In this study, DSC with the dynamic measurement method is used to determine the properties of PCMs. Two measuring equipment are used in this study. First of all, for original PCMs and PCMs melted, the experiments are carried out using DSC Q 200 equipment from TA Instruments with aluminum pans and lids under nitrogen atmosphere. Samples between $6 \mathrm{mg}$ to $7 \mathrm{mg}$ are sealed in an aluminum pan and lid. For original PCMs, PCMs melted, and PCM in liquid state, the experiments are conducted using DSC STA 8000 equipment from Perkin Elmer Company with ceramic sample pans and lids under argon atmosphere. Samples between $105 \mathrm{mg}$ to $110 \mathrm{mg}$ are sealed in a ceramic pan and lid.

The dynamic DSC condition is 4 steps. The start temperature is $15^{\circ} \mathrm{C}$, and the first step is to hold for $1 \mathrm{~min}$ at $15^{\circ} \mathrm{C}$ due to the temperature stabilizing. The second step is to heat from $15^{\circ} \mathrm{C}$ to $105^{\circ} \mathrm{C}$ at $5^{\circ} \mathrm{C} / \mathrm{min}$, and the third step is to hold for 1 min at $105^{\circ} \mathrm{C}$. In the case of the last step, there are two types of cooling systems. The first type for original PCMs and PCMs melted is to be cooled down from $105^{\circ} \mathrm{C}$ to $-40^{\circ} \mathrm{C}$ at a cooling rate of $5^{\circ} \mathrm{C} / \mathrm{min}$. The other type for $\mathrm{PCMs}$ is decreased from $105^{\circ} \mathrm{C}$ to $15^{\circ} \mathrm{C}$ at $5^{\circ} \mathrm{C} /$ min. Dynamic DSC temperature profiles and measurement conditions for thermophysical property analyses of PCMs are shown in Figures 2.2 to 2.3 and Tables 2.2 to 2.3 , respectively.

Isothermal mode in DSC measurement is performed for the determination of time 
until steady state is achieved. Isothermal temperature is determined by onset, peak, and end temperatures from dynamic DSC results. 


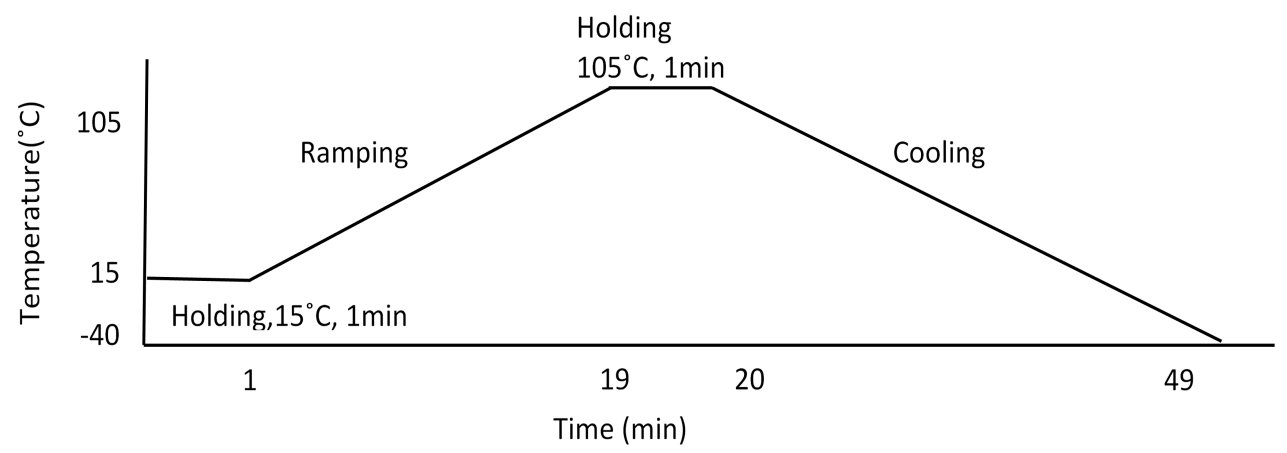

Figure 2.2: Dynamic DSC temperature profile with the first cooling system

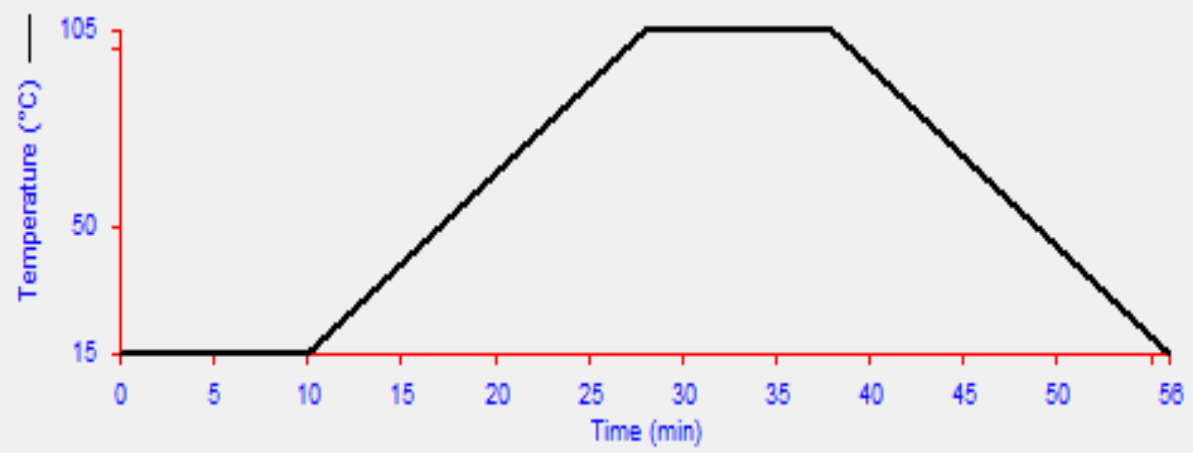

Figure 2.3: Dynamic DSC temperature profile with the second cooling system 
Table 2.2: Measurement condition of DSC analysis with the first cooling system

\begin{tabular}{|c|c|c|c|c|}
\hline $\begin{array}{c}\text { Dynamic } \\
\text { Mode }\end{array}$ & State & $\begin{array}{c}\text { Temperature } \\
\text { Range }\end{array}$ & $\begin{array}{c}\text { Heating Rate } \\
\text { or Cooling } \\
\text { Rate }\end{array}$ & Time \\
\hline Step 1 & Holding & $15^{\circ} \mathrm{C}$ & - & $1 \mathrm{~min}$ \\
\hline Step 2 & Heating & $15^{\circ} \mathrm{C}^{\sim} 105^{\circ} \mathrm{C}$ & $5^{\circ} \mathrm{C} / \mathrm{min}$ & $18 \mathrm{~min}$ \\
\hline Step 3 & Holding & $105^{\circ} \mathrm{C}$ & - & $1 \mathrm{~min}$ \\
\hline Step 4 & Cooling & $105^{\circ} \mathrm{C}^{\sim}-40^{\circ} \mathrm{C}$ & $5^{\circ} \mathrm{C} / \mathrm{min}$ & $29 \mathrm{~min}$ \\
\hline
\end{tabular}

Table 2.3: Measurement condition of DSC analysis with the second cooling system

\begin{tabular}{|c|c|c|c|c|}
\hline $\begin{array}{c}\text { Dynamic } \\
\text { Mode }\end{array}$ & State & $\begin{array}{c}\text { Temperature } \\
\text { Range }\end{array}$ & $\begin{array}{c}\text { Heating Rate } \\
\text { or Cooling } \\
\text { Rate }\end{array}$ & Time \\
\hline Step 1 & Holding & $15^{\circ} \mathrm{C}$ & - & $10 \mathrm{~min}$ \\
\hline Step 2 & Heating & $15^{\circ} \mathrm{C}^{\sim} 105^{\circ} \mathrm{C}$ & $5^{\circ} \mathrm{C} / \mathrm{min}$ & $18 \mathrm{~min}$ \\
\hline Step 3 & Holding & $105^{\circ} \mathrm{C}$ & - & $10 \mathrm{~min}$ \\
\hline Step 4 & Cooling & $105^{\circ} \mathrm{C}^{\sim} 15^{\circ} \mathrm{C}$ & $5^{\circ} \mathrm{C} / \mathrm{min}$ & $18 \mathrm{~min}$ \\
\hline \hline $\begin{array}{c}\text { Isothermal } \\
\text { Mode }\end{array}$ & State & $\begin{array}{c}\text { Temperature } \\
\text { Range }\end{array}$ & Heating Rate & Time \\
\hline Step 1 & Holding & $\begin{array}{c}\text { Onset Temp. } \\
\text { Peak Temp. } \\
\text { End Temp. }\end{array}$ & - & 60 min \\
\hline
\end{tabular}




\subsubsection{Enthalpy Curves}

Phase Change Materials (PCMs) can absorb and store 5-14 times more heat than sensible heat storage materials can even though temperature range around the melting temperature is narrow. During the change of material phases, the temperature does not change and store any energy. The phase change is finished, and then the temperature is increased or decreased. This description is shown in Figure 2.4. (Günther et al. [2009]; Infinity R Corporation [2017b]).

Enthalpy change curve, such as the stored heat curve as a function of temperature, can represent the DSC thermogram curve. In addition, the enthalpy change curve can provide thermophysical properties of PCM by one curve only. Since the specific heat

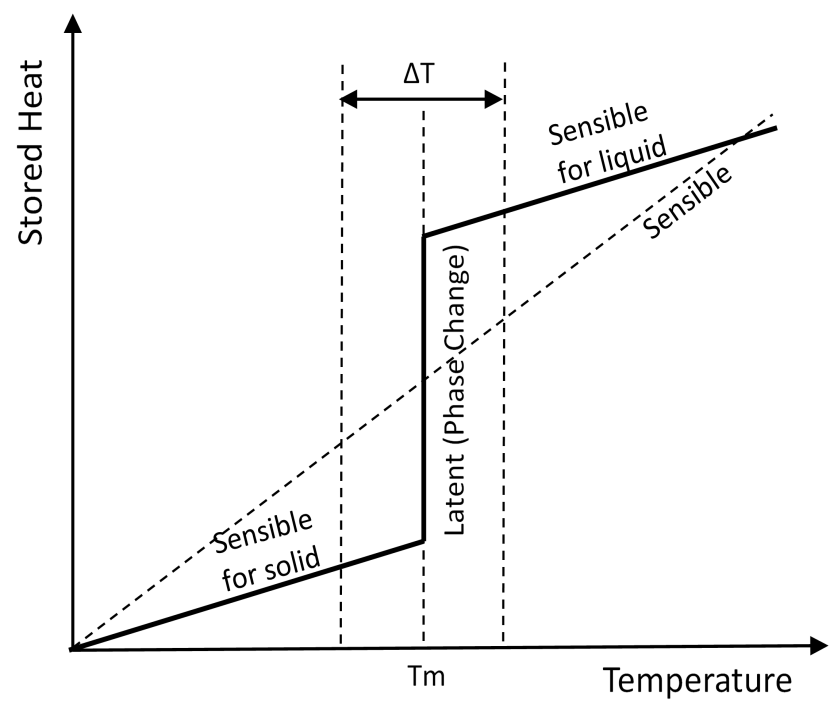

Figure 2.4: A comparison of stored heat in latent material and sensible material (Günther et al. [2009]; Infinity R Corporation [2017b]) 
capacity from DSC result is not changed while the phase change occurs, the equation of enthalpy change can be expressed as:

$$
\Delta H=\int_{T_{1}}^{T_{2}} C_{p}(T) d T=\int_{T_{1}}^{T_{2}} \frac{1}{m} \frac{\delta Q / d t}{d T / d t} d T=\int_{T_{1}}^{T_{2}} \frac{1}{m} \frac{\delta Q}{d T} d T
$$

Where $\Delta H$ is the enthalpy $(\mathrm{J} / \mathrm{g}), \mathrm{T}_{1}$ and $\mathrm{T}_{2}$ are temperature range $\left({ }^{\circ} \mathrm{C}\right), C_{p}$ is the specific heat capacity at constant pressure $\left(\mathrm{J} / \mathrm{g}^{\circ} \mathrm{C}\right), \mathrm{m}$ is the mass of the sample $(\mathrm{g})$, $\delta Q / d t$ is the heat flow $(\mathrm{W} / \mathrm{g})$, and $d T / d t$ is the heating rate $\left({ }^{\circ} \mathrm{C} / \mathrm{sec}\right)$.

\subsubsection{Specific Heat Capacity Calculations}

The specific heat capacity at constant pressure $\left(C_{p}\right)$ is an important function, which can be measured by DSC equipment, because the amplitude of the DSC curve is proportional to the heat capacity at constant pressure during the phase change or chemical reactions. Also, heat capacity shows how much heat is needed during increasing temperature by $1^{\circ} \mathrm{C}$ for the sample (Menczel et al. [2009]). The specific heat capacity can also be measured by the DSC measurement, and the equation can be expressed as:

$$
C p(T)=\left[\frac{60}{H R}\right] \frac{\Delta y}{m}
$$

Where $C_{p}$ is the specific heat capacity of a material at a temperature $(T)$, and 60 is the conversion constant from minute to second, $H R$ is the heating rate $\left({ }^{\circ} \mathrm{C} / \mathrm{min}\right), \Delta y$ is the variation of heat flow in the y-axis $(\mathrm{mW})$ such as between base line and the 
sample of a DSC curve at the temperature, and $m$ is the mass $(\mathrm{mg})$. Based on the equation, $\left[\frac{60}{H R}\right]$ is the constant value and can be adapted to the specific heat capacity $\left(\mathrm{J} / \mathrm{g}^{\circ} \mathrm{C}\right)($ Saeed $[2016])$.

Also, as shown in Figure 2.4, the specific heat capacity can be calculated from the enthalpy as function of temperature curve. In sensible parts of the liquid state and the solid state, the specific heat capacities of solid and liquid states can be directly taken from the enthalpy-temperature curve.

Since the stored energy is the same at a constant pressure during the phase change process, equation (2.47) can be changed shown by:

$$
C p=\left(\frac{\partial H}{\partial T}\right)_{p}
$$

Where $\partial H$ is the enthalpy $(\mathrm{J} / \mathrm{g})$, and $\partial T$ is the temperature gradient $\left({ }^{\circ} \mathrm{C}\right)$ (Menczel et al. [2009]; Marin et al. [2003]).

In this study, the dynamic mode in DSC measurement is used to assess the specific heat capacity by DSC STA 8000 equipment from Perkin Elmer Company with ceramic pans and lids under argon atmosphere and DSC Q 200 equipment from TA Instruments with aluminum pans and lids under nitrogen atmosphere, respectively. 


\subsubsection{Heat Flow Meter}

In this study, heat flow meter equipment is used to measure the apparent thermal conductivities, volumetric specific heat capacities, and enthalpies of PCMs. The experiments are conducted using heat flow meter FOX 314 equipment from TA Instruments. Also, this equipment is designed by ASTM C 518-04 "Standard Test Method for Steady-State Thermal Transmission Properties by Means of the Heat Flow Meter Apparatus" and calibrated by using the NIST SRM 1450b (Standard Reference Material of the National Institute of Standards and Technology), and the Special High Accuracy (0.5\%) EPS (Expanded Polystyrene) NIST Standard. Thermal conductivities of PCMs are measured based on ASTM C1045-1 as "Standard Practice for Calculating Thermal Transmission Properties under Steady-State Conditions" (TA Instruments [2016]).

\subsubsection{Thermal Conductivity}

In this study, heat flow meter FOX 314 equipment is used to determine the thermal conductivity of PCM. Thermal conductivities of each PCMs, which are fully melted and fully frozen products, are measured under NIST 1450b calibration condition. Temperature conditions of PCMs are shown in Table 2.4. The temperature of the lower plate is higher than that of the upper plate, and there are high sensitive heat flow transducers and thermocouples in each plate. 
The heat flow meter equipment can measure thickness of the sample by using two plates automatically within $+/-0.025 \mathrm{~mm}$ accuracy. Also, there are high output transducers, which are consisted of hundreds of small thermocouples, along surfaces of both plates. Hundreds of small thermocouples allow high sensitivity for the transducers and an integration of the signals. Temperature of the plates can be preserved at any temperature within $+/-0.02^{\circ} \mathrm{C}$.

Thermal conductivity of a PCM can be calculated by using one-dimensional Fourier's law given by:

$$
q=-k \frac{d T(x)}{d x}
$$

where $q$ is heat flux $\left(\mathrm{W} / \mathrm{m}^{2}\right), k$ is thermal conductivity $(\mathrm{W} / \mathrm{mK})$, and $\frac{d T(x)}{d x}$ is temperature gradient $(\mathrm{K} / \mathrm{m})$ (Husayni [1999]).

Electric signals of the heat flow transducers $Q(\mu V)$ are proportional to the heat flux $q$ through the sample given by:

$$
q=k_{\text {cal }} T_{\text {cal }}\left(\Delta T_{\text {cal }} / \Delta x_{\text {cal }}\right)=S_{\text {cal }}\left(T_{\text {cal }}\right) Q
$$

The heat flux is proportional to the thermal conductivity and the temperature difference between the hot and cold plates, and inversely proportional to thickness. Because there are changes to the physical properties of the transducer with temperature, temperature calibration should be progressed to get the temperature based 
Table 2.4: Temperature conditions for measuring thermal conductivities

\begin{tabular}{|c|c|c|c|c|c|c|}
\hline \multirow{2}{*}{ PCMs } & \multicolumn{2}{|c|}{ Temperature for melting $\left({ }^{\circ} \mathrm{C}\right)$} & \multicolumn{2}{|c|}{ Temperature for freezing $\left({ }^{\circ} \mathrm{C}\right)$} \\
\cline { 2 - 7 } & $\begin{array}{c}\text { Upper } \\
\text { plate }\end{array}$ & $\begin{array}{c}\text { Lower } \\
\text { plate }\end{array}$ & Average & $\begin{array}{c}\text { Upper } \\
\text { plate }\end{array}$ & $\begin{array}{c}\text { Lower } \\
\text { plate }\end{array}$ & Average \\
\hline Specimen 1 & 21 & 35 & 28 & 14 & 26 & 20 \\
\hline Specimen 2 & 21 & 35 & 28 & 14 & 26 & 20 \\
\hline Specimen 3 & 33 & 43 & 38 & 21 & 31 & 26 \\
\hline Specimen 4 & 39 & 49 & 44 & 31 & 41 & 36 \\
\hline
\end{tabular}

on calibration factor $S \operatorname{cal}(T)$. Also, the calibration factors are necessary to reference the real temperature of the transducers, since both transducers have their own temperature (TA Instruments [2016]; Husayni [1999]).

The Calibration factors $\left(S_{\text {cal }} T\right)$ are used to calculate thermal conductivity $\left(k_{\text {test }}\right)$ given by:

$$
k_{\text {test }}=S_{\text {cal }}\left(T_{\text {cal }}\right) Q \Delta x_{\text {cal }} / \Delta T_{\text {test }}
$$

The average of two thermal conductivity values is a final result of the thermal conductivity test (TA Instruments [2016]).

\subsubsection{Volumetric Heat Capacity}

Volumetric specific heat capacity can be estimated by the total amount of the heat flow per square area absorbed by the sample at the temperature set point of each plate. The amount of the heat flow per square area $(H)$ can be calculated by measured heat 
flow meter signal $Q U_{i}$ (upper plate) and $Q L_{i}$ (lower plate) as:

$$
H=\sum_{i=1}^{N}\left[S U_{\text {cal }}\left(Q U_{i}-Q U_{\text {equil }}\right)+S L_{\text {cal }}\left(Q L_{i}-Q L_{\text {equil }}\right)\right] \tau
$$

Where $S U_{c a l}$ and $S L_{c a l}$ are the heat flow meters (upper and lower plates) calibration factors, and $Q U_{\text {equil }}$ and $Q L_{\text {equil }}$ are final equilibrium results from the heat flow meter signals. $\tau$ is the time interval, normally $\sim 1.3$ seconds (Tleoubaev [2007]).

The final equilibrium values $\left(Q U_{\text {equil }}\right.$ and $\left.Q L_{\text {equil }}\right)$ are subtracted from the measured heat flow meter signals. If the final equilibrium values, which should be subtracted, are not considered, the sum $H$ (the amount of the heat flow per square area) value will not be arrived at a plateau and will show a slow drift of the sum $H$ due to the small edge heat losses (Tleoubaev and Brzezinski [2007]).

The volumetric specific heat capacity can be measured as the amount of heat absorbed from the specimen, and the results of the volumetric specific heat capacity can be indicated as the results of a Differential Scanning Calorimetry (DSC). The volumetric specific heat capacity equation can be found as:

$$
C_{p} \rho=\left(H_{\text {total }} / \Delta T-H_{H F M s}\right) / L
$$

Where $C_{p} \rho$ is the volumetric specific heat capacity $\left(\mathrm{J} / \mathrm{m}^{3} \mathrm{~K}\right), H_{\text {total }}$ is the total heat per unit of the square $\left(\mathrm{J} / \mathrm{m}^{2}\right), \Delta T$ is temperature difference $(\mathrm{K}), H_{H F M s}$ is the heat 
per unit of the square of heat flow meters, and $L$ is the sample's thickness (Tleoubaev and Brzezinski [2007]; Tleoubaev [2007]).

\subsubsection{Enthalpy Curves}

The enthalpy change curve, such as the enthalpy as a function of temperature curve, can be obtained by the amount of heat received from the sample, and the equation of the enthalpy change can be expressed as:

$$
\Delta h=\sum\left(H_{\text {total }}-H_{H F M s} \Delta T\right)
$$

Where $\Delta h$ is the enthalpy change $\left(\mathrm{J} / \mathrm{m}^{2}\right), H_{\text {total }}$ is the amount of heat absorbed, $H_{H F M s}$ is the heat per unit of the square of the heat flow meters, and $\Delta T$ is the temperature difference (Tleoubaev [2007]).

The enthalpy change curves calculated by heat flow meter equipment represent much more precise thermophysical properties than the curves calculated by DSC equipment. As the enthalpy curves are made under dynamic DSC mode using DSC equipment, the results often have margins of errors. This is the reason why high heating rates can affect temperature gradient in a sample, as when the heat flux signal originates both of from a sample at one temperature and from a temperature range. In order to detect the precise heat stored, the enthalpy as a function of temperature curves can be drawn using heat flow meter equipment and DSC equipment. 


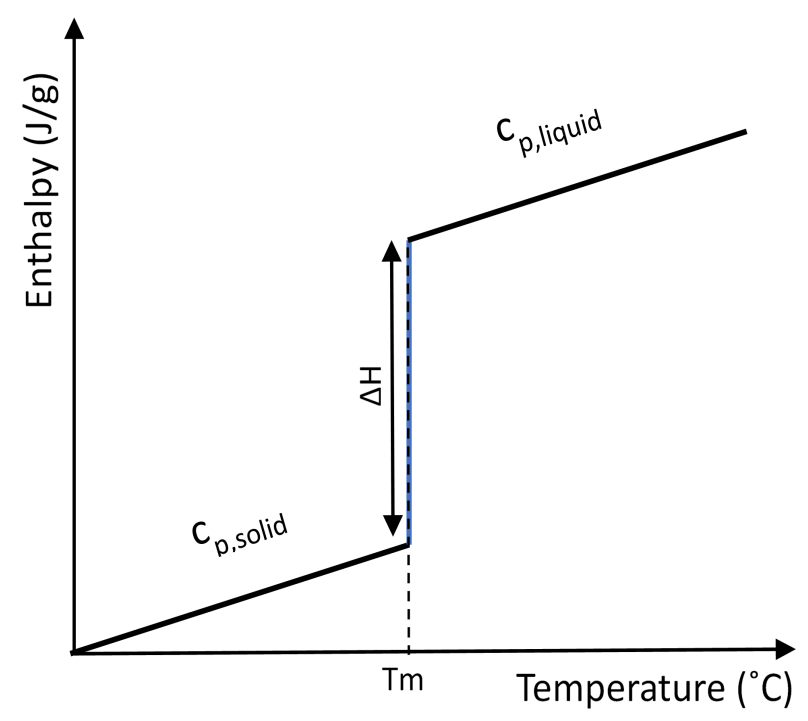

Figure 2.5: The enthalpy as a function of temperature curve of an ideal PCM

The phase change enthalpy $(\Delta H)$, the heat capacities of the solid state $\left(C_{p, s o l i d}\right)$ and the liquid state $\left(C_{p, \text { liquid }}\right)$, and the melting temperature $\left(T_{m}\right)$ can be obtained from the enthalpy as a function of temperature curve as shown in Figure 2.5. (Günther et al. [2009]; McNaughton and Mortimer [1975]; TA Instruments [2016]).

Temperature conditions for measuring volumetric specific heat capacities and enthalpy change curves of PCMs are shown in Table 2.5, and all of the samples are conducted under the same temperature condition. 
Table 2.5: Temperature conditions for measuring volumetric specific heat capacity and enthalpy

\begin{tabular}{|c|c|}
\hline \multicolumn{2}{|c|}{ Temperature $\left({ }^{\circ} \mathrm{C}\right)$} \\
\hline Upper plate & Lower plate \\
\hline 15 & 15 \\
\hline 19 & 19 \\
\hline 23 & 23 \\
\hline 27 & 27 \\
\hline 31 & 31 \\
\hline 35 & 35 \\
\hline 39 & 39 \\
\hline 43 & 43 \\
\hline 47 & 47 \\
\hline 51 & 51 \\
\hline
\end{tabular}




\subsubsection{Thermal Diffusivity Calculations}

The thermal diffusivity is a crucial element to determine the heat properties of PCMs. The thermal diffusivity indicates the ability of a material to store and transfer thermal energy, such as the heat of PCMs when the diffusion occurs during heat transfer. Also, accurate thermal diffusivity values are necessary to make a model and control a heat for materials which are conducted, insulated, or have withstood temperature change.

The thermophysical property, which is the speed of heat conduction during the temperature change, can be evaluated by the thermal diffusivity. Also, as the thermal diffusivity measures higher, the heat propagation is the faster.

In this study, the thermal diffusivity was calculated given by:

$$
\alpha=\frac{k}{\rho C_{p}}
$$

Where $\alpha$ is the thermal diffusivity $\left(\mathrm{m}^{2} / \mathrm{s}\right), k$ is the thermal conductivity from the heat flow meter result $(\mathrm{W} /(\mathrm{mK})), \rho$ is the density $\left(\mathrm{kg} / \mathrm{m}^{3}\right)$, and $C_{p}$ is the specific heat capacity $\left(\mathrm{J} / \mathrm{g}^{\circ} \mathrm{C}\right)$ from the result of the DSC measurement (Koschenz and Lehmann [2004]; Elgafy and Lafdi [2005]). 


\subsection{Numerical Simulation}

The heating system consists of a Phase Change Material (PCM) plate between the roof top slab and the bottom plaster slab. PCM, which is applied in a building, can absorb heat energy and change phase from a solid state to a liquid state in a day (during the charging process). Also, the PCM in the roof can release the heat energy and change its phase from a liquid state to a solid state at night (during the discharging process) to save energy.

The purpose of the numerical simulation is to investigate potential for energy savings with incorporating a PCM in a building. In order to assess potential for energy savings, thermal performances of buildings applying PCM plates are simulated using ABAQUS. The thermal performance of the heating system and the effects of various factors, such as heat of fusion, phase change material melting temperature, and thermal conductivity, are analyzed through the simulation.

\subsubsection{Verification Study}

Verification studies are designed and conducted to check the accuracy of the result obtained by using ABAQUS. An aluminum structure with a dimension of $0.097 \mathrm{x}$ $0.025 \times 0.045(\mathrm{~m})$ is considered in the verification study. Based on Fourier's Law, time achieved at steady-state condition is given by: 


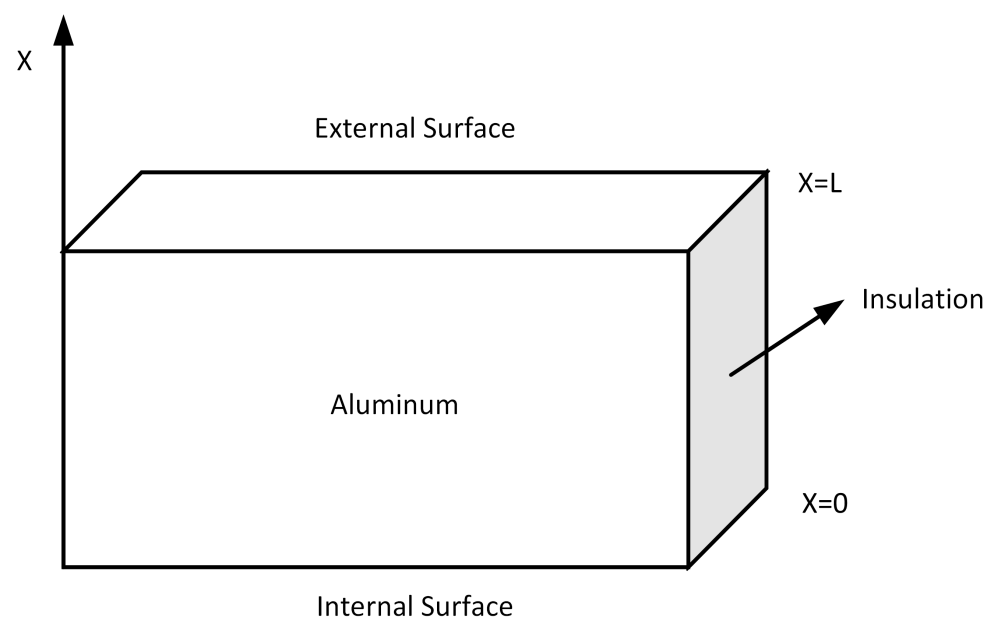

Figure 2.6: Al structure for verification study

$$
T(x, t)=\frac{T_{2}-T_{1}}{L} x+T_{1}+\sum_{n=1}^{\infty} B_{n} \sin \left(\frac{n \pi x}{L}\right) e^{-\alpha \lambda t}
$$

In this study, three conditions with various initial conditions and boundary conditions are considered as shown in Figure 2.6 and Table 2.6.

For the first verification study, initial condition, $23^{\circ} \mathrm{C}$ at $x=0$, is applied into the $\mathrm{Al}$ sample. Boundary conditions such as temperature boundary condition, $T_{1}=23$ and $T_{2}=35$, and convection boundary condition, $-35 \mathrm{~W} / \mathrm{m}^{2}$ on the outdoor, are considered in this study. For the second and third verification studies, the initial condition is not considered, but convection boundary condition, $-35 \mathrm{~W} / \mathrm{m}^{2}$ on the outdoor, is considered. Temperature boundary conditions are $T_{1}=0$ and $T_{2}=35$ for the second study, and $T_{1}=0$ and $T_{2}=0$ for the third study as shown in Table 2.6. 


\subsubsection{Mathematical Model}

The simulation structure consists of three layers, which are subjected to internal and external boundary conditions as shown in Figure 2.7.

In order to determine the numerical model, the following assumptions are made: 1) heat transfer is one-dimensional; 2) thermal properties are constant; 3) the PCM is homogeneous and isotropic; 4) natural convection can be ignored; 5) there is no interfacial resistance between the layers.

The composite roof is maintained at uniform temperature initially. The boundary

Table 2.6: Test conditions for verification studies

\begin{tabular}{|c|c|c|c|}
\hline \multirow{2}{*}{ Materials } & \multirow{2}{*}{ Conditions } & \multicolumn{2}{|c|}{ Boundary Conditions } \\
\hline & & Temperature & Convection \\
\hline $\mathrm{Al}$ & $\begin{array}{l}\text { 1. Initial Condition } \\
23^{\circ} \mathrm{C} \\
\text { 2. Boundary Conditions } \\
\text { 3. } \mathrm{L}=0.225 \mathrm{~m} \\
\text { 4. } x_{1}=0.025 \mathrm{~m} \\
\quad x_{2}=0.2 \mathrm{~m}\end{array}$ & $\begin{array}{l}T_{1}=23 \\
\quad T_{2}=35\end{array}$ & $\begin{array}{c}\text { Convection }=-35 \\
\mathrm{~W} / \mathrm{m}^{2}\end{array}$ \\
\hline $\mathrm{Al}$ & $\begin{array}{l}\text { 1. Initial Condition } \\
23^{\circ} \mathrm{C} \\
\text { 2. Boundary Conditions } \\
\text { 3. } \mathrm{L}=0.225 \mathrm{~m} \\
\text { 4. } x_{1}=0.025 \mathrm{~m} \\
x_{2}=0.2 \mathrm{~m}\end{array}$ & $\begin{array}{l}T_{1}=0 \\
T_{2}=35\end{array}$ & $\begin{array}{c}\text { Convection }=-35 \\
\mathrm{~W} / \mathrm{m}^{2}\end{array}$ \\
\hline $\mathrm{Al}$ & $\begin{array}{l}\text { 1. Initial Condition } \\
23^{\circ} \mathrm{C} \\
\text { 2. Boundary Conditions } \\
\text { 3. } \mathrm{L}=0.225 \mathrm{~m} \\
\text { 4. } x_{1}=0.025 \mathrm{~m} \\
\quad x_{2}=0.2 \mathrm{~m}\end{array}$ & $\begin{array}{l}T_{1}=0 \\
\quad T_{2}=0\end{array}$ & $\begin{array}{c}\text { Convection }=-35 \\
\mathrm{~W} / \mathrm{m}^{2}\end{array}$ \\
\hline
\end{tabular}


conditions on the external surface are required since the exterior surface is exposed to solar radiation, which is heat transfer by electromagnetic waves or photons and affected from heat by convection, which is the displacement of volumes of a substance in a gaseous phase. Also, conduction, which is the heat flow via solid or liquid by vibration and collision of molecules and free electrons, is happening on the external surface.

According to the above assumptions, the governing equation, the initial condition, and the boundary condition are composed as below. In this study, the governing equation is

$$
k \frac{\partial^{2} T}{\partial x^{2}}=\rho c_{p} \frac{\partial T}{\partial t}
$$

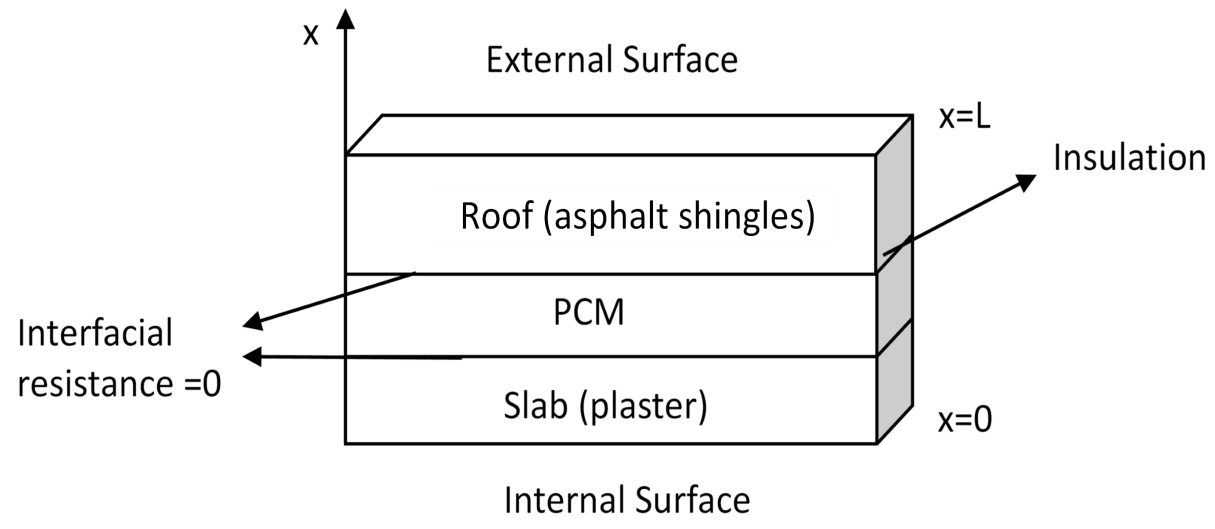

Figure 2.7: A building roof 
where:

$$
c_{p}=c_{p} \quad\left(T_{e}<T<T_{o}\right) \quad \text { or } \quad c_{p}=\frac{L}{T_{e}-T_{o}}+c_{p}\left(T_{o}\right) \quad\left(T_{o} \leq T \leq T_{e}\right)
$$

Where $k$ is the thermal conductivity $(\mathrm{W} / \mathrm{mK}), \rho$ is the density $\left(\mathrm{kg} / \mathrm{m}^{3}\right), C_{p}$ is the specific heat capacity $\left(\mathrm{J} / \mathrm{g}^{\circ} \mathrm{C}\right), T_{e}$ is the end temperature $\left({ }^{\circ} \mathrm{C}\right), T_{o}$ is the onset temperature $\left({ }^{\circ} \mathrm{C}\right)$, and $L$ is the latent heat $(\mathrm{J} / \mathrm{g})$. Material properties are dependent on the function of temperature.

Since temperature of the composite roof is initially maintained uniformly, the initial condition is

$$
T(x, t)=T_{\text {init }} \quad \text { at } \quad t=0
$$

Since the external surface is exposed to solar radiation, the radiation effect should be considered on boundary conditions. Thus, the external boundary condition is

$$
k \frac{\partial T}{\partial x}=q_{r a d}+h_{o}\left(T_{\infty}-T_{x=L}\right) \quad \text { at } \quad x=L
$$

Where $q_{r a d}$ is heat flow by radiation, $h_{o}$ is outside heat transfer coefficient, and $T_{\infty}$ is ambient temperature.

For the internal surface $(x=0)$, the boundary condition is

$$
k \frac{\partial T}{\partial x}=h_{i}\left(T_{x=0}-T_{\text {room }}\right) \quad \text { at } \quad x=0
$$

Where $h_{i}$ is inside heat transfer coefficient. 


\subsubsection{Case Study: Simulation Conditions}

In this study, in order to evaluate the thermal performance of a roof with the PCM plate, the numerical Finite Element Analysis (FEA), corresponding to a transient heat transfer analysis with the various initial conditions and the boundary conditions, is conducted. The roof structure incorporating the PCM with a dimensions of $0.097 \times 0.025 \times 0.045(\mathrm{~m})$ is considered in this study. The roof model consists of a three-layer assembly as shown in Figure 2.8, which is subjected to the internal and external boundary conditions. The three-layer part consists of the roof, such as asphalt shingles, the PCM, and the slab, such as a plaster. The material properties, such as the thermal conductivity, the density, the specific heat capacity, and the latent heat of the PCM are applied into the numerical simulation. The initial conditions are $35^{\circ} \mathrm{C}$ on the outdoor and $25^{\circ} \mathrm{C}$ on the indoor at $\mathrm{t}=0$ sec. While thermal radiation and convection as the boundary conditions are applied on the outdoor, convection is also the boundary condition applied on the indoor. All results are run for 2000 seconds for each step, and two steps (such as the daytime and the nighttime) are run to simulate the roof systems with the PCMs

In order to assess the thermal performace of a roof with the PCM plate, internal temperature variation as a function of time, which is related to heat capacity, heat of fusion, phase change temperature, and thermal conductivity, is measured through the simulation. Index and parameters for analysis of the simulation are shown in Table 
Table 2.7: Internal temperature variation related to various parameters

\begin{tabular}{|c|c|}
\hline \multirow{2}{*}{ Index } & Parameters \\
\hline \multirow{4}{*}{$\begin{array}{c}\text { Internal temperature } \\
\text { as a function of time }\end{array}$} & Heat capacity \\
\cline { 2 - 2 } & $\begin{array}{c}\text { Phase change } \\
\text { temperature }\end{array}$ \\
\cline { 2 - 2 } & Thermal conductivity \\
\hline
\end{tabular}

2.7 .

Internal temperature factor as index is an important component to analyze the thermal performance of a roof with the PCM plate. The reasons for choosing this index are that latent heat storage of the PCM can absorb and release heat energy, and the stored heat energy can manipulate to maintain internal temperature. When

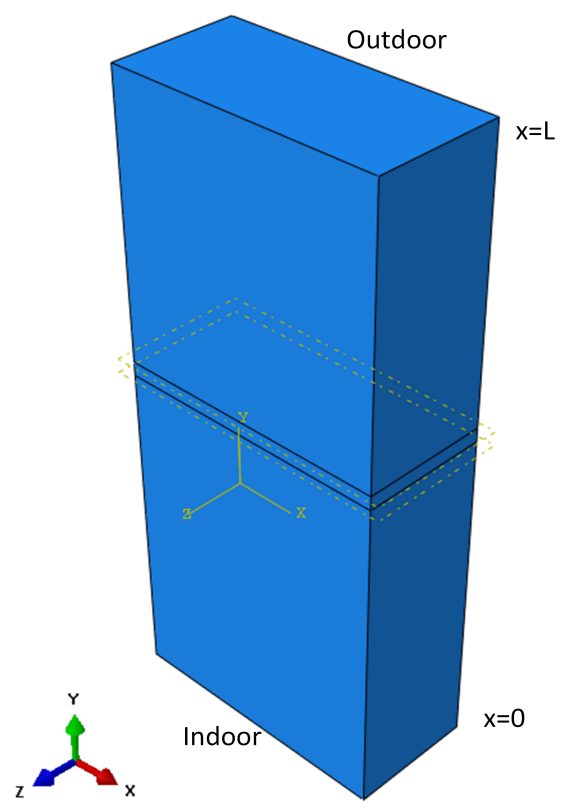

Figure 2.8: Geometry of a roof with the PCM 
internal temperature is maintained uniformly, the heat energy of a house or a building can be saved. Thus, efficient energy use and conservation are possible under uniform internal temperature condition. For these reasons, internal temperature variation is measured with various parameters.

In a Thermal Energy Storage (TES) system, there are two kinds of storage systems. The first system is for the sensible heat, and the second thing is for the latent heat. The sensible heat can store or release heat energy over a range of temperature without phase change, and the sensible heat depends on the specific heat capacity. Energy storage by heat of fusion (latent heat) as parameter is an important factor. This is the reason why latent heat storage has 5-14 times more store capacity than the sensible heat storage at a very narrow temperature range, and can absorb and release heat at a constant temperature during phase transition.

The phase change temperature of the PCM is also a significant parameter because a considerable change of enthalpy occurs near the melting temperature of the PCM. PCMs store heat energy when the temperautre exceeds their meling temeprature by transitioning from a solid state to a liquid state. Also, the stored heat energy can be released as the temperature is decreased below their melting temperature. These phenomena indicate the latent heat contribution for increasing the energy storage capacity of the PCM (Hembade et al. [2013]).

Lastly, thermal conductivity of the PCM is also an essential factor to consider when studying thermal performance of PCMs. High thermal conductivity can ac- 
celerate to absorb and release heat energy at a high specific heat, which provides additional sensible heat capacity (Socaciu [2012b]). Thermal conductivity is dependent on the speed heat flows into PCMs, and heat flow speed is related to the gap of fluctuation under internal temperature variation. A small gap of internal temperature variation means that internal temperature condition can maintain uniform temperature. Therefore, thermal conductivity is also considered as a parameter for the simulation. 


\section{Chapter 3}

\section{Results and Discussion}

\subsection{DSC Analysis}

Phase Change Materials (PCMs) are widely used for thermal energy storage such as the sensible heat storage and the latent heat storage, and are crucial factors in the efficient use of energy. The purpose of this study is to directly determine thermophysical properties for the thermal energy storage of PCMs from DSC curve results in the dynamic DSC mode.

\subsubsection{Dynamic DSC Curves}

\subsubsection{Original Phase Change Materials}

The Differential Scanning Calorimetry (DSC) with the dynamic DSC mode can be conducted to measure thermophysical properties of four kinds of macro-encapsulated PCMs, which change their phases at $21^{\circ} \mathrm{C}, 23^{\circ} \mathrm{C}, 26^{\circ} \mathrm{C}$, and $30^{\circ} \mathrm{C}$, respectively. The general DSC results provide the onset temperature $\left(\mathrm{T}_{o}\right)$, the peak temperature $\left(\mathrm{T}_{p}\right)$

as the melting temperature $\left(\mathrm{T}_{m}\right)$, the end temperature $\left(\mathrm{T}_{e}\right)$, the enthalpy $(\Delta \mathrm{H})$, and 
the heat flow of PCMs.

Figures 3.1 to 3.4 show thermograms of four kinds of basic PCMs under the heating temperature range from $15^{\circ} \mathrm{C}$ to $105^{\circ} \mathrm{C}$ and the cooling temperature range from $105^{\circ} \mathrm{C}$ to $-40^{\circ} \mathrm{C}$ with a heating rate and a cooling rate of $5{ }^{\circ} \mathrm{C} /$ min using $\mathrm{DSC} Q$ 200 from TA Instruments. Figures 3.5 to 3.8 indicate thermograms of original PCMs from $15^{\circ} \mathrm{C}$ to $105^{\circ} \mathrm{C}$ with a heating rate and a cooling rate of $5^{\circ} \mathrm{C} / \mathrm{min}$ using $\mathrm{DSC}$ STA 8000 equipment from Perkin Elmer Company.

A phase change shows as a peak on the thermogram. Theoretically, when the PCM melts during the phase change, the temperature does not change, and the PCM absorbs the energy. However, experimentally, during the phase change, temperature change of a PCM is indicated as the DSC curve result. In addition, this status takes an endothermic reaction and is shown as a negative heat flow curve on the thermograms of Figures 3.1 to 3.4. During the phase change such as from the liquid state to the solid state, the process of solidification takes an exothermic reaction and is shown as a positive heat flow curve on the thermograms of Figures 3.1 to 3.4. Figures 3.5 to 3.8 indicate the reverse thermograms of the previous results, as an endothermic reaction has a positive heat flow curve.

Figure 3.1 shows the dynamic DSC curve of the PCM melted at $21^{\circ} \mathrm{C}$. The onset temperature, the peak temperature (the melting temperature), and the end temperature for the endothermic reaction are $26.67^{\circ} \mathrm{C}, 31.33^{\circ} \mathrm{C}$, and $43^{\circ} \mathrm{C}$, respectively. The enthalpy (the latent heat of fusion) is $156 \mathrm{~J} / \mathrm{g}$. In the exothermic reaction, 


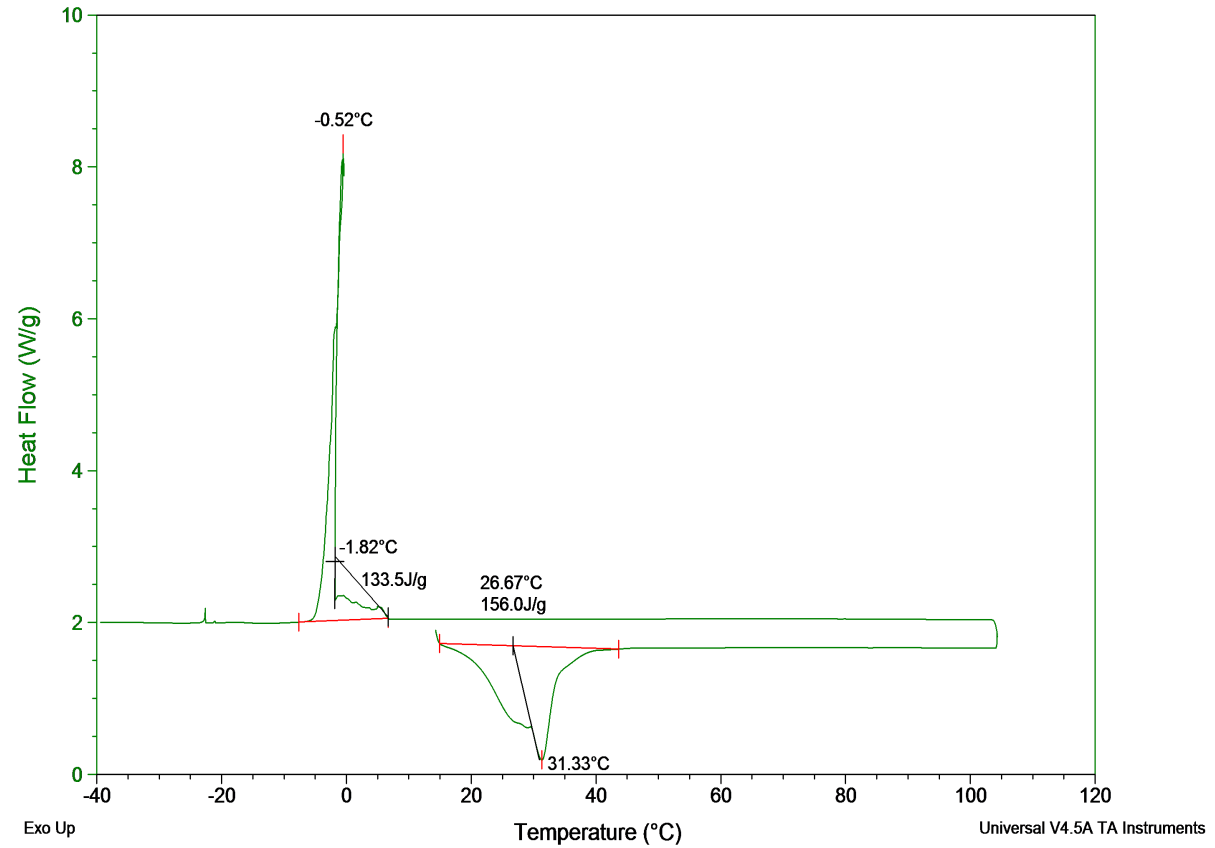

Figure 3.1: Dynamic DSC curve of the PCM melted at $21^{\circ} \mathrm{C}$

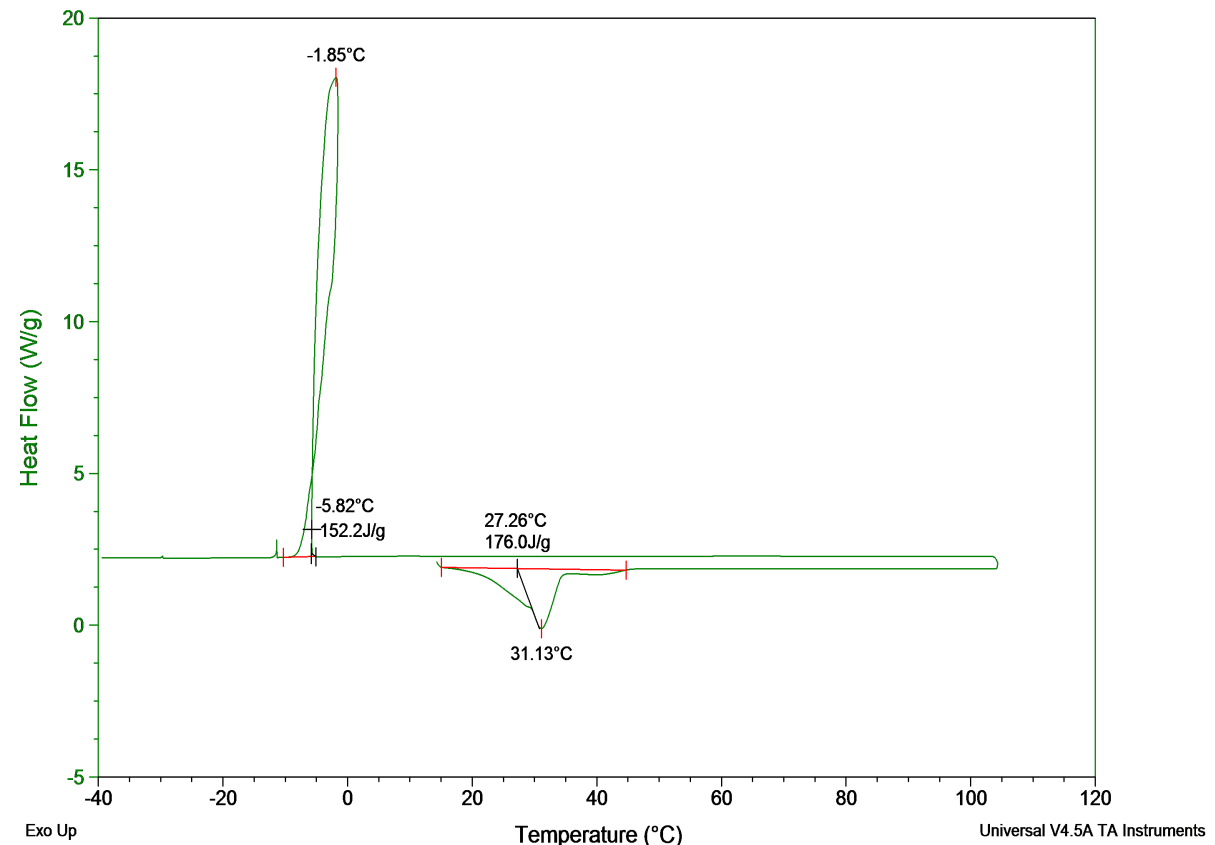

Figure 3.2: Dynamic DSC curve of the PCM melted at $23^{\circ} \mathrm{C}$ 


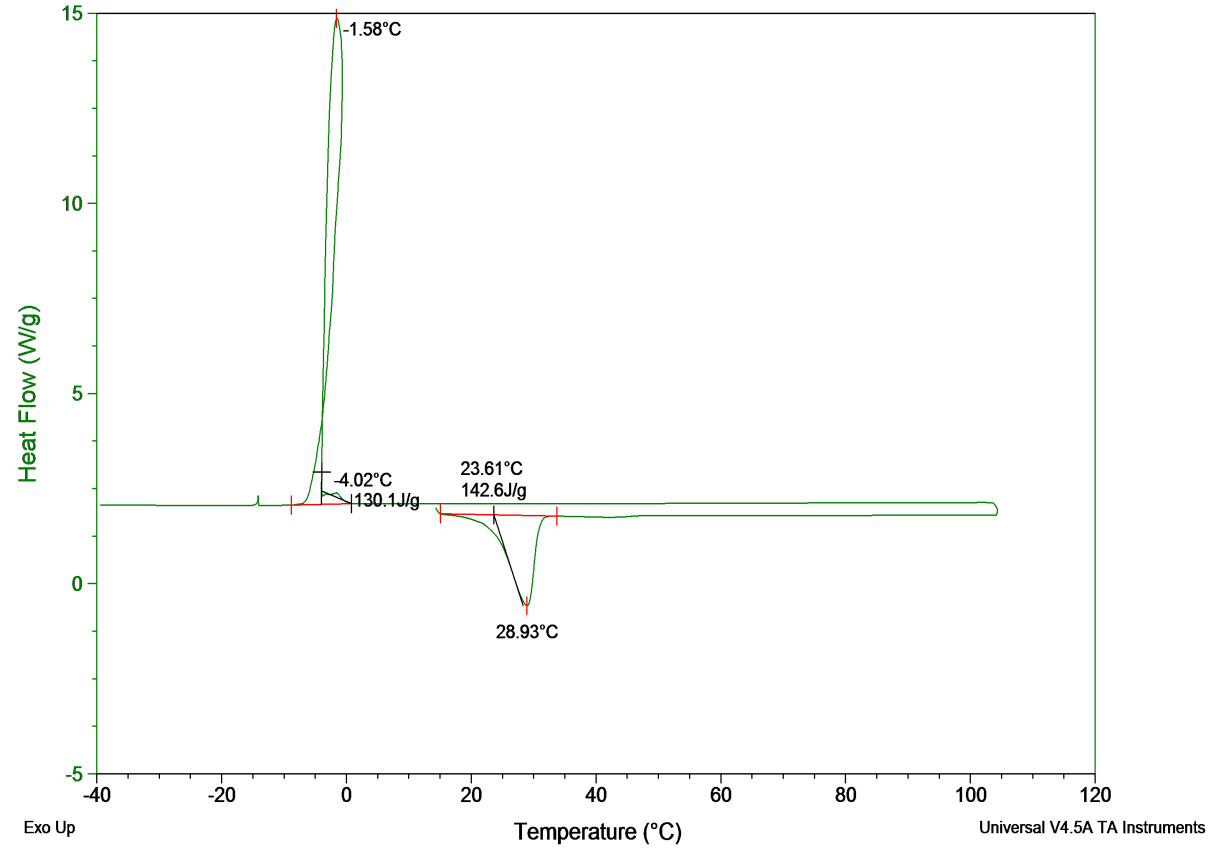

Figure 3.3: Dynamic DSC curve of the PCM melted at $26^{\circ} \mathrm{C}$

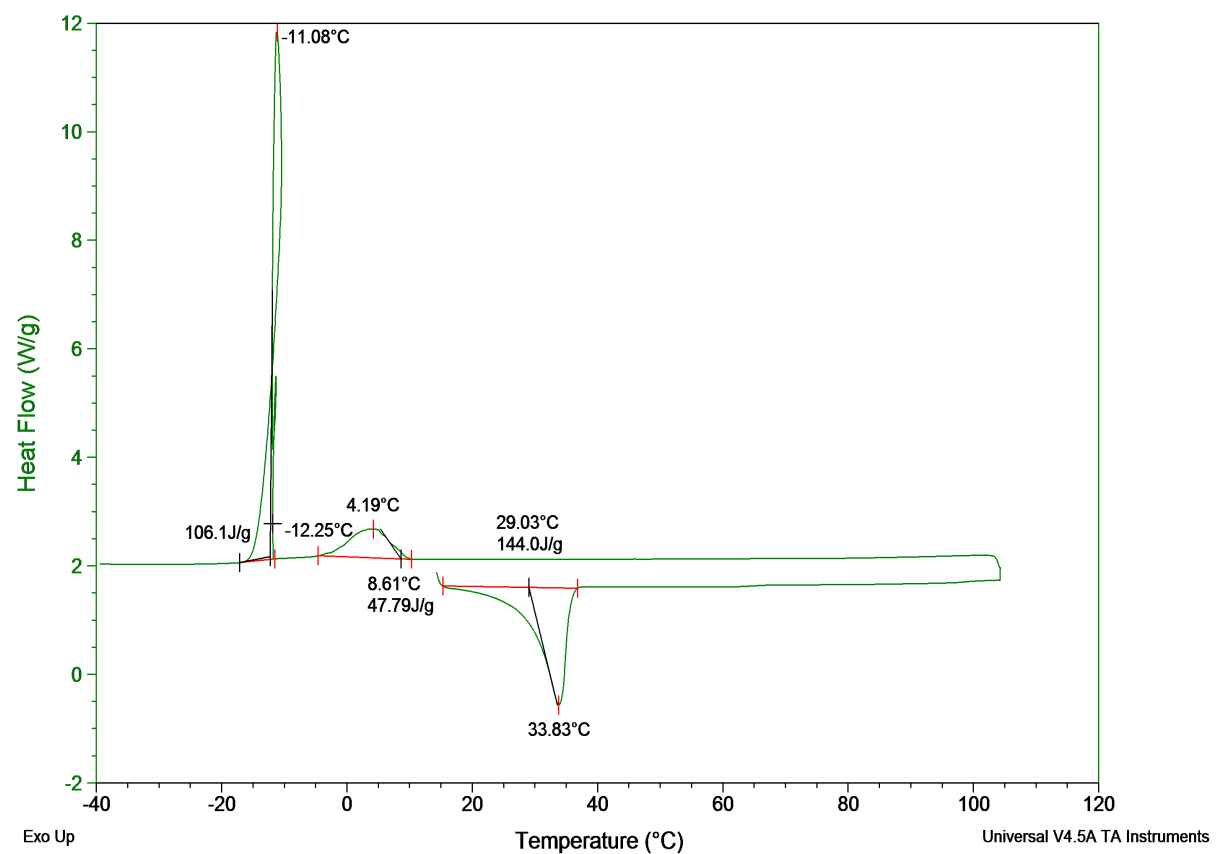

Figure 3.4: Dynamic DSC curve of the PCM melted at $30^{\circ} \mathrm{C}$ 
the temperatures and the enthalpy are $-1.82^{\circ} \mathrm{C},-0.52^{\circ} \mathrm{C},-7.61^{\circ} \mathrm{C}$, and $133.5 \mathrm{~J} / \mathrm{g}$, respectively. Figure 3.2 displays that the onset, the peak, and the end temperatures for the endothermic reaction are $27.26^{\circ} \mathrm{C}, 31.13^{\circ} \mathrm{C}$, and $44^{\circ} \mathrm{C}$, respectively. The enthalpy is $176 \mathrm{~J} / \mathrm{g}$. In the exothermic process, the temperatures and the enthalpy are $-5.82^{\circ} \mathrm{C},-1.85^{\circ} \mathrm{C},-10.39^{\circ} \mathrm{C}$, and $152.5 \mathrm{~J} / \mathrm{g}$, respectively. As shown in Figure 3.3 for the PCM melted at $26^{\circ} \mathrm{C}$ under the endothermic process, the temperatures are $23.61^{\circ} \mathrm{C}$, $28.93^{\circ} \mathrm{C}$, and $34^{\circ} \mathrm{C}$, respectively. The enthalpy is $142 \mathrm{~J} / \mathrm{g}$. Under the exothermic process, the temperatures and enthalpy are $-4.02^{\circ} \mathrm{C},-1.58^{\circ} \mathrm{C},-8.86^{\circ} \mathrm{C}$, and $130.1 \mathrm{~J} / \mathrm{g}$, respectively. In Figure 3.4, the dynamic DSC curve for the endothermic reaction shows that the onset temperature, the peak temperature, and the end temperature are $29.03^{\circ} \mathrm{C}, 33.83^{\circ} \mathrm{C}$, and $37^{\circ} \mathrm{C}$, respectively. The enthalpy is $144 \mathrm{~J} / \mathrm{g}$. In the case of the exothermic reaction, two exothermic peaks are indicated on thermogram. For the first curve, the onset, the peak, and the end temperatures are $8.61^{\circ} \mathrm{C}, 4.19^{\circ} \mathrm{C}$, and $-4.46^{\circ} \mathrm{C}$, respectively. The enthalpy is $47.79 \mathrm{~J} / \mathrm{g}$. For the second curve, the temperatures and the enthalpy are $-12.25^{\circ} \mathrm{C},-11.08^{\circ} \mathrm{C},-17.12^{\circ} \mathrm{C}$, and $106.1 \mathrm{~J} / \mathrm{g}$, respectively.

In Figures 3.1 to 3.4, there are sharp and narrow peaks under the exothermic reactions. Generally, a pure material melts with a sharp and narrow peak. However, because of time and energy flowing into a sample, a peak can broaden, and the height of the peak is reduced. PCMs used in this study are not pure materials, and are based on salt hydrates. The phenomena of PCM having sharp peaks under exothermic reactions most likely due to the low content of salt hydrates, and the salt 
hydrates dissolve in water present in a sample.

Figure 3.5 shows the dynamic DSC curve of the PCM melted at $21^{\circ} \mathrm{C}$. The onset temperature, the peak temperature (the melting temperature), and the end temperature are $21.93^{\circ} \mathrm{C}, 25.97^{\circ} \mathrm{C}$, and $42^{\circ} \mathrm{C}$, respectively. The enthalpy (the latent heat of fusion) is $7.0514 \mathrm{~J} / \mathrm{g}$, and the specific heat capacity is $0.4658 \mathrm{~J} / \mathrm{g}{ }^{\circ} \mathrm{C}$. Figure 3.6 displays that the onset, the peak, and the end temperatures are $23.44^{\circ} \mathrm{C}, 25.83^{\circ} \mathrm{C}$, and $41^{\circ} \mathrm{C}$, respectively. The enthalpy is $6.1061 \mathrm{~J} / \mathrm{g}$, and the specific heat capacity is $0.3782 \mathrm{~J} / \mathrm{g}{ }^{\circ} \mathrm{C}$. As shown in Figure 3.7 for the PCM melted at $26^{\circ} \mathrm{C}$, two peaks occur in the dynamic DSC curve. For the first DSC peak curve, the onset temperature, the peak temperature, and the end temperature are $30.65^{\circ} \mathrm{C}, 36.88^{\circ} \mathrm{C}$, and $44{ }^{\circ} \mathrm{C}$, respectively. The enthalpy and the specific heat capacity are $4.2289 \mathrm{~J} / \mathrm{g}$ and 0.5853 $\mathrm{J} / \mathrm{g}{ }^{\circ} \mathrm{C}$, respectively. For the second peak curve, the onset, the peak, and the end temperatures are $48.08^{\circ} \mathrm{C}, 51.43^{\circ} \mathrm{C}$, and $61^{\circ} \mathrm{C}$, respectively. The enthalpy and the specific heat capacity are $1.9534 \mathrm{~J} / \mathrm{g}$ and $0.4003 \mathrm{~J} / \mathrm{g}{ }^{\circ} \mathrm{C}$, respectively. In Figure 3.8, the dynamic DSC curve shows two peaks as Figure 3.7. For the first DSC curve, the onset temperature, the peak temperature, and the end temperature are $37.95^{\circ} \mathrm{C}$, $42.63^{\circ} \mathrm{C}$, and $51^{\circ} \mathrm{C}$, respectively. The enthalpy and the specific heat capacity are shown to be $4.1065 \mathrm{~J} / \mathrm{g}$ and $0.6732 \mathrm{~J} / \mathrm{g}{ }^{\circ} \mathrm{C}$, respectively. For the second curve, the onset, the peak, and the end temperatures are $59.56^{\circ} \mathrm{C}, 82.86^{\circ} \mathrm{C}$, and $100^{\circ} \mathrm{C}$, respectively. The enthalpy and the specific heat capacity are $50.1028 \mathrm{~J} / \mathrm{g}$ and $2.0746 \mathrm{~J} / \mathrm{g}$ ${ }^{\circ} \mathrm{C}$, respectively. 


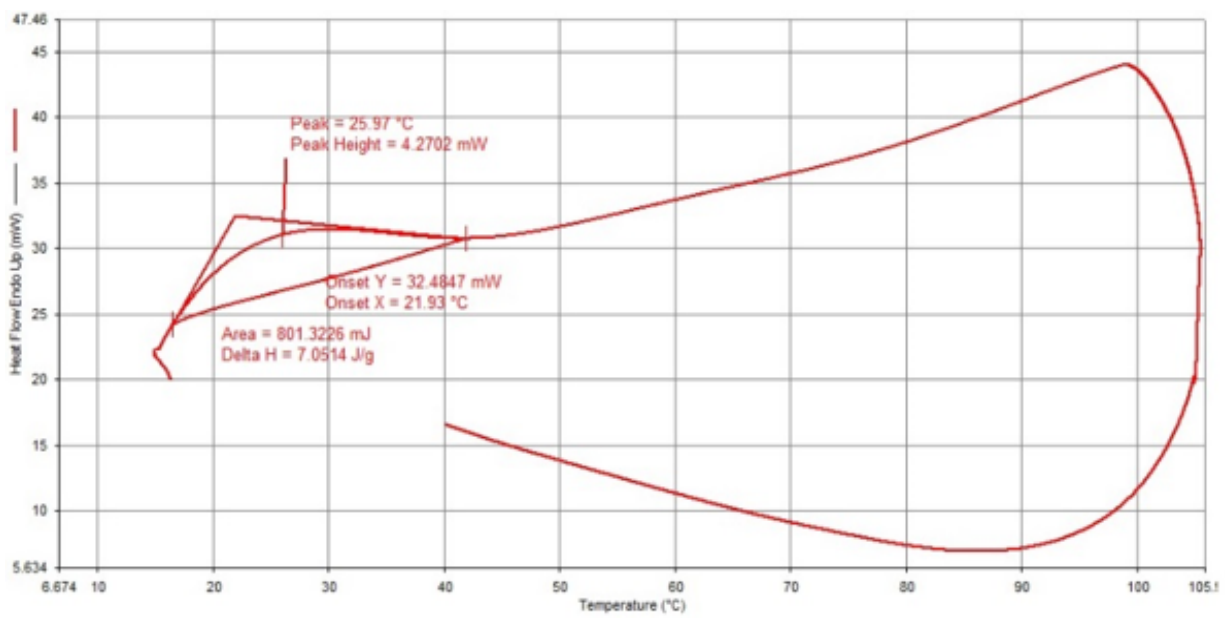

Figure 3.5: Dynamic DSC curve of the PCM melted at $21^{\circ} \mathrm{C}$

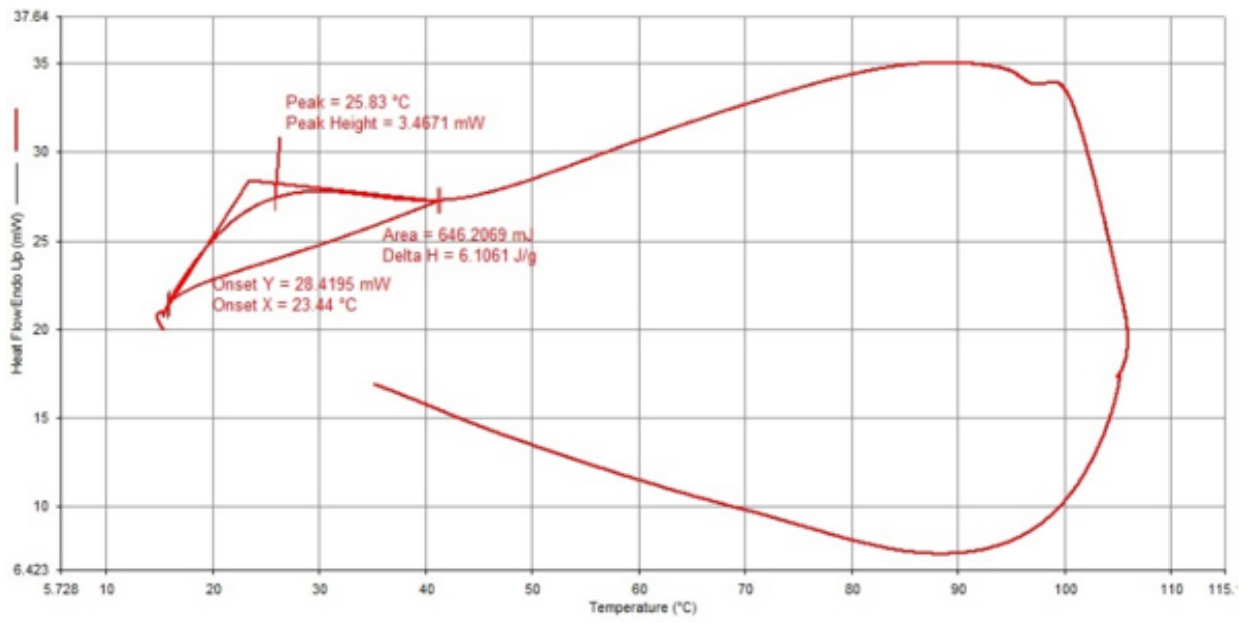

Figure 3.6: Dynamic DSC curve of the PCM melted at $23^{\circ} \mathrm{C}$ 


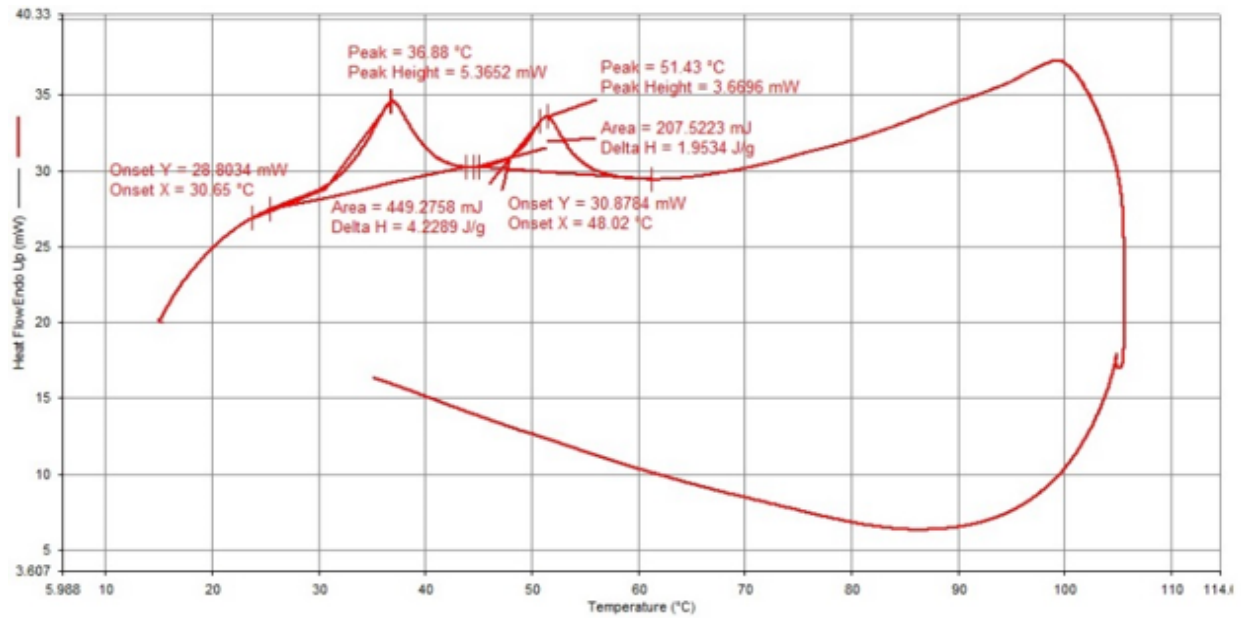

Figure 3.7: Dynamic DSC curve of the PCM melted at $26^{\circ} \mathrm{C}$

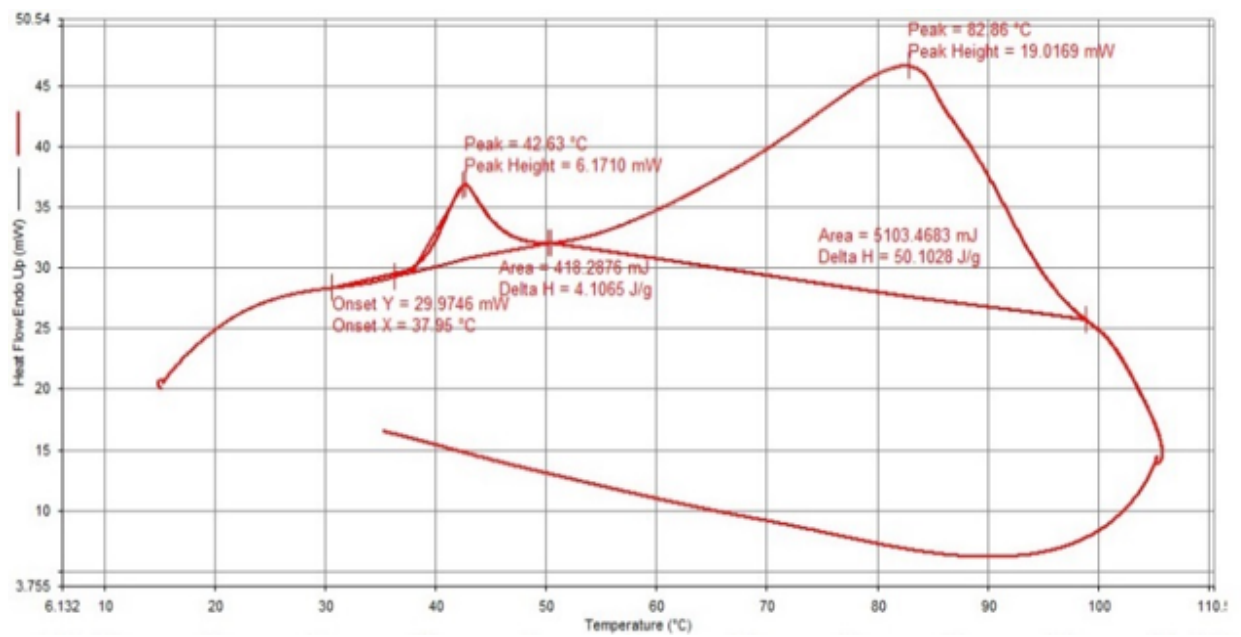

Figure 3.8: Dynamic DSC curve of the PCM melted at $30^{\circ} \mathrm{C}$ 
Table 3.1: Thermal properties of PCMs by measuring dynamic DSC using Q 200

\begin{tabular}{|c|c|c|c|c|c|}
\hline PCM & Type of process & $\begin{array}{c}\text { Onset temp } \\
\left({ }^{\circ} \mathrm{C}\right)\end{array}$ & $\begin{array}{l}\text { Peak temp } \\
\qquad\left({ }^{\circ} \mathrm{C}\right)\end{array}$ & $\begin{array}{c}\text { End temp } \\
\qquad\left({ }^{\circ} \mathrm{C}\right)\end{array}$ & $\begin{array}{c}\text { Enthalpy } \\
\qquad(\mathrm{J} / \mathrm{g})\end{array}$ \\
\hline $21^{\circ} \mathrm{C}$ & \multirow{4}{*}{ Endothermic } & 26.67 & 31.33 & 43 & 156 \\
\hline $23^{\circ} \mathrm{C}$ & & 27.26 & 31.13 & 44 & 176 \\
\hline $26^{\circ} \mathrm{C}$ & & 23.61 & 28.93 & 34 & 142 \\
\hline $30^{\circ} \mathrm{C}$ & & 29.03 & 33.83 & 37 & 144 \\
\hline PCM & Type of process & $\begin{array}{c}\text { Onset temp } \\
\left({ }^{\circ} \mathrm{C}\right)\end{array}$ & $\begin{array}{l}\text { Peak temp } \\
\qquad\left({ }^{\circ} \mathrm{C}\right)\end{array}$ & $\begin{array}{c}\text { End temp } \\
\qquad\left({ }^{\circ} \mathrm{C}\right)\end{array}$ & $\begin{array}{c}\text { Enthalpy } \\
(\mathrm{J} / \mathrm{g})\end{array}$ \\
\hline $21^{\circ} \mathrm{C}$ & \multirow{5}{*}{ Exothermic } & -1.82 & -0.52 & -7.61 & 133.5 \\
\hline $33^{\circ} \mathrm{C}$ & & -5.82 & -1.85 & -10.39 & 152.2 \\
\hline $26^{\circ} \mathrm{C}$ & & -4.02 & -1.58 & -8.86 & 130.1 \\
\hline \multirow{2}{*}{$30^{\circ} \mathrm{C}$} & & 8.61 & 4.19 & -4.46 & 47.79 \\
\hline & & -12.25 & -11.08 & -17.12 & 106.1 \\
\hline
\end{tabular}

A Thermal Energy Storage (TES) is an important factor in estimating stored or released energy during the phase change. If the phase change is not finished, it is impossible for a TES system to store or release the total value of the enthalpy. For this reason, the onset temperature and the end temperature such as the temperature variation of the PCM are crucial factors to evaluate the characteristic of the PCM in a TES system (Pielichowska and Pielichowski [2014]). Tables 3.1 and 3.2 summarize the results of thermal properties of PCMs by measuring the dynamic DSC.

For comparing each propertie of the PCMs, Figures 3.9 and 3.10 show the temperature properties of the original PCMs, which are measured from DSC Q 200 equipment (TA Instruments) under the endothermic and exothermic reactions, respectively. Fig- 
Table 3.2: Thermal properties of PCMs by measuring dynamic DSC using STA 8000

\begin{tabular}{|c|c|c|c|c|c|c|}
\hline $\mathrm{PCM}$ & $\begin{array}{c}\text { Onset temp } \\
\left({ }^{\circ} \mathrm{C}\right)\end{array}$ & $\begin{array}{c}\text { Peak temp } \\
\left({ }^{\circ} \mathrm{C}\right)\end{array}$ & $\begin{array}{c}\text { End temp } \\
\left({ }^{\circ} \mathrm{C}\right)\end{array}$ & $\begin{array}{c}\text { Onset temp } \\
\left({ }^{\circ} \mathrm{C}\right)\end{array}$ & $\begin{array}{c}\text { Peak temp } \\
\left({ }^{\circ} \mathrm{C}\right)\end{array}$ & $\begin{array}{c}\text { End temp } \\
\left({ }^{\circ} \mathrm{C}\right)\end{array}$ \\
\hline $21^{\circ} \mathrm{C}$ & 21.93 & 25.97 & 42 & - & - & - \\
\hline $23^{\circ} \mathrm{C}$ & 23.44 & 25.83 & 41 & - & - & - \\
\hline $26^{\circ} \mathrm{C}$ & 30.65 & 36.88 & 44 & 48.08 & 51.43 & 61 \\
\hline $30^{\circ} \mathrm{C}$ & 37.95 & 42.63 & 51 & 59.56 & 82.86 & 100 \\
\hline & Enthalpy & Enthalpy & Heat flow & Heat flow & $\begin{array}{c}\text { Heat } \\
\text { Capacity } \\
\left(\mathrm{J} / \mathrm{g}^{\circ} \mathrm{C}\right)\end{array}$ & $\begin{array}{c}\text { Heat } \\
\text { Capacity } \\
\left(\mathrm{J} / \mathrm{g}^{\circ} \mathrm{C}\right)\end{array}$ \\
\hline $21^{\circ} \mathrm{C}$ & 7.0514 & - & 4.2702 & - & 0.4658 & - \\
\hline $23^{\circ} \mathrm{C}$ & 6.1061 & - & 3.4671 & - & 0.3782 & - \\
\hline $26^{\circ} \mathrm{C}$ & 4.2289 & 1.9534 & 5.3652 & 3.6696 & 0.5853 & 0.4003 \\
\hline $30^{\circ} \mathrm{C}$ & 4.1065 & 50.1028 & 6.171 & 19.0169 & 0.6732 & 2.0746 \\
\hline
\end{tabular}

ure 3.11 indicates temperature properties of the original PCMs, which are measured using DSC STA 8000 equipment (Perkin Elmer Company) under only the endothermic reaction. Figures 3.12 and 3.13 show enthalpies of the PCMs, which are determined by DSC Q 200 equipment under the endothermic and exothermic reactions, respectively. For Figure 3.14, enthalpy measurements for only the endothermic reaction are performed with DSC STA 8000 equipment. In Figures 3.9 to 3.14, specimen 1, 2, 3, and 4 indicate the original PCMs melted at $21^{\circ} \mathrm{C}, 23^{\circ} \mathrm{C}, 26^{\circ} \mathrm{C}$, and $30^{\circ} \mathrm{C}$, respectively.

Figures 3.9 and 3.10 show the onset temperature, the peak temperature, and the end temperature of four kinds of original PCMs under the endothermic reaction and the exothermic reaction. Four specimens exceed their own melting temperature, 


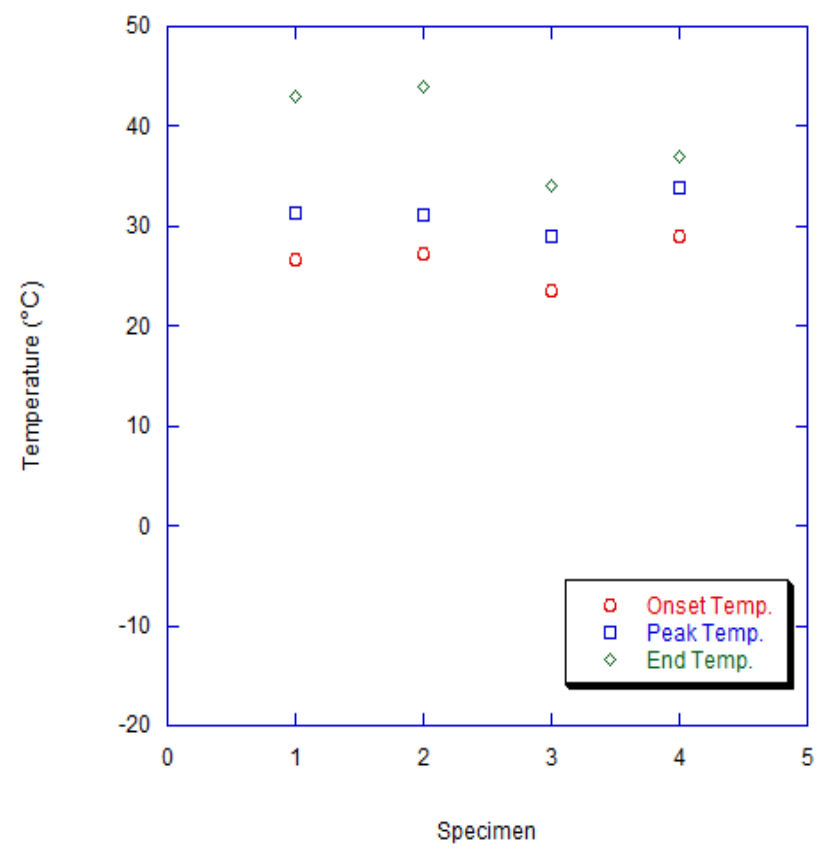

Figure 3.9: Temperature properties of PCMs under endothermic reaction

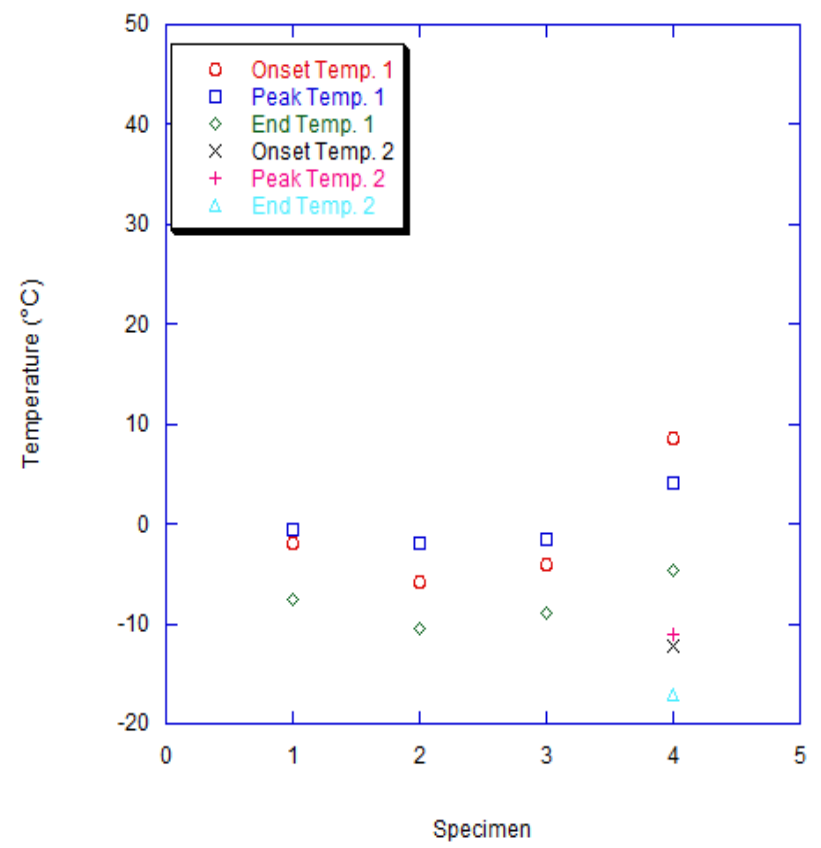

Figure 3.10: Temperature properties of PCMs under exothermic reaction 


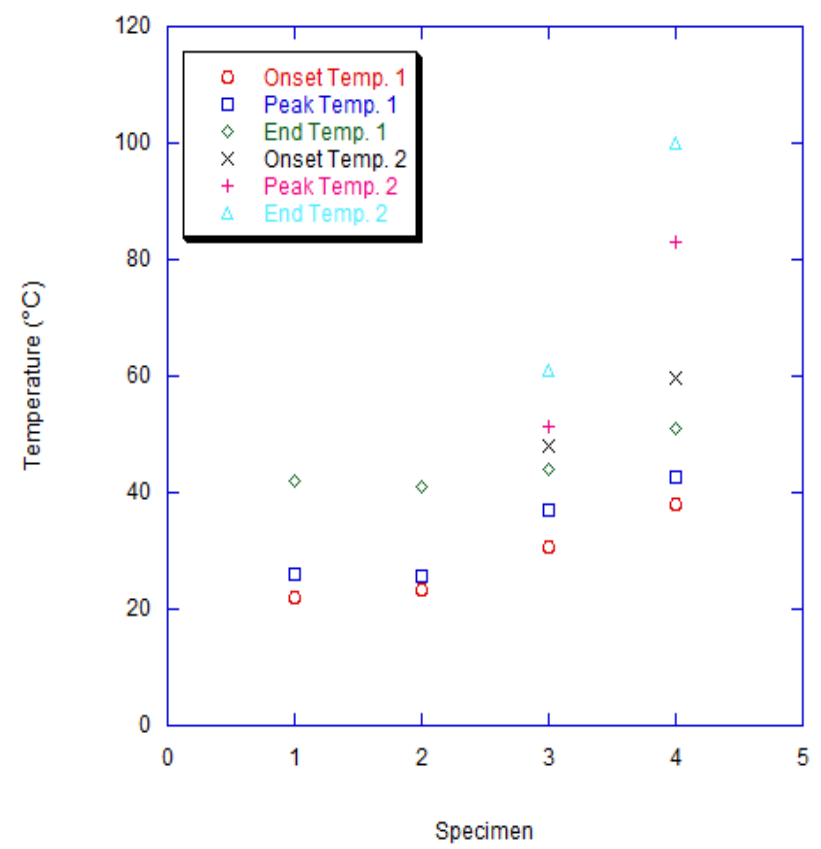

Figure 3.11: Temperature properties of PCMs under endothermic reaction

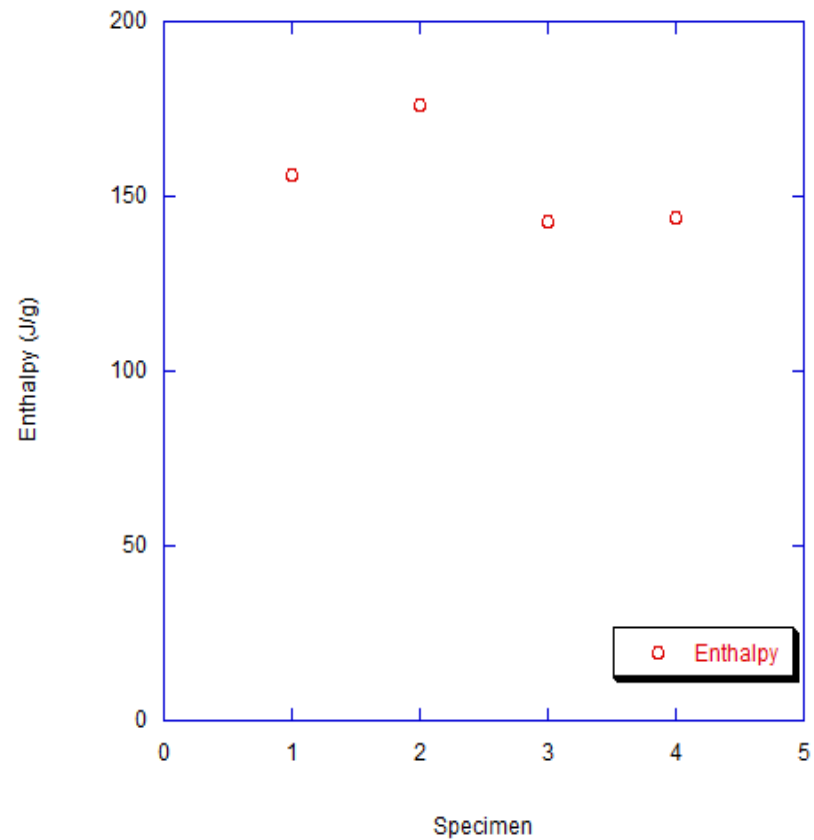

Figure 3.12: Enthalpy of PCMs under endothermic reaction 


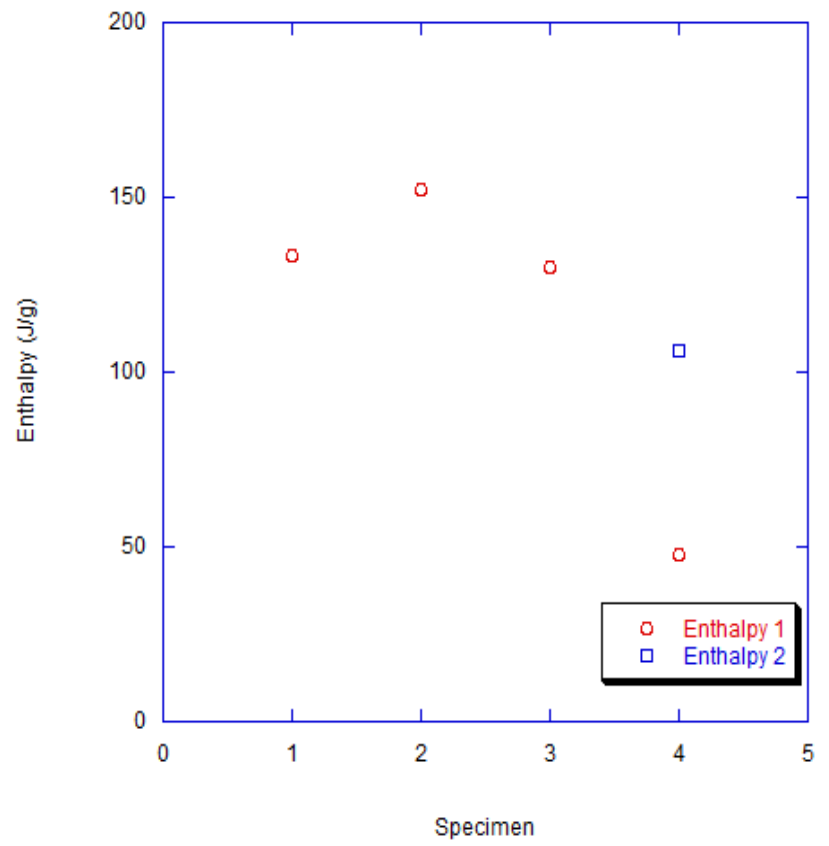

Figure 3.13: Enthalpy of PCMs under exothermic reaction

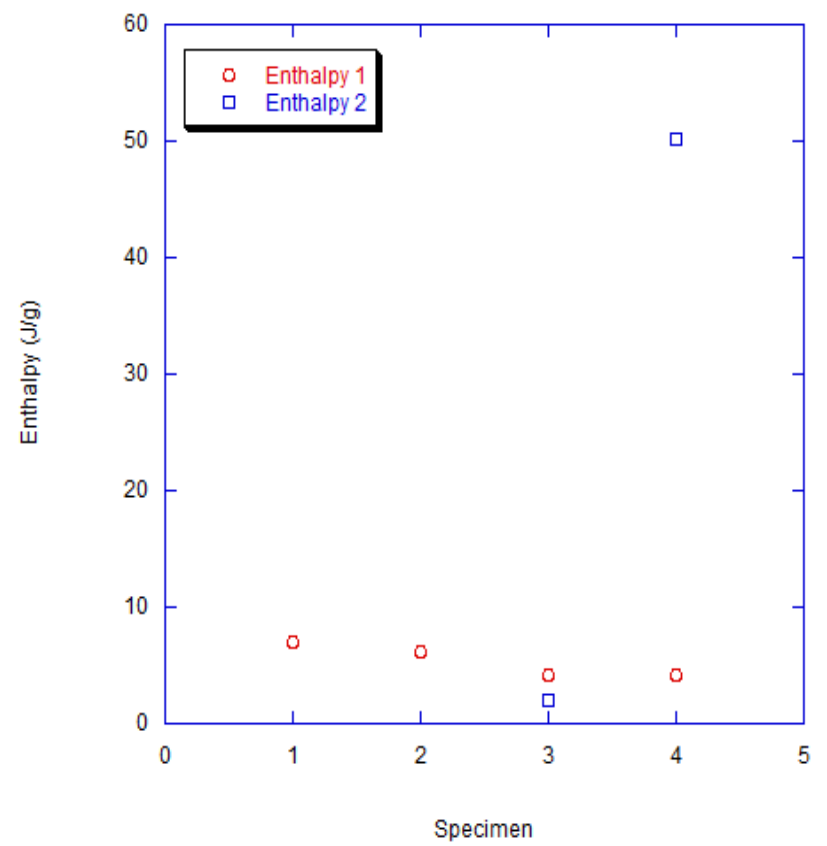

Figure 3.14: Enthalpy of PCMs under endothermic reaction 
which are known theoretically, but their onset and peak temperatures does not show a constant temperature increase. The reasons speculated for the onset and the peak temperatures not showing a constant temperature increase are phase segregation in the solid state or a mixing problem of PCMs on macro-encapsulated PCM samples because PCMs are tested in the solid state.

Typically, a PCM solidification phase from the liquid state to the solid state occurs at a slightly lower temperature rather than its own freezing temperature, and the slightly lower temperature means the freezing temperature of the PCM. However, as shown in Figure 3.10, the freezing temperatures of four kinds of PCMs are drastically decreased by about $30^{\sim} 40^{\circ} \mathrm{C}$ rather than their own phase change temperatures, which are given theoretically. The reason for the freezing temperature decrease is because supercooling happens during the solidification progress.

Figure 3.11 shows the onset, the peak, and the end temperatures of four kinds of PCMs. As the melting temperature of the PCM sample is increased, the onset, the peak, and the end temperatures are also increased. Figures 3.12 and 3.13 indicate enthalpies of PCMs under the endothermic and exothermic reactions using DSC Q 200 equipment. Figure 3.14 shows enthalpies of PCMs for only the endothermic reaction using DSC STA 8000 equipment. Enthalpy 1 is from the first curve of DSC data, and enthalpy 2 is from the second curve of the DSC result. As the PCM is melted at a high temperature, the PCM has low enthalpy and high heat capacity. When the PCM has a low melting temperature, the PCM can store $1.24^{\sim} 1.75$ times more 
internal energy and use less energy to increase the temperature of material rather than the PCM, which has a high melting temperature.

The temperature tendency is shown in Figure 3.11. When PCM's own melting temperatures are increased, temperature properties are also increased. However, DSC STA 8000 equipment by Perkin Elmer Company cannot measure until $-40^{\circ} \mathrm{C}$ for the exothermic reaction because of the temperature limitation of the machine. For this reason, the PCM samples are measured the thermal properties again using DSC Q 200 equipment (TA Instruments). From the results of the thermal properties, a noticeable temperature tendency is not indicated on temperature properties but the experimental melting temperatures of the PCMs from the DSC graphs appear to exceed their own melting temperature.

\subsubsection{Phase Change Materials Melted}

The dynamic DSC technique was performed to assess the material properties of the PCMs made into the liquid state at above room temperature $\left(22^{\circ} \mathrm{C}\right)$. Some samples were in the solid state, and some samples were in the liquid state at room temperature $\left(22^{\circ} \mathrm{C}\right)$, even though the PCM samples melted at $21^{\circ} \mathrm{C}$ must be in the liquid state, and the PCM samples melted at $23^{\circ} \mathrm{F}$ must be in the solid state. For this reason, the PCMs were made into the liquid state at above room temperature, and thermophysical properties were compared. Also, as mentioned above Chapter, because of the temperature limitation of the machine (DSC STA 8000 equipment, Perkin Elmer 
Company), thermophysical properties were measured by using different two machines.

Figures 3.15 and 3.16 show dynamic DSC curves of two types of PCMs measured using DSC Q 200 equipment (TA Instruments), and Figures 3.17 and 3.18 indicate dynamic DSC curves evaluated using DSC STA 8000 equipment (Perkin Elmer Company). Figures 3.19 to 3.20 and Figures 3.22 to 3.23 are the temperature properties and enthalpies for the endothermic reaction and the exothermic reaction measured using DSC Q 200 equipment, respectively. Figures 3.21 and 3.24 are the temperature properties and enthalpies for only the endothermic reaction evaluated by the DSC STA 8000 equipment, respectively. In Figures 3.19 to 3.24, specimens 1 to 4 indicate the original PCM melted at $21^{\circ} \mathrm{C}$, the $\mathrm{PCM}$ (melted at $21^{\circ} \mathrm{C}$ ) made into the liquid state, the original $\mathrm{PCM}$ melted at $23^{\circ} \mathrm{C}$, and the $\mathrm{PCM}$ (melted at $23^{\circ} \mathrm{C}$ ) made into the liquid state, respectively.

As shown in Figures 3.1 and 3.15 (or specimens 1 and 2 in Figure 3.19) measured using DSC Q 200 equipment, dynamic DSC curves (temperature properties) are not different between the original PCM and the PCM made into the liquid state under the endothermic reaction. However, in terms of the exothermic reaction, freezing temperatures and enthalpies of the PCMs show the different results between the original PCM and the PCM made into the liquid state. The PCM made into the liquid state has a lower freezing temperature and enthalpy than the original PCM. It is speculated that phase segregation happens during the solidification at room temperature for the original PCM. Also, the PCM made into the liquid state seems 


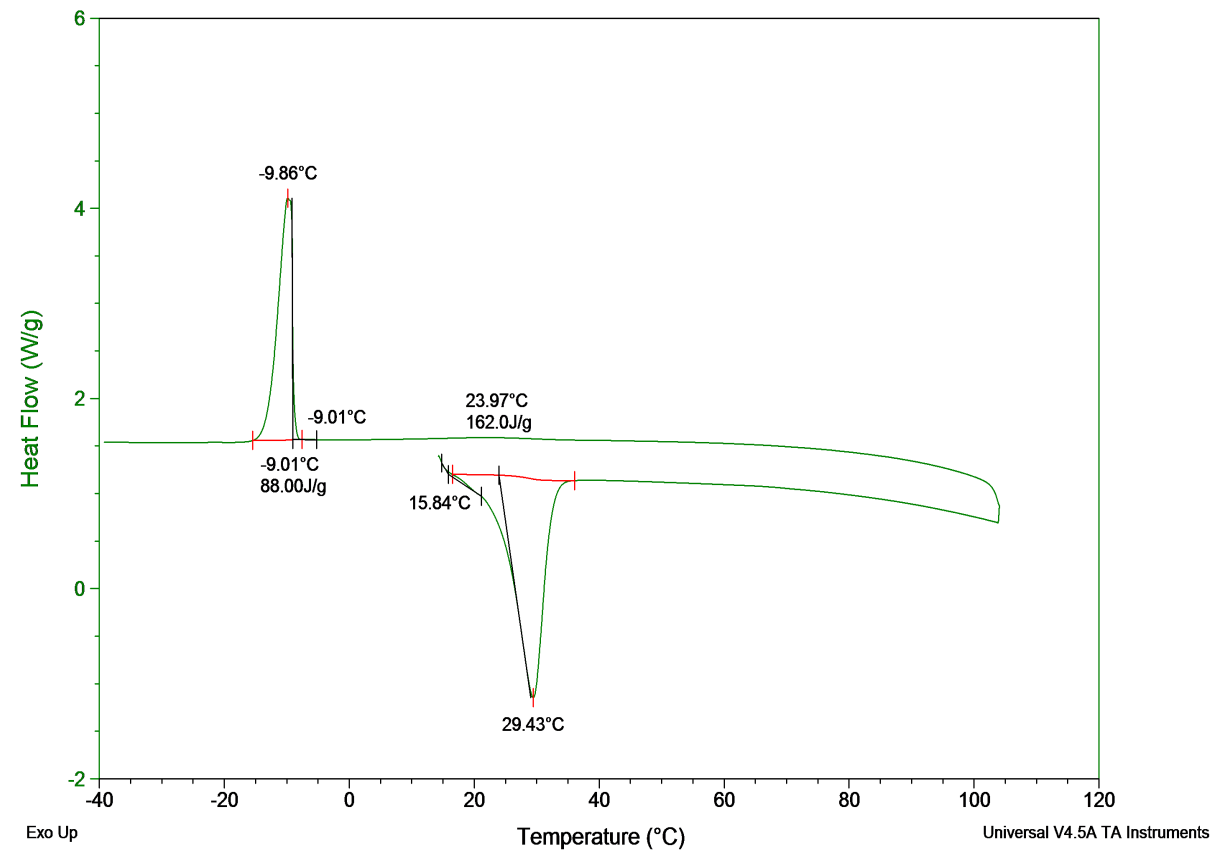

Figure 3.15: Dynamic DSC curve of the PCM melted at $21^{\circ} \mathrm{C}$ and made into the liquid state at above room temperature

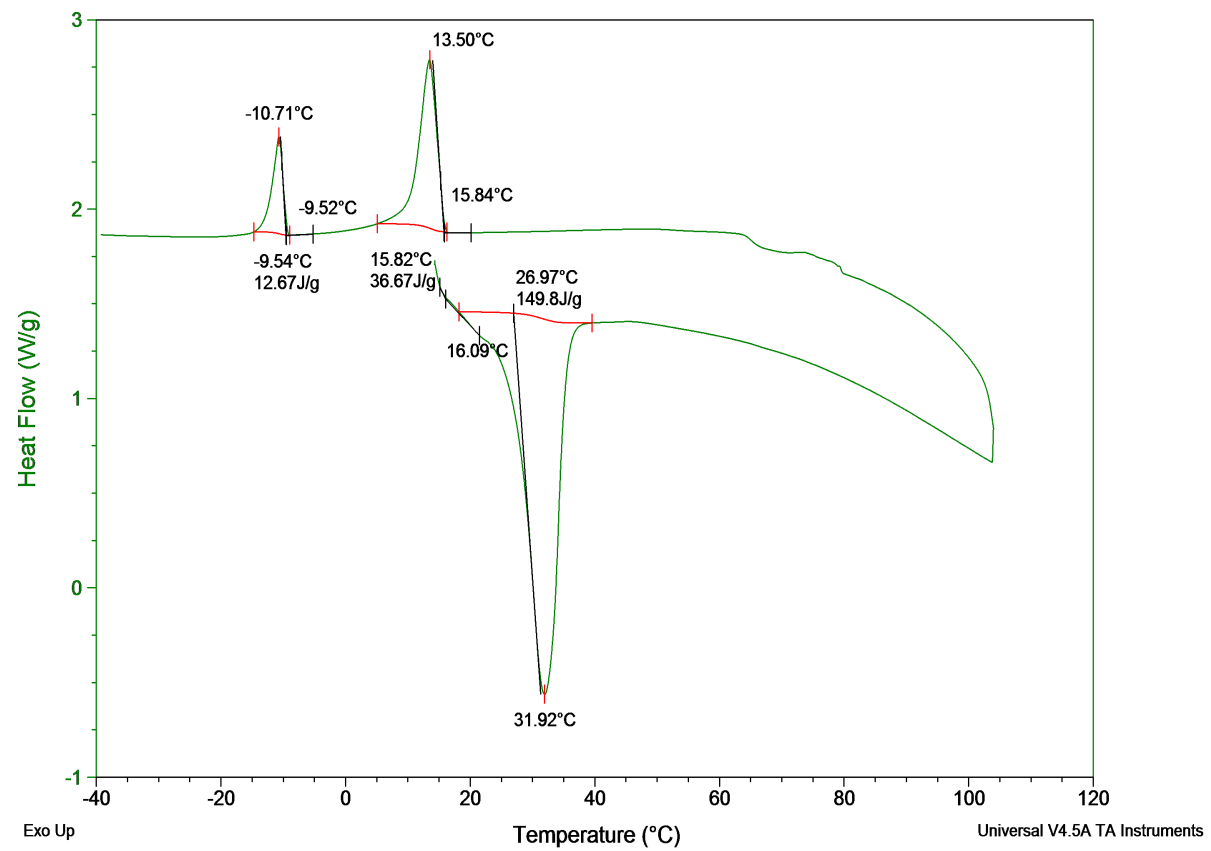

Figure 3.16: Dynamic DSC curve of the PCM melted at $23^{\circ} \mathrm{C}$ and made into the liquid state at above room temperature 


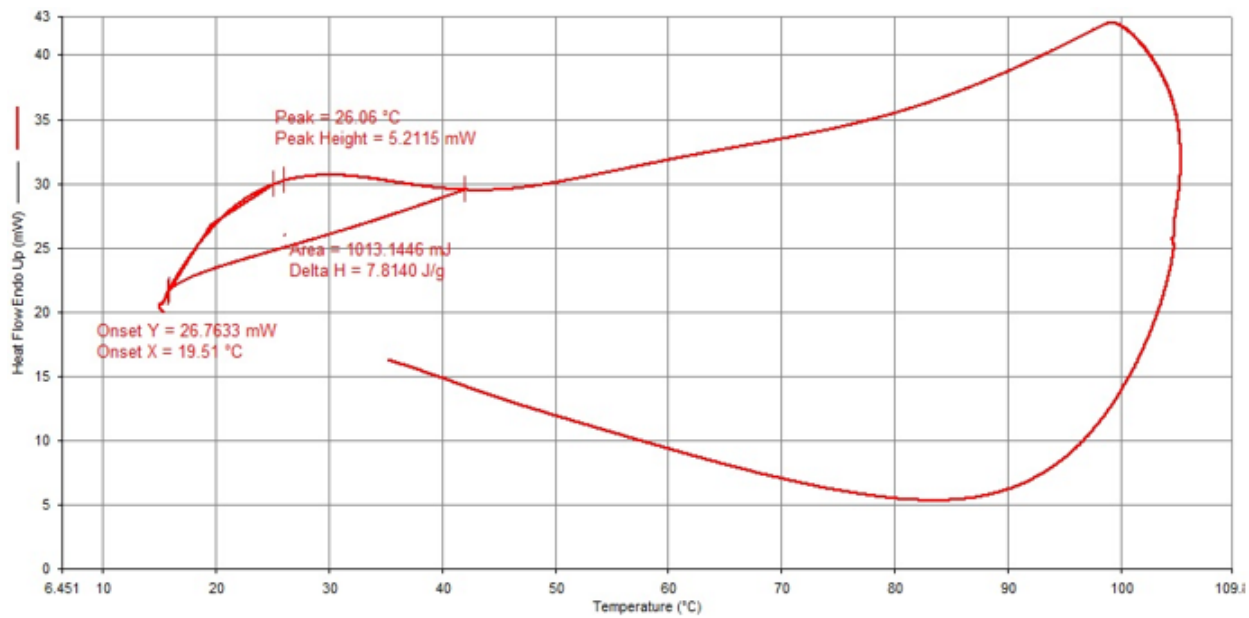

Figure 3.17: Dynamic DSC curve of the PCM melted at $21^{\circ} \mathrm{C}$ and made into the liquid state at above room temperature

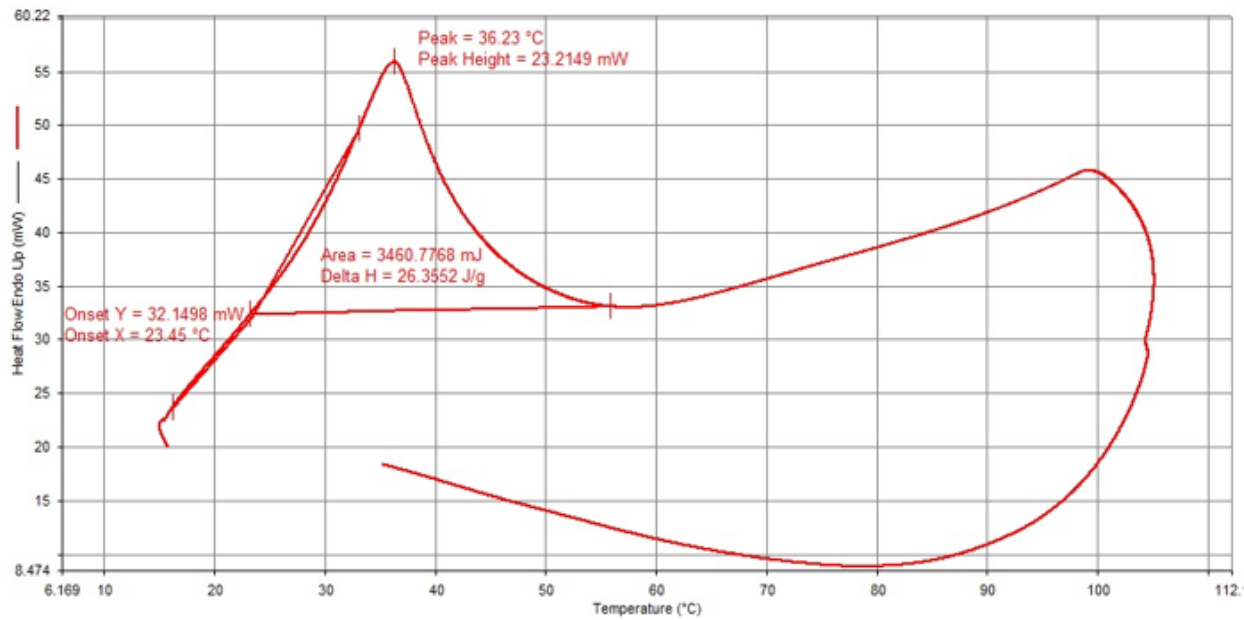

Figure 3.18: Dynamic DSC curve of the PCM melted at $23^{\circ} \mathrm{C}$ and made into the liquid state at above room temperature 
to solve the problem of phase segregation during the melting process at above room temperature. As shown in Figures 3.5 and 3.17 (or specimens 1 and 2 in Figure 3.21) measured by DSC STA 8000 equipment, dynamic DSC curves also show similar curves and similar temperature properties under the endothermic reaction.

As shown in Figures 3.2 and 3.16 (in the case of $\mathrm{PCM}$ melted at $23^{\circ} \mathrm{C}$ ), dynamic DSC curves show similar curves and temperature properties for the endothermic reaction, but under the exothermic reaction, DSC curves show the difference clearly between the original PCM and the PCM made into the liquid state. In Figure 3.16, the endothermic curve has a single peak, but the exothermic curve has a primary peak and a secondary peak. The primary peak under the exothermic curve seems to be an exothermic change of phase of the PCM such as solidification, and the secondary peak is the freezing of the solution of salt hydrate present in the PCM sample.

For the PCM melted at $23^{\circ} \mathrm{C}$ (Figures 3.6 and 3.18), the PCM in the liquid state has a larger temperature range and a higher heat flow than the temperature range and the heat flow of the original PCM. A large temperature range and a higher heat flow mean that the PCM can store much more the total value of the enthalpy. This may be the result of a mixing problem for the original PCM or during the solidification of the original PCM, phase separation can happen because of considerable variations of the heat flow and the enthalpy of the original $\mathrm{PCM}$, which melts at $23^{\circ} \mathrm{C}$, and the PCM, which is made into the liquid state. Moreover, something such as oil occurred from a sample when the sample was at room temperature for a few minutes. 


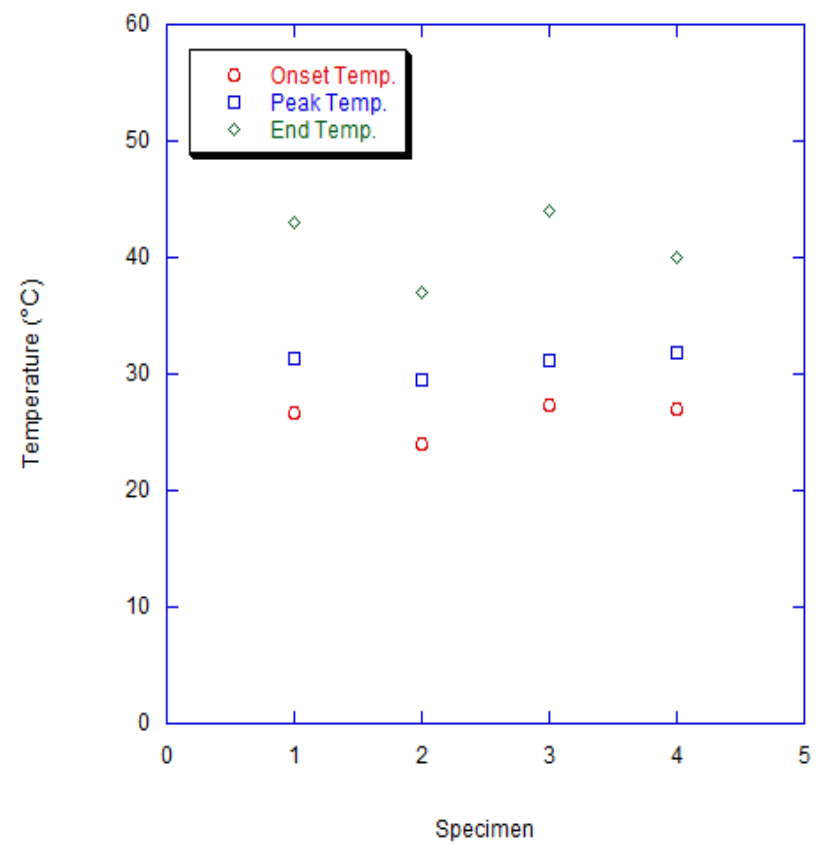

Figure 3.19: Temperature properties of original PCMs and PCMs made into the liquid state measured using DSC Q 200 equipment under endothermic reaction

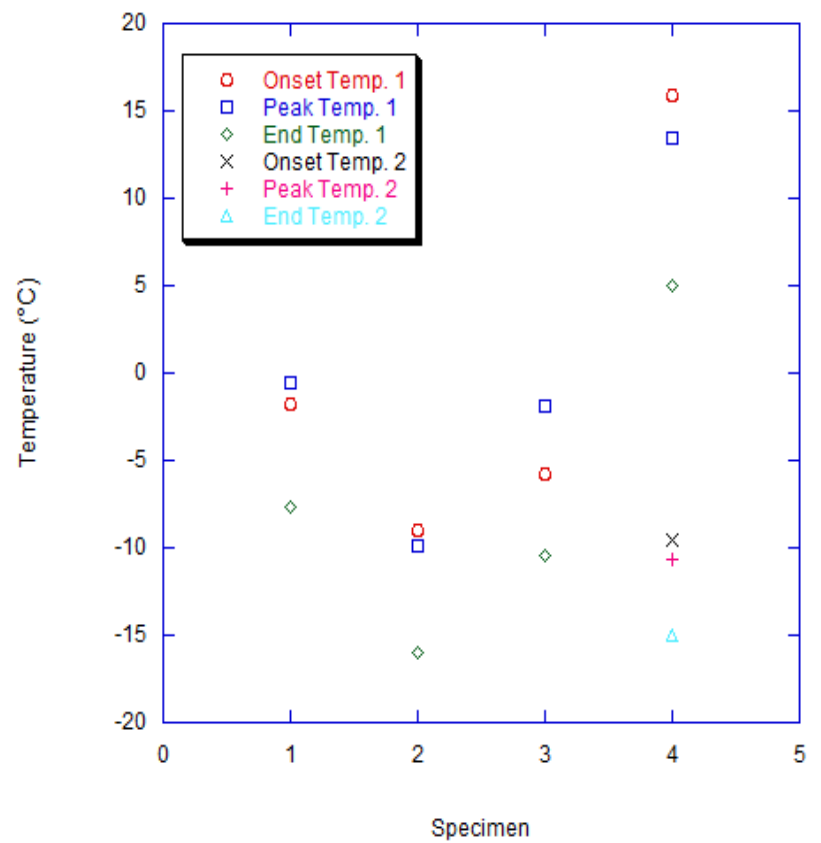

Figure 3.20: Temperature properties of original PCMs and PCMs made into the liquid state measured using DSC Q 200 equipment under exothermic reaction 


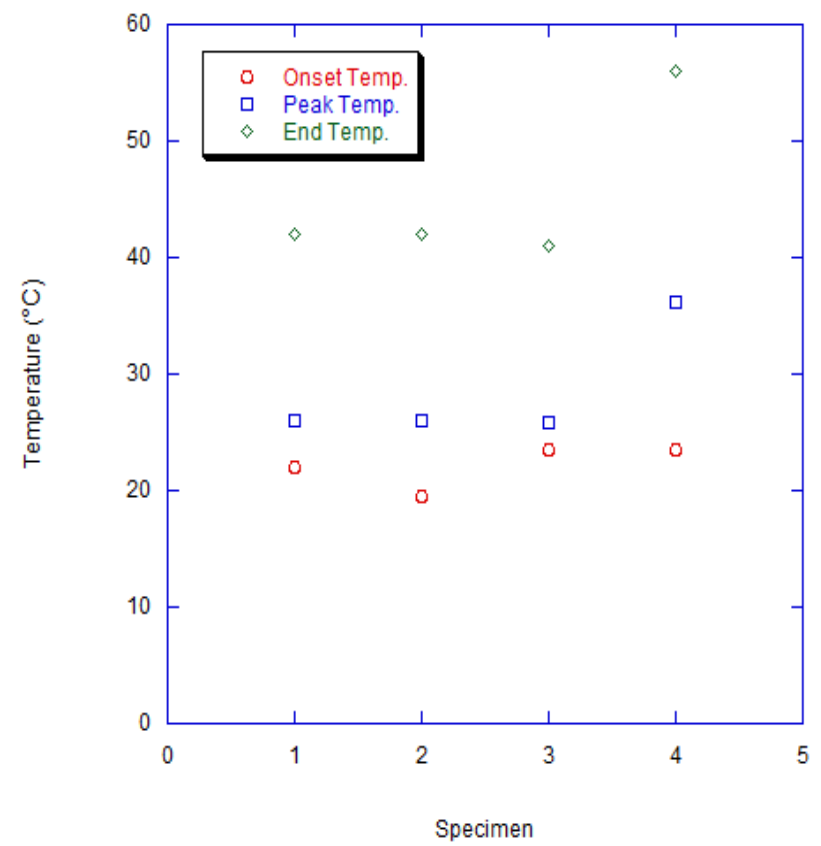

Figure 3.21: Temperature properties of original PCMs and PCMs made into the liquid state measured using DSC STA 8000 equipment under endothermic reaction

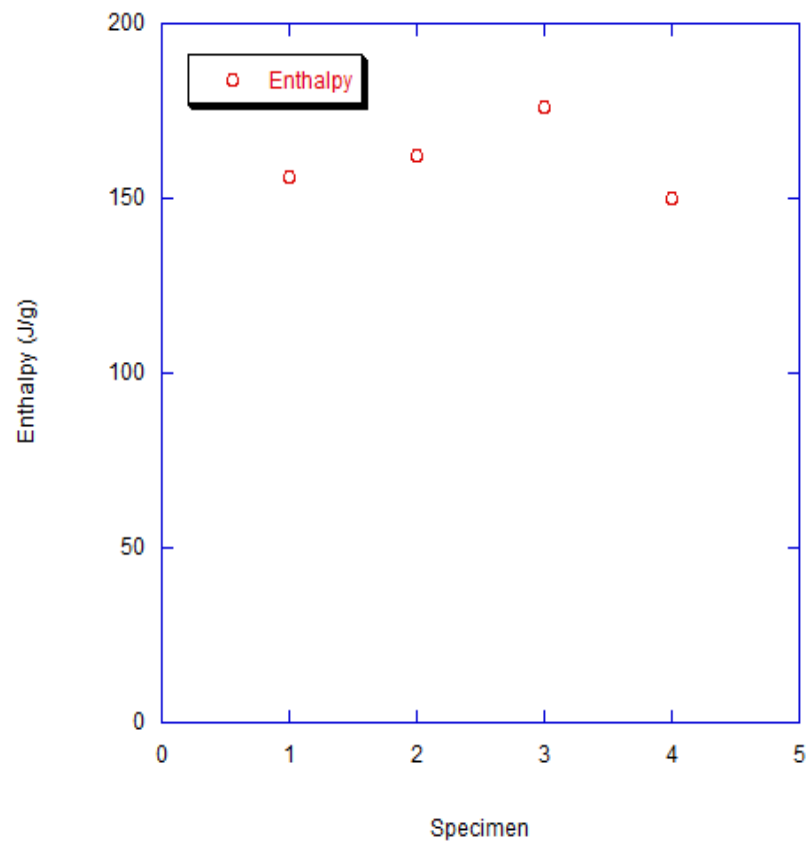

Figure 3.22: Enthalpy of original PCMs and PCMs made into the liquid state measured using DSC Q 200 equipment under endothermic reaction 


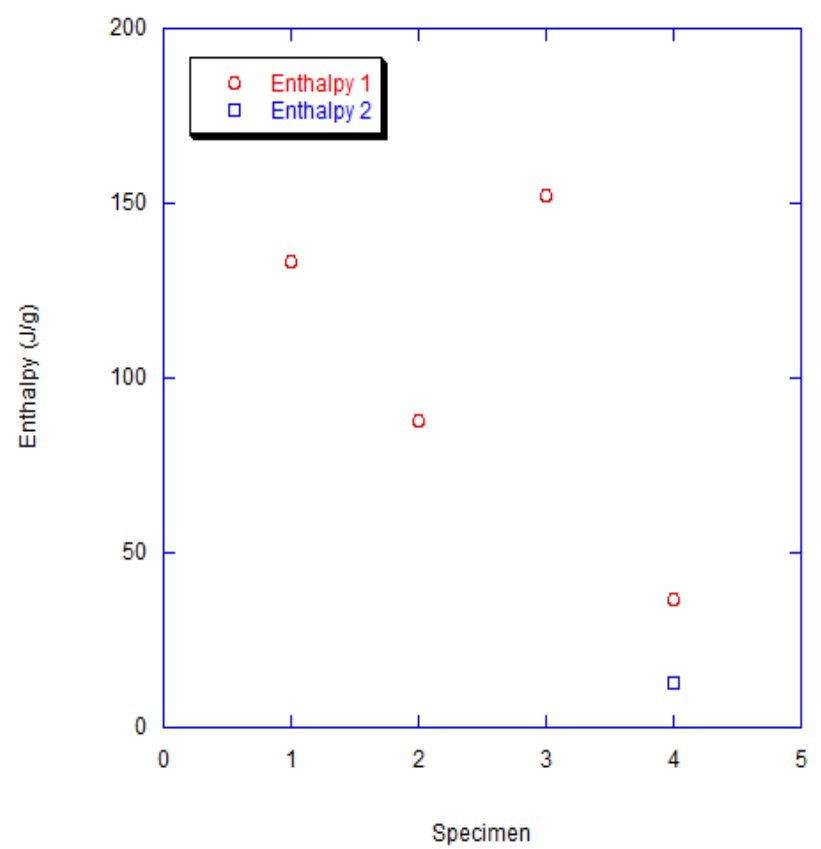

Figure 3.23: Enthalpy of original PCMs and PCMs made into the liquid state measured using DSC Q 200 equipment under exothermic reaction

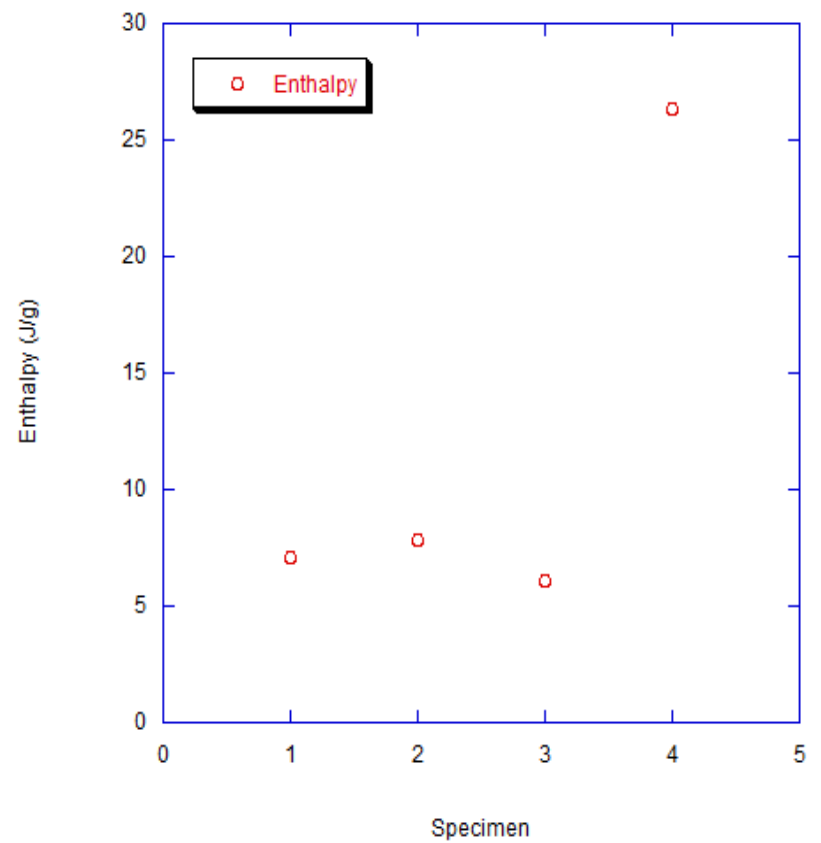

Figure 3.24: Enthalpy of original PCMs and PCMs made into the liquid state measured using DSC STA 8000 equipment under endothermic reaction 


\subsubsection{Phase Change Material in Liquid State}

In this study, the dynamic DSC method was carried out to evaluate the thermophysical property of the PCM, which was in liquid state at room temperature. Even though the PCM sample melted at $23^{\circ} \mathrm{C}$ must be in the solid state at room temperature $\left(22^{\circ} \mathrm{C}\right)$, some samples were in the solid state, and some samples were in the liquid state. Therefore, the PCM in the liquid state at room temperature was measured to find out the thermophysical property under the dynamic DSC mode using DSC STA 8000 equipment from Perkin Elmer Company.

Figure 3.25 shows a DSC curve, and Figures 3.26 to 3.27 compare the temperature properties and the enthalpies of three types of the PCMs melted at $23^{\circ} \mathrm{C}$, respectively. Specimens 1 to 3 mean the original $\mathrm{PCM}$ melted at $23^{\circ} \mathrm{C}$, the $\mathrm{PCM}$ made into the liquid state at above room temperature, and the PCM in the liquid state at room temperature, respectively.

The obtained dynamic DSC data, displayed in Figure 3.25, shows the similar DSC curve to Figure 3.18. The PCM in the liquid state shows $25.12^{\circ} \mathrm{C}$ at the onset temperature, $39.23^{\circ} \mathrm{C}$ at the peak temperature, $60^{\circ} \mathrm{C}$ at the end temperature, 30.0592 $\mathrm{J} / \mathrm{g}$ of the enthalpy, and $24.1058 \mathrm{~mW}$ of the heat flow in Figure 3.25. As shown in Figure 3.26, even though the onset temperatures of the three types of PCMs are similar, the peak temperature and the end temperature indicate different temperature conditions. The enthalpies demonstrate clearly different results between the original 
$\mathrm{PCM}$ and the PCMs in liquid state. It is speculated that the temperature range of the PCM would be affected to store or release energy, and that phase separation can occur during the process from the liquid state to the solid state.

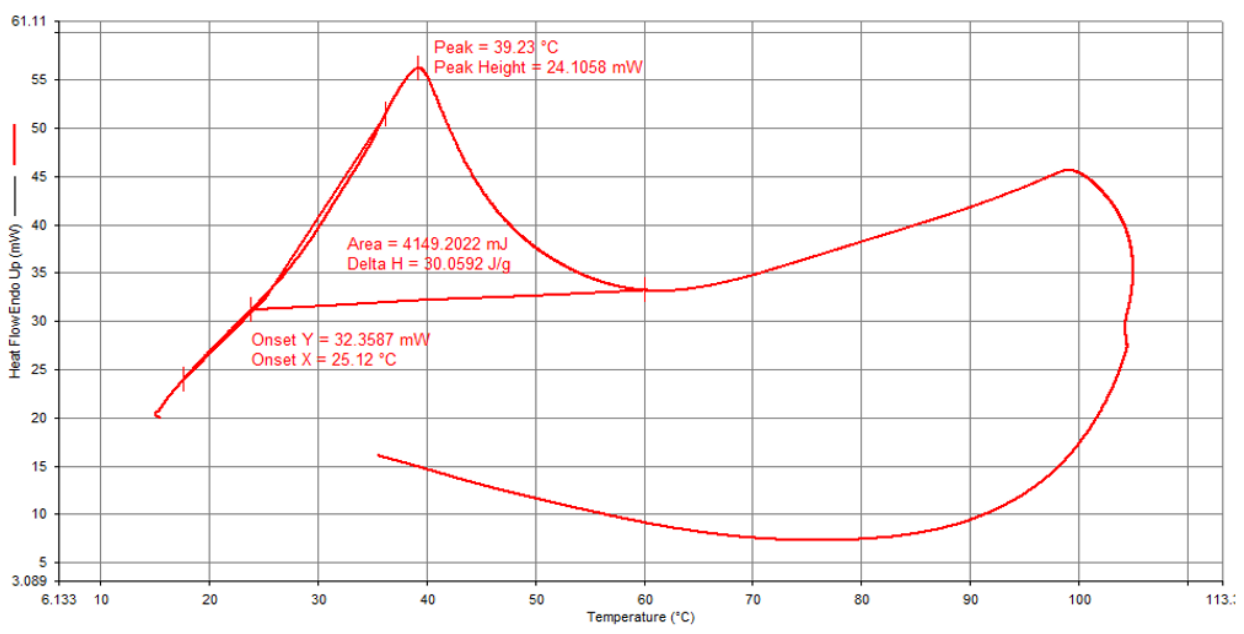

Figure 3.25: Dynamic DSC curve of the PCM in the liquid state 


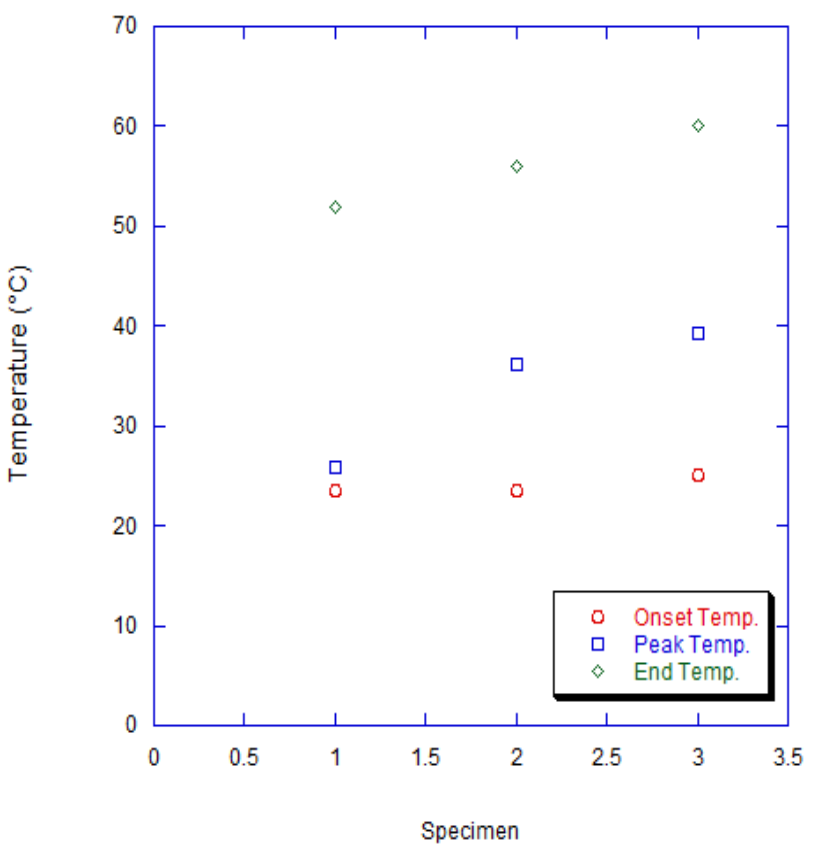

Figure 3.26: Temperature properties of PCMs

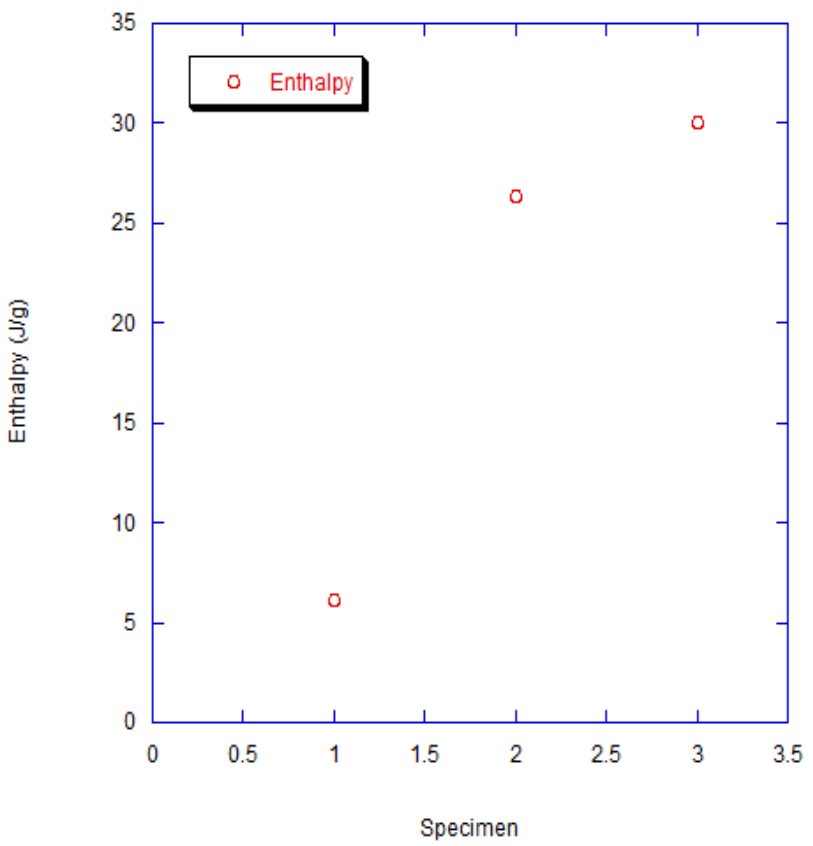

Figure 3.27: Enthalpies of PCMs 


\subsubsection{Isothermal DSC Curves}

\subsubsection{Original Phase Change Materials}

The Differential Scanning Calorimetry (DSC) with the isothermal DSC mode using DSC STA 8000 equipment from Perkin Elmer Company can be performed to assess the thermal properties and the heat storage capacities of four types of the PCMs. In addition, an isothermal DSC curve such as the heat flux signal vs. time for each temperature is effective in determining how much time is required at each temperature until the steady-state condition is achieved (ASTM International [2016]). In this study, the isothermal DSC method is conducted to measure the steady-state condition of four kinds PCMs, which have the phase change at $21^{\circ} \mathrm{C}, 23^{\circ} \mathrm{C}, 26^{\circ} \mathrm{C}$, and $30^{\circ} \mathrm{C}$, respectively.

Figures 3.28 to 3.32 show isothermal DSC curves of the PCMs, and the isothermal DSC mode is held for 60 minutes at the constant onset temperature, the peak temperature, and the end temperature of each of the PCM samples.

As shown in Figures 3.28 though 3.30 and Figure 3.32, the exothermic reactions occur at the onset temperature conditions, and the endothermic reactions occur at the peak temperature and the end temperature conditions. The steady-state conditions are achieved after about 35 minutes at each temperature step. Moreover, a small fluctuation (red circle) happens in Figures 3.28, 3.30, 3.31, and 3.32. It is speculated that a few minutes are needed until temperature stabilization is achieved at each 
of the test temperatures. A large endothermic reaction occurs as temperature steps increase. This is the reason why the cumulative energy storage from the enthalpy change increases as temperature steps increase.

For the second isothermal DSC curve of the PCM melted at $26^{\circ} \mathrm{C}$ in Figure 3.31, since this specimen (the PCM melted at $26^{\circ} \mathrm{C}$ ) has already changed from the solid state to the liquid state, all temperature steps indicate the endothermic reaction, and a large endothermic reaction takes place as temperature steps increase.

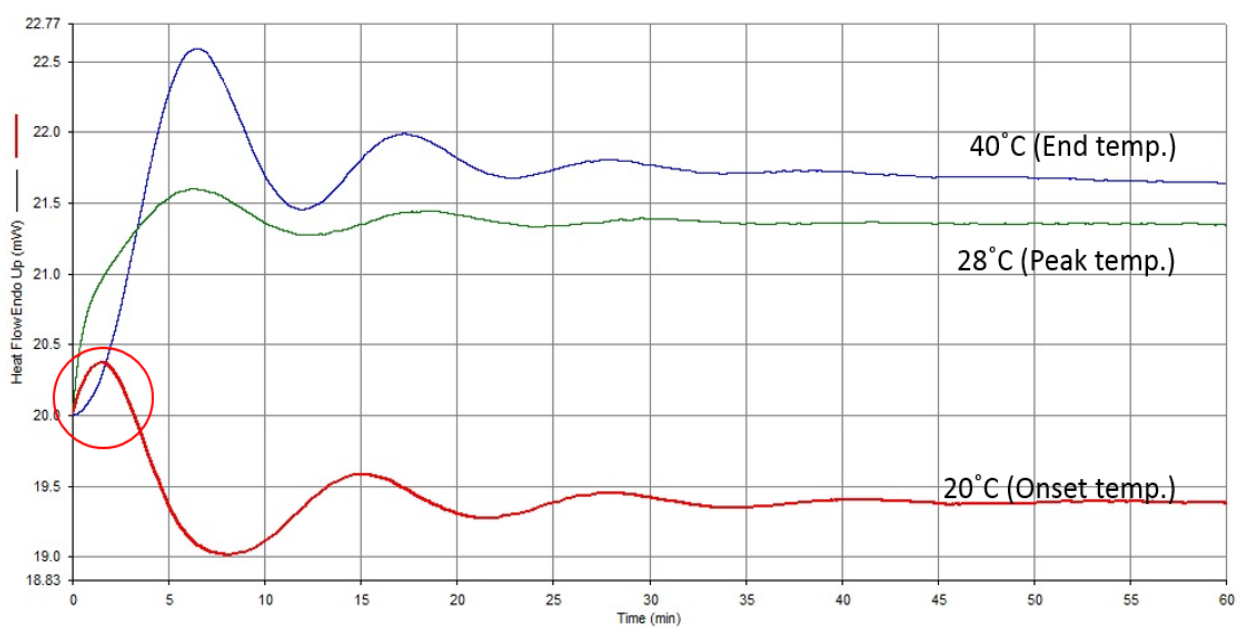

Figure 3.28: Isothermal DSC curve of the PCM melted at $21^{\circ} \mathrm{C}$ 


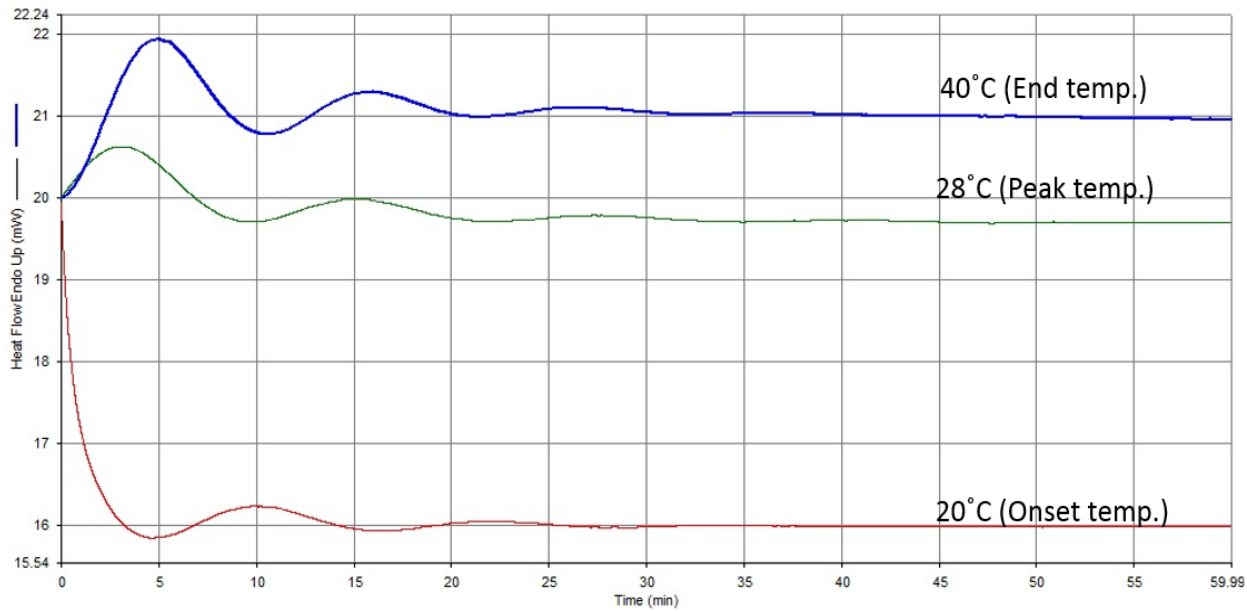

Figure 3.29: Isothermal DSC curve of the PCM melted at $23^{\circ} \mathrm{C}$

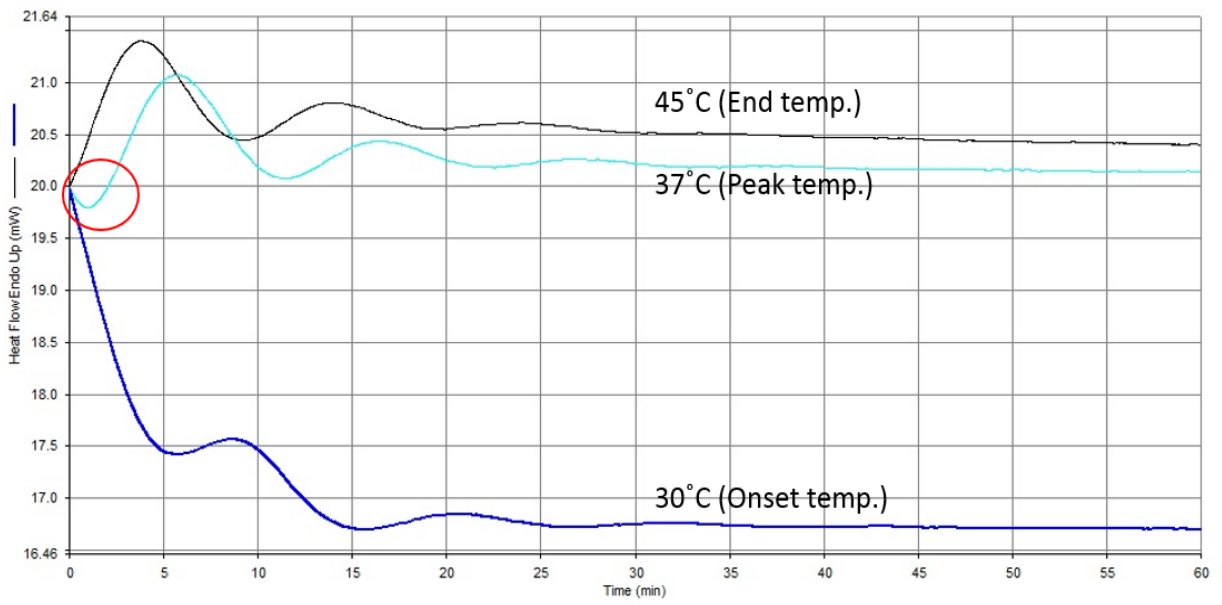

Figure 3.30: The first isothermal DSC curve of the PCM melted at $26^{\circ} \mathrm{C}$ 


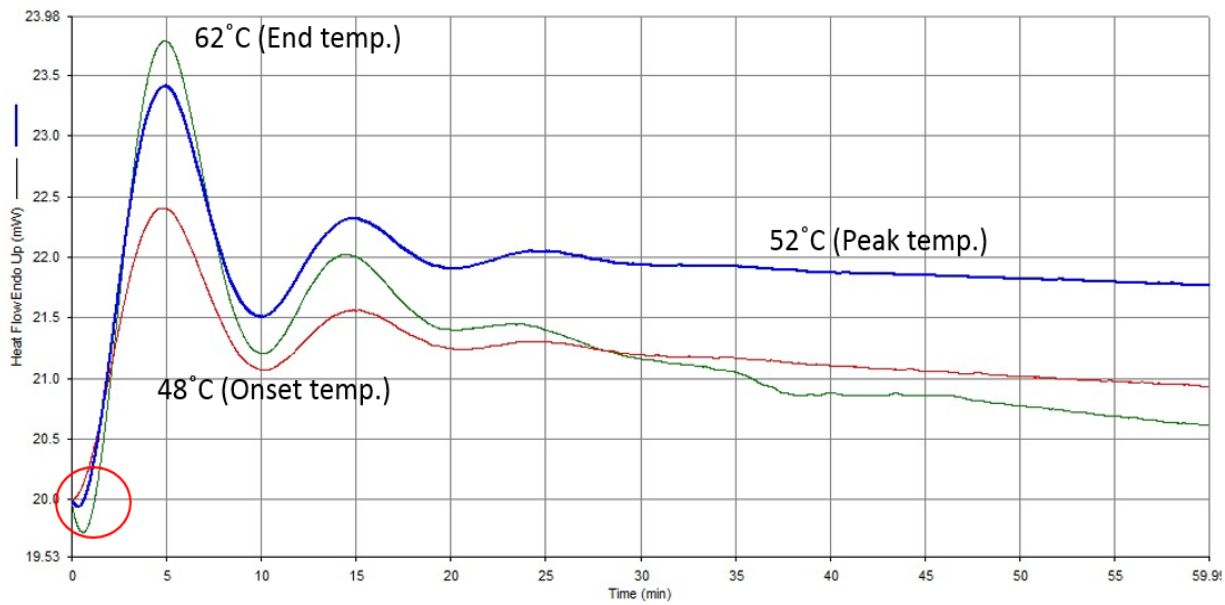

Figure 3.31: The second isothermal DSC curve of the PCM melted at $26^{\circ} \mathrm{C}$

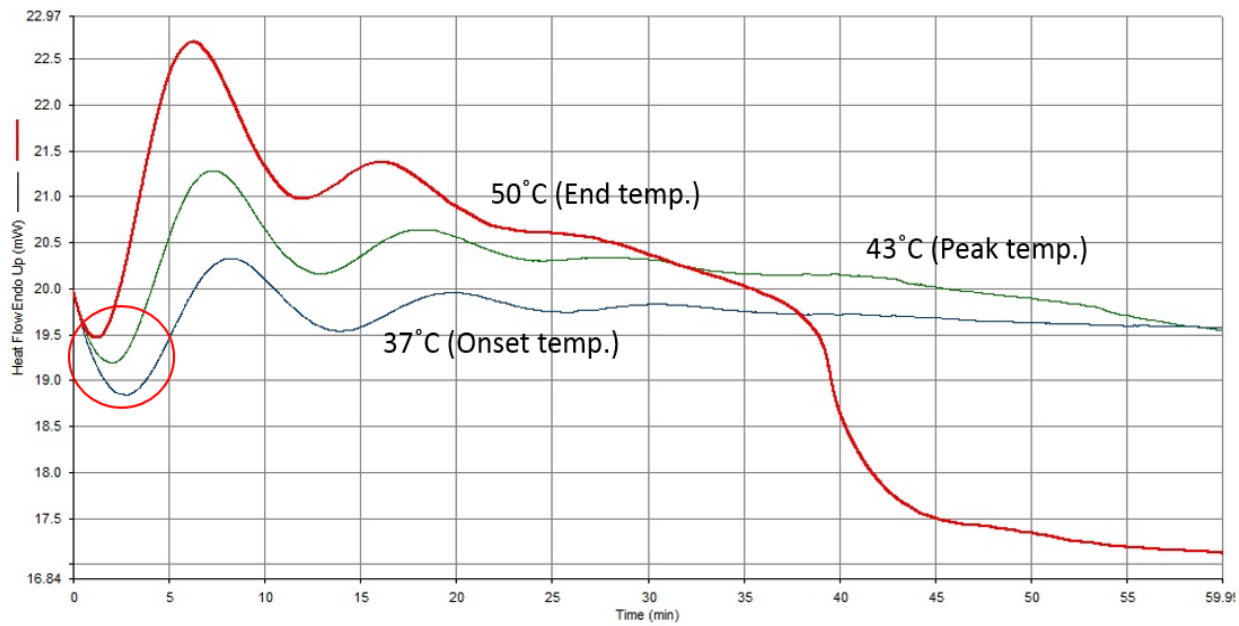

Figure 3.32: Isothermal DSC curve of the PCM melted at $30^{\circ} \mathrm{C}$ 


\subsubsection{Phase Change Materials Melted}

The isothermal DSC technique was conducted to measure the time for the equilibrium of the PCMs made into the liquid state at above room temperature $\left(22^{\circ} \mathrm{C}\right)$. In this study, two PCM samples, which melted at $21^{\circ} \mathrm{C}$ and $23^{\circ} \mathrm{C}$, respectively, were used, and these were made into the liquid state at above room temperature. The reason thses PCMs were made to the liquid states was because these samples were in the solid and liquid state together at room temperature. These PCMs were maintained for 60 minutes at the onset temperature, the peak temperature, and the end temperature of each PCM under the isothermal DSC mode.

Figures 3.33 and 3.34 indicate isothermal DSC curves for the PCMs, which melt at $21^{\circ} \mathrm{C}$ and $23^{\circ} \mathrm{C}$, respectively, and are made into the liquid state at above room temperature.

As shown in Figures 3.33 and 3.34, in common with the reactions of the original PCMs, the exothermic reactions happen at the onset temperature conditions, and the endothermic reactions occur at the peak temperature and the end temperature conditions. The steady-state conditions are achieved after about 35 minutes at each temperature step. In addition, a few fluctuations occur for temperature stabilization during the isothermal DSC process at the end temperature condition.

Isothermal DSC curves in Figure 3.34 clearly demonstrate the difference in the amount of heat absorption of the original PCM melted at $23^{\circ} \mathrm{C}$ in Figure 3.29. In 
addition, as shown in Figure 3.24, specimens 3 and 4 (the original PCM melted at $23^{\circ} \mathrm{C}$ and the PCM made into the liquid state) show the different amount of the enthalpy. This means that as the amount of the enthalpy is increased, the absorbed energy is increased, and the heat storage capacity is also increased. Therefore, as the amount of the enthalpy and temperature steps are increased, the amount of heat absorption is also increased.

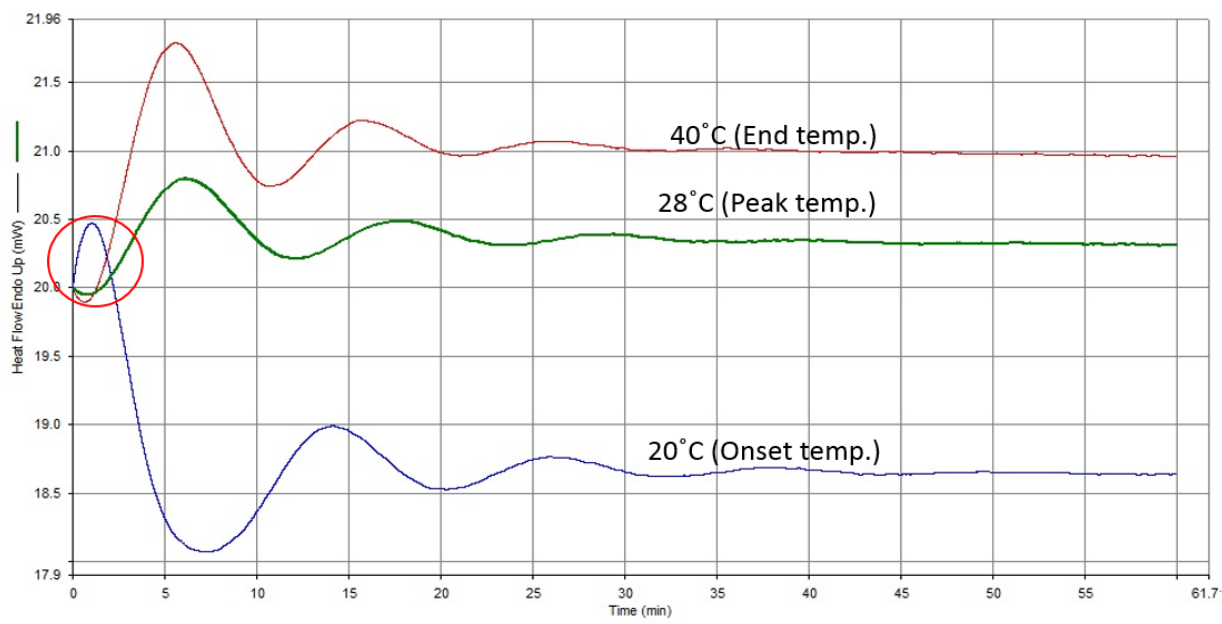

Figure 3.33: Isothermal DSC curve of the PCM melted at $21^{\circ} \mathrm{C}$ and made into the liquid state 


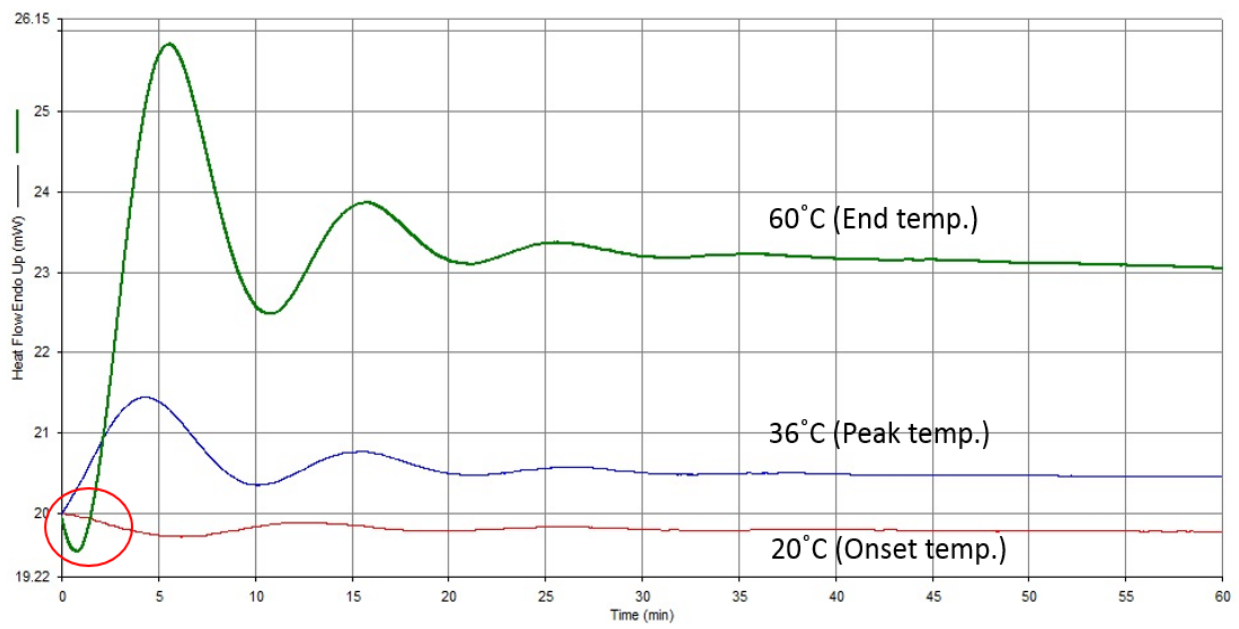

Figure 3.34: Isothermal DSC curve of the PCM melted at $23^{\circ} \mathrm{C}$ and made into the liquid state

\subsubsection{Phase Change Material in Liquid State}

In this study, the isothermal DSC technique was carried out to evaluate the steadystate condition of the PCM, which was in the liquid state at room temperature. The PCM, which changed the phase at $23^{\circ} \mathrm{C}$, must be in the solid state at room temperature $\left(22^{\circ} \mathrm{C}\right)$, but since this sample was in the solid state or the liquid state at room temperature, the PCM in the liquid state was tested in this study.

Figure 3.35 shows the isothermal DSC curves of the PCM, which melts at $23^{\circ} \mathrm{C}$, within the liquid state, and the PCM in the liquid state is maintained for 60 minutes at the constant onset temperature condition, the peak temperature condition, and the end temperature condition, respectively.

As shown in Figure 3.35, the endothermic reactions occur at the peak temperature 
and the end temperature conditions. The endothermic reaction also occurs at the onset temperature condition. Theoretically, the exothermic reaction must occur at the onset temperature condition because this PCM is in the solid state at the onset temperature condition.

Even though the exothermic reaction has to occur at the onset temperature condition, the endothermic reaction occurs in the result. In Figure 3.35, the amount of absorbed heat during the isothermal DSC measurement at the onset temperature condition is smaller than the amounts of absorbed heat during the isothermal DSC measurement at the peak temperature and the end temperature conditions.

While the endothermic reaction is progressing at the onset temperature condition, the small amounts of the exothermic reaction happens as well. This principle is similar to that of the endothermic and exothermic reactions of into ice. Until water solidifies

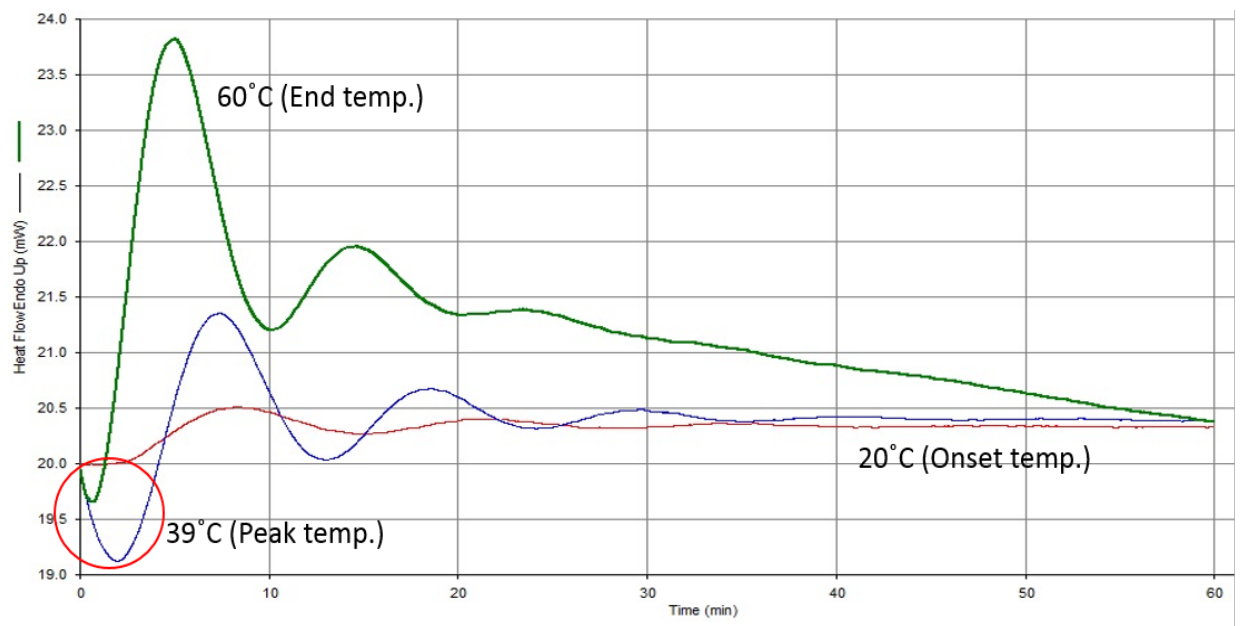

Figure 3.35: Isothermal DSC curve of the PCM in the liquid state 
ice, water has not only an exothermic reaction, but also a small endothermic reaction. Since water has a small endothermic reaction, the surrounding temperature of water is decreased. This reaction can be applied to the result of the isothermal DSC curve at the onset temperature condition since the PCM in the liquid state changes to the solid state at the onset temperature condition. For this reason, during the isothermal DSC measurement at the onset temperature condition, an endothermic reaction is generated, and the amounts of heat absorbed by the endothermic reaction are also very small. 


\subsubsection{Enthalpy Curves}

Phase Change Materials (PCMs) can be used as thermal storage materials with a high storage density. The thermophysical properties of the PCMs can be measured using the enthalpy curves as a function of temperature (the enthalpy vs. temperature) of the PCMs with high precision. The enthalpy curves are also necessary for assessment

of a thermal energy storage (TES) system (Or'ø et al. [2012]). Compared with data from the DSC measurement, the enthalpy-temperature curves are indicated in this study.

Figures 3.36 to 3.39 and Figures 3.42 to 3.45 show the enthalpy-temperature curves of four kinds of the original PCMs, which melt at $21^{\circ} \mathrm{C}, 23^{\circ} \mathrm{C}, 26^{\circ} \mathrm{C}$, and $30^{\circ} \mathrm{C}$, respectively. Figures 3.40 to 3.41 and Figures 3.46 to 3.47 show the enthalpy as a function of temperature curves of PCMs, which melt at $21^{\circ} \mathrm{C}$ and $23^{\circ} \mathrm{C}$, and are made into liquid state, respectively. Figure 3.48 indicates the enthalpy curve of the PCM, which melts at $23^{\circ} \mathrm{C}$ and is within the liquid state at room temperature.

As shown in Figures 3.36 to 3.48, the specific heat capacities of the solid phase and the liquid phase, the peak temperatures (the melting temperatures), the enthalpies, and the total energy storage capacities of the PCMs can be directly estimated from the enthalpy curves. The sensible heat position for the solid state and the sensible heat position for the liquid state indicate the specific heat capacity of the PCM in the solid state and in the liquid state, respectively. The specific heat capacities are 
calculated using equation 2.47 , and the latent position $(\Delta H)$ in the enthalpy as a function of temperature curve is determined from the result of the dynamic DSC measurement. The enthalpy-temperature curves in Figures 3.36 to 3.41 are obtained from the calculation of the dynamic DSC curves using DSC Q 200 equipment from TA Instruments. The enthalpy curves in Figures 3.42 to 3.48 are calculated from results of the dynamic DSC curves using DSC STA 8000 equipment from Perkin Elmer Company.

The stored heat curve as a function of temperature for a PCM generally has over three parts such as the specific heat capacity (the sensible heat part) of the solid phase region, the specific heat capacity (the sensible heat part) for the liquid phase region, and the melting latent heat in the curve.

A sensible heat storage can store thermal energy by increasing the temperature under the solid state or the liquid state of a PCM. The sensible heat storage is involved in the change of the heat capacity and the temperature of a PCM during storing or releasing energy (Pielichowska and Pielichowski [2014]). The initial temperature is increased up to the melting temperature (the peak temperature) of the PCM through sensible heating.

As shown in Figure 2.4, when the temperature is reached at the melting temperature, the temperature of the PCM is no longer increased and decreased until the phase change of the PCM is completed. The ideal PCM has a melting range and stores any energy during the melting temperature range. In addition, the enthalpy 


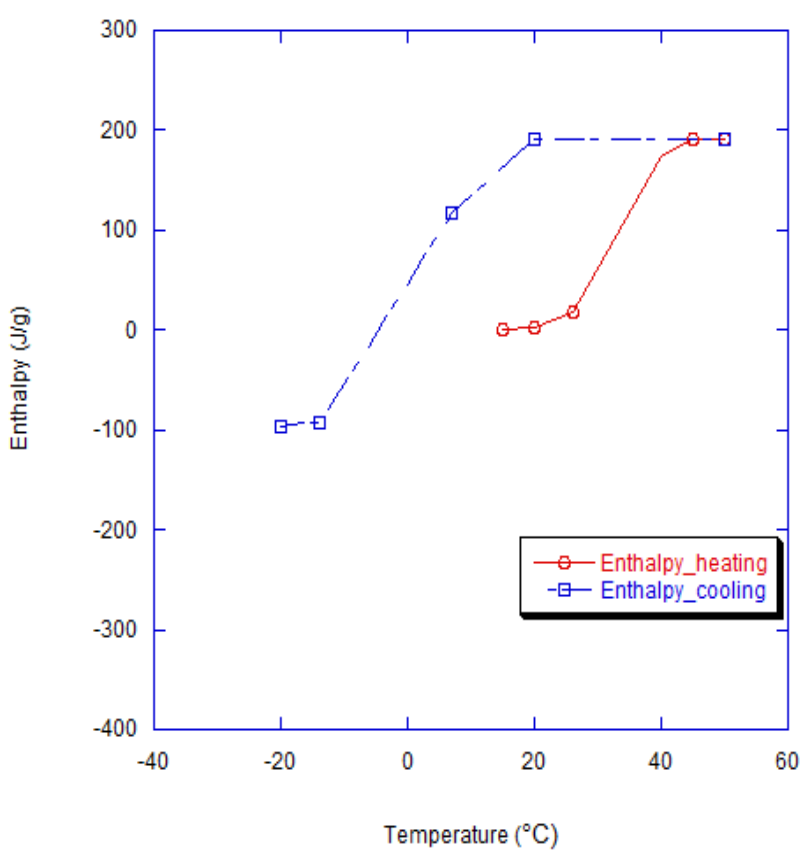

Figure 3.36: Enthalpy curve of the PCM melted at $21^{\circ} \mathrm{C}$

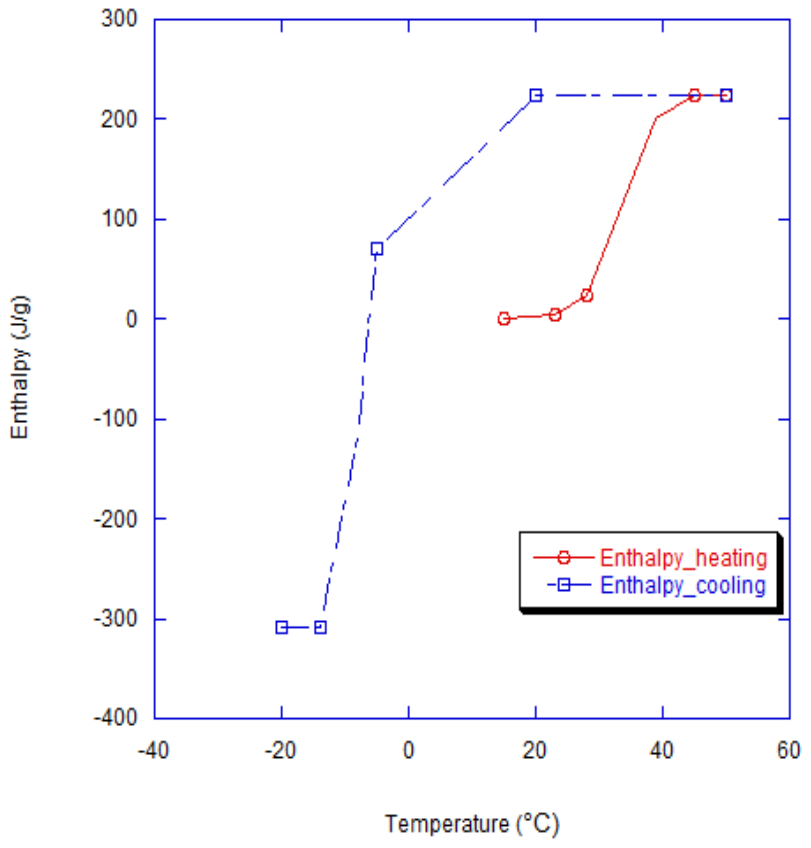

Figure 3.37: Enthalpy curve of the PCM melted at $23^{\circ} \mathrm{C}$ 


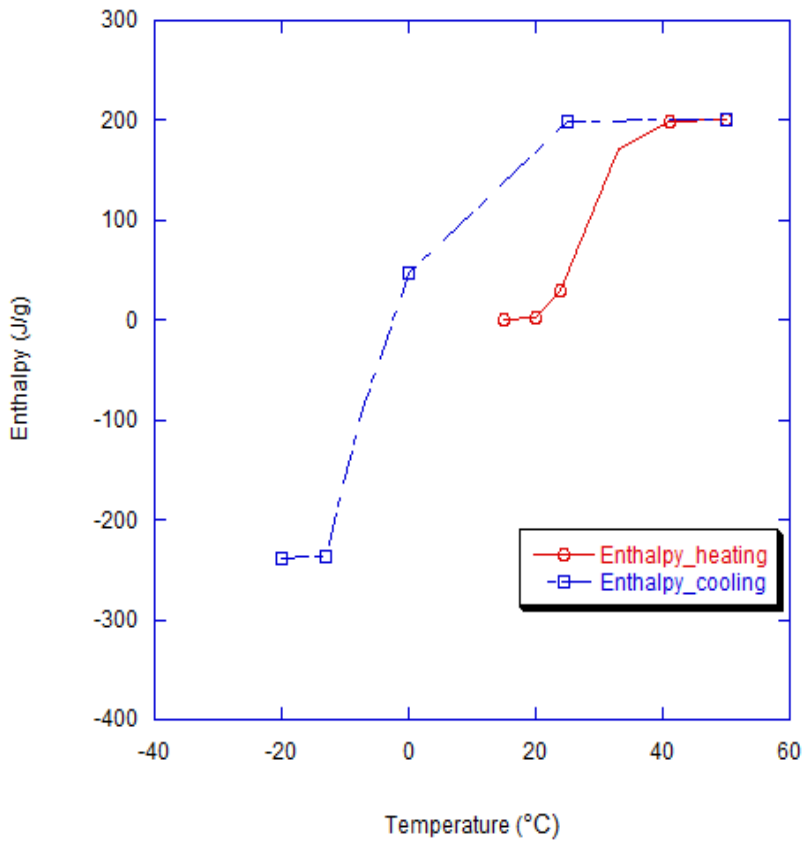

Figure 3.38: Enthalpy curve of the PCM melted at $26^{\circ} \mathrm{C}$

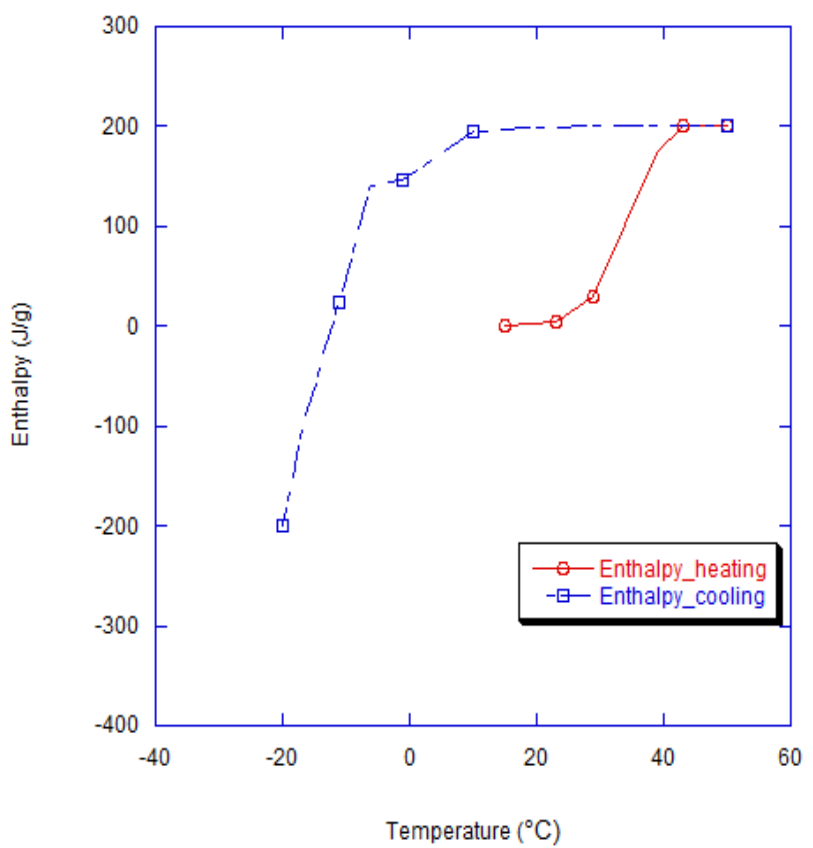

Figure 3.39: Enthalpy curve of the PCM melted at $30^{\circ} \mathrm{C}$ 


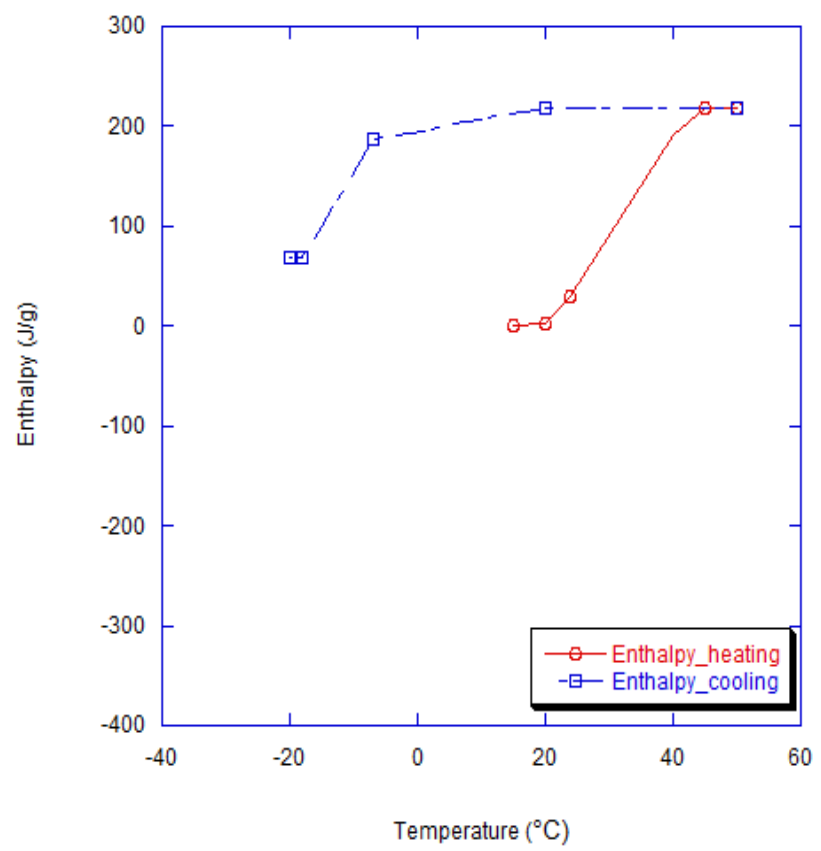

Figure 3.40: Enthalpy curve of the PCM made into the liquid state and melted at $21^{\circ} \mathrm{C}$

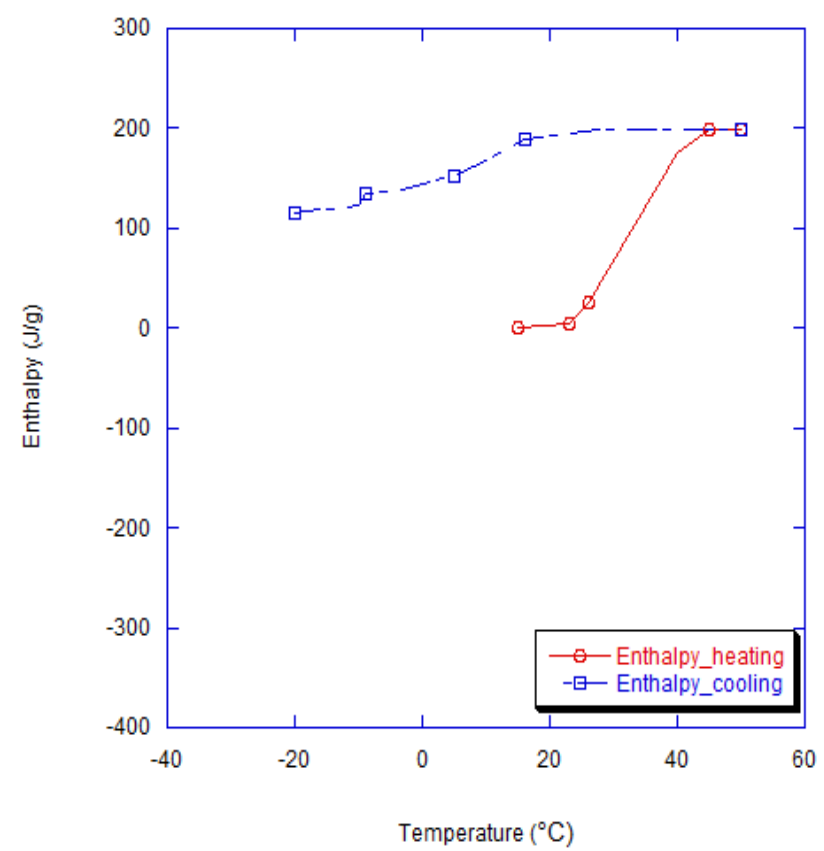

Figure 3.41: Enthalpy curve of the PCM made into the liquid state and melted at $23^{\circ} \mathrm{C}$ 


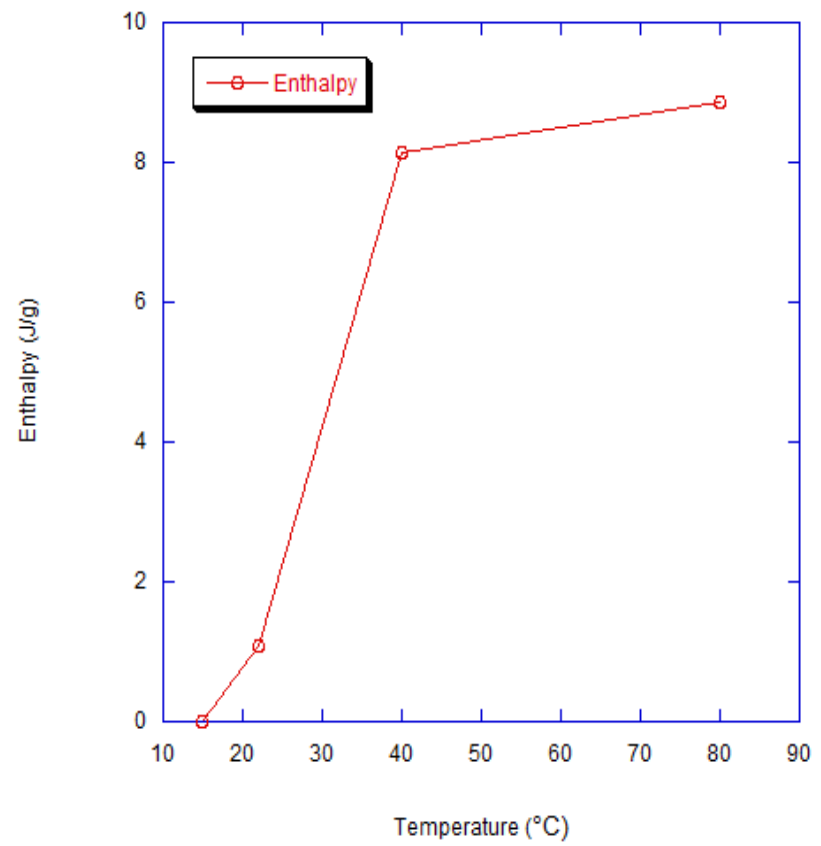

Figure 3.42: Enthalpy curve of the PCM melted at $21^{\circ} \mathrm{C}$

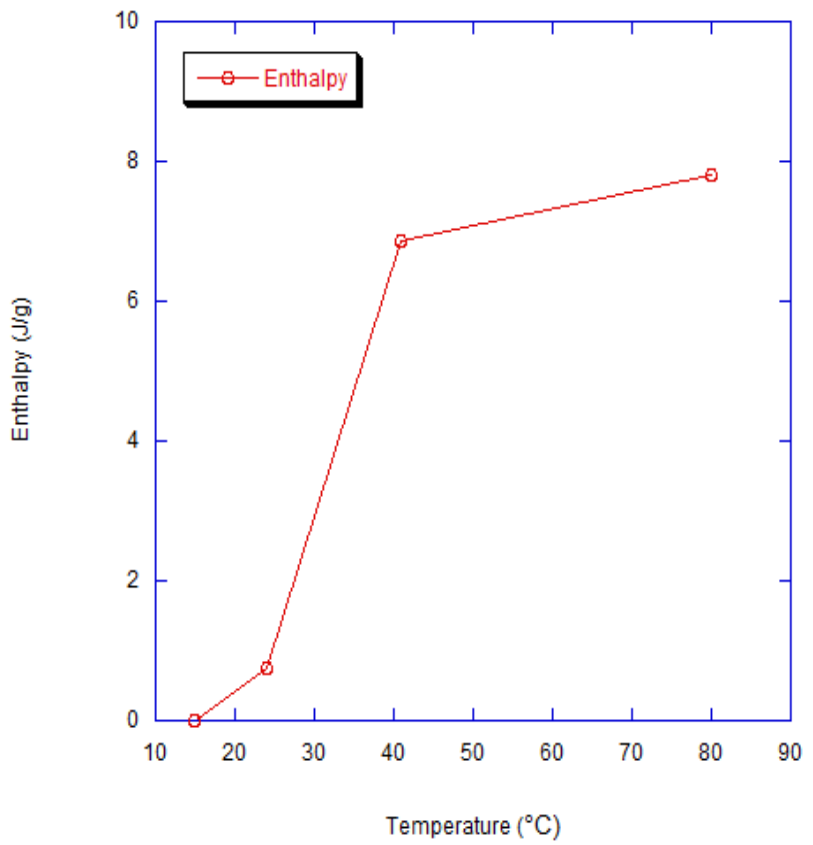

Figure 3.43: Enthalpy curve of the PCM melted at $23^{\circ} \mathrm{C}$ 


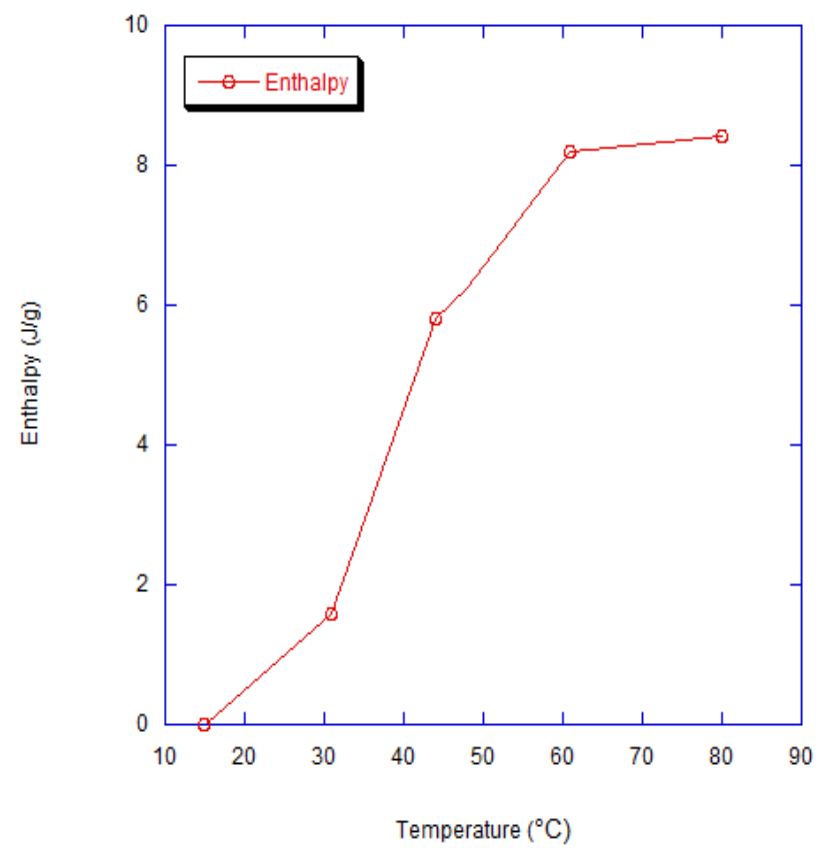

Figure 3.44: Enthalpy curve of the PCM melted at $26^{\circ} \mathrm{C}$

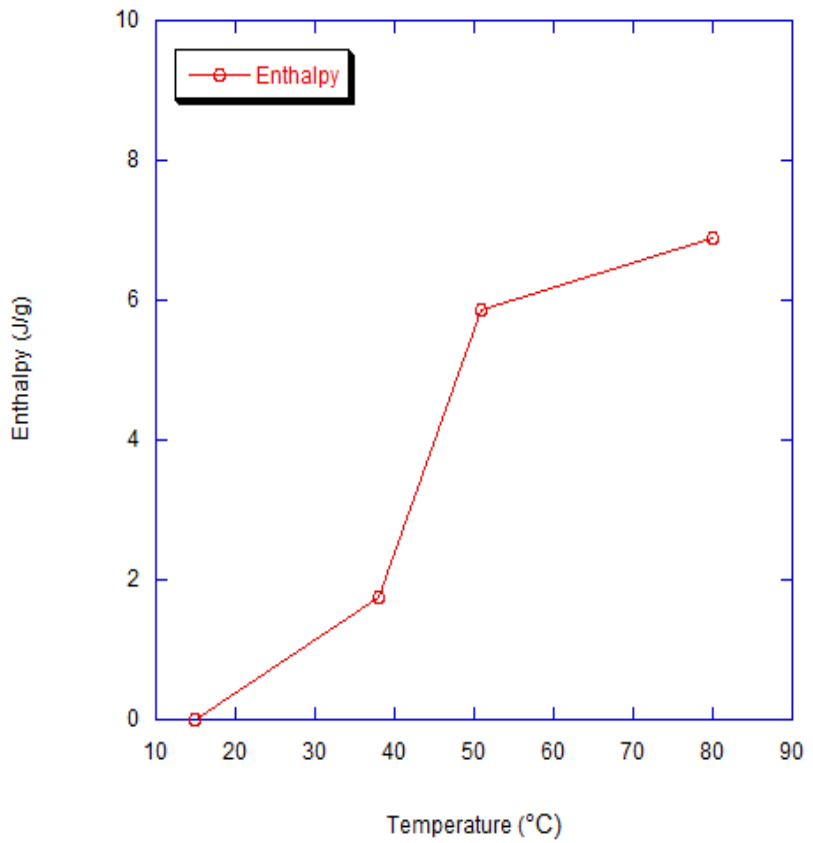

Figure 3.45: Enthalpy curve of the PCM melted at $30^{\circ} \mathrm{C}$ 


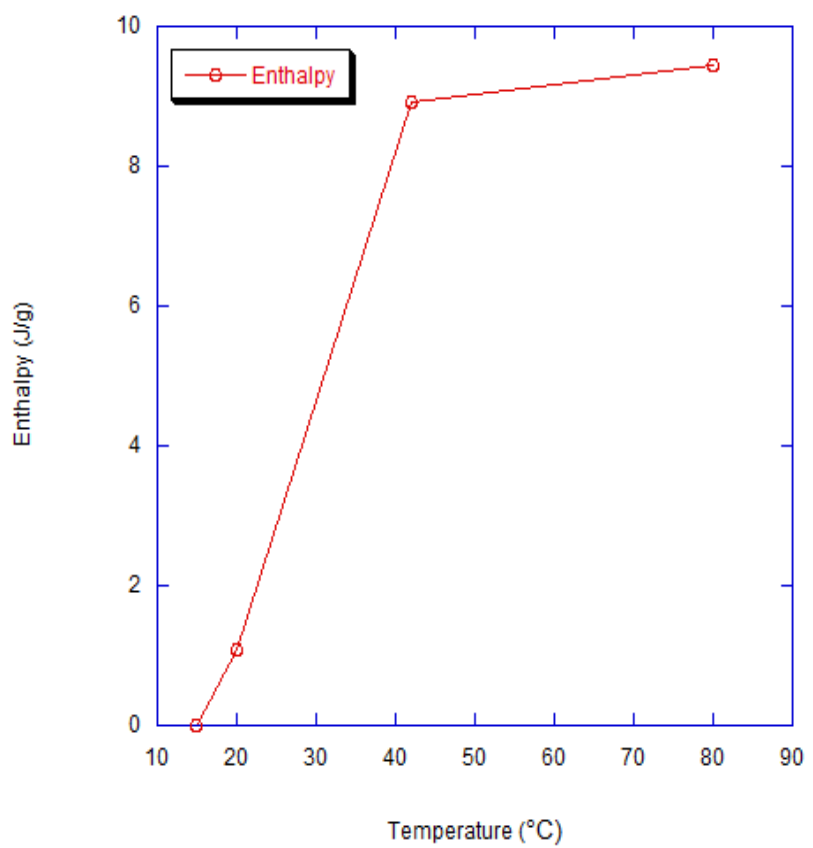

Figure 3.46: Enthalpy curve of the PCM made into the liquid state and melted at $21^{\circ} \mathrm{C}$

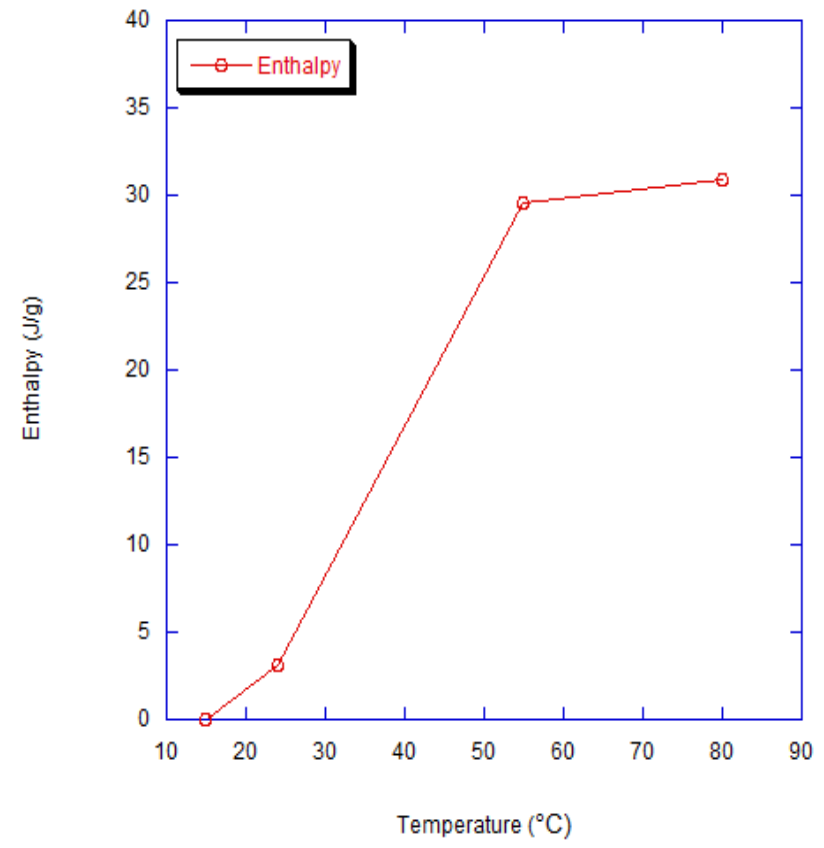

Figure 3.47: Enthalpy curve of the PCM made into the liquid state and melted at $23^{\circ} \mathrm{C}$ 


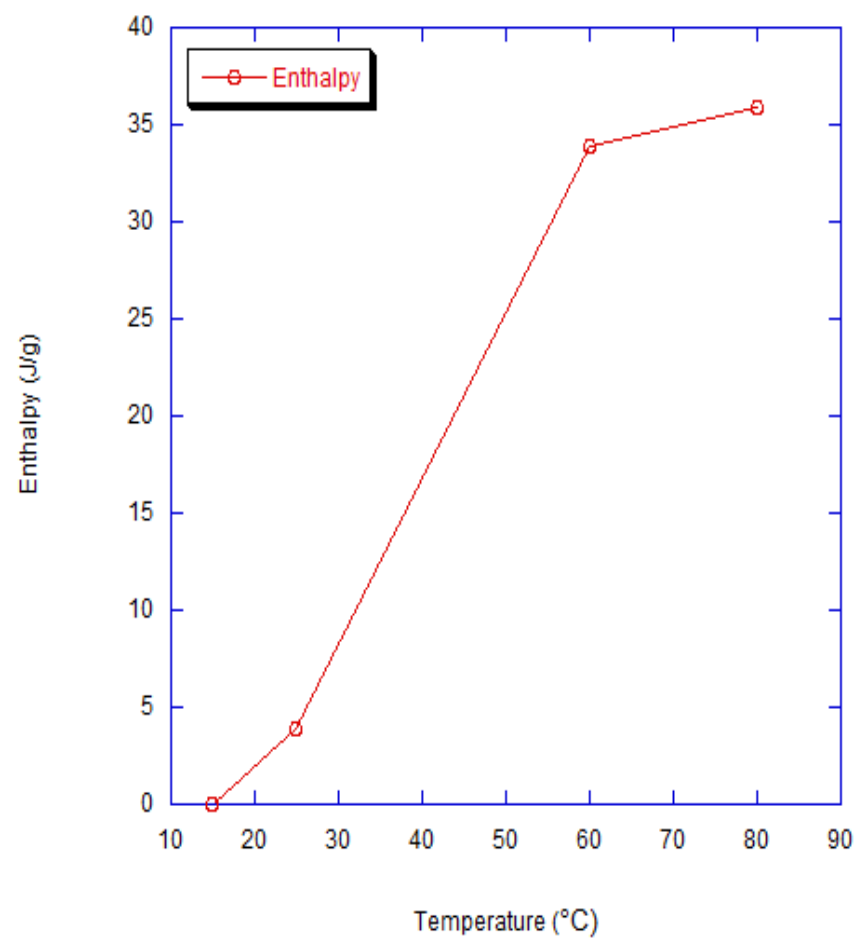

Figure 3.48: Enthalpy curve of the PCM in the liquid state at room temperature

of the PCM $(\Delta H)$ is not attributed to a single temperature, but the enthalpy of the PCM is attributed to the melting temperature range (Günther et al. [2009]).

As shown in Figures 3.36 to 3.48, the energy is increased during the phase change. This phenomenon is speculated that the energy is applied to loosen or break apart the molecular or atomic bond structures of the PCMs by the latent heat. This means energy is not rarely used to increase the temperature, but most of the energy is being absorbed into the molecular or atomic bond structures of the PCMs (Warzoha et al. $[2015])$.

The sensible heats in the solid state and the liquid state indicate their specific 
heat capacities when the temperature is increased. Also, when a PCM is reached in the fully liquid state, the PCM can have a maximum storage capacity. Thus, the total stored energy for a TES system with the PCM is given by, (Pielichowska and Pielichowski [2014]; Tao et al. [2015])

$$
Q=m \int_{T_{i}}^{T_{m}} C_{p, \text { solid }} d T+m \Delta h+m \int_{T_{m}}^{T_{f}} C_{p, l i q u i d} d T
$$

Where the first term and last term are the sensible heat of the solid phase and the liquid phase, and the second term is the latent heat during the phase transition. $m$ is a mass of the $\mathrm{PCM}, T_{i}$ is the initial temperature, $T_{m}$ is the melting temperature, $T_{f}$ is the finish temperature, and $\Delta h$ is the enthalpy (the latent heat of fusion).

As shown in Figures 3.36 to 3.48, the total stored energy for a TES system depends on not only the latent heat during the phase change, but also the sensible heat contribution in the total stored energy. This is the reason why as the temperature range is wide, the contribution of sensible heat is more important since the temperature range is affected by the sensible heat calculation, and the sensible heat depends on the specific heat capacity of the solid region or the liquid region.

PCMs have the total stored energy for a TES system from the melting progress or the solidification progress. In the case of the total stored energy from the melting progress, Figures 3.36 to 3.41 show that the six kinds of PCMs have the total stored energy for TES systems between $192 \mathrm{~J} / \mathrm{g}$ to $224 \mathrm{~J} / \mathrm{g}$ for a temperature range of ap- 
proximately $\pm 20^{\circ} \mathrm{C}$ around the peak temperature (the melting temperature). Figures 3.42 to 3.46 show that the five kinds of the PCMs have the total stored energy for the TES systems between $7 \mathrm{~J} / \mathrm{g}$ to $9 \mathrm{~J} / \mathrm{g}$ for a temperature range from $15^{\circ} \mathrm{C}$ to $80^{\circ} \mathrm{C}$. Figures 3.47 and 3.48 indicate that the PCMs in the liquid state have the total stored energy between $31 \mathrm{~J} / \mathrm{g}$ to $36 \mathrm{~J} / \mathrm{g}$ for a temperature range of approximately $33^{\circ} \mathrm{C}$ around the peak temperature (the melting temperature).

As shown in Figures 3.36 to 3.41, in terms of the total stored energy from the solidification progress, the PCM samples have the total stored energy of $288.36 \mathrm{~J} / \mathrm{g}$, $531.9 \mathrm{~J} / \mathrm{g}, 437.82 \mathrm{~J} / \mathrm{g}, 401.27 \mathrm{~J} / \mathrm{g}, 149.61 \mathrm{~J} / \mathrm{g}$, and $131.07 \mathrm{~J} / \mathrm{g}$ for a temperature range from $50^{\circ} \mathrm{C}$ to $-20^{\circ} \mathrm{C}$, respectively. As shown in Figures 3.36 to 3.39, the high sensible heats such as the specific heat capacities of the PCMs in the solid state and the liquid state occur in the exothermic reaction. The sensible heat stores or releases energy over a range of temperature without phase transition but depends on the heat flow of the PCM. In order to determine the specific heat capacity, the heat flow of the PCM should be considered to calculate the specific heat capacity using equation 2.46 or equation 2.47 or equation 2.48 .

In this study, the sharp heat flow peak happens at a narrow temperature range. Because the PCMs release much more energy than they absorb, the high sensible heats in the exothermic reaction are recorded. Therefore, in this study, much more energy is calculated than the actual energy released. This is the reason why supercooling happens during the solidification, so this result of PCMs releasing much more energy 
is not exactly correct.

A total amount of stored energy such as the amount of the enthalpy under phase transition relies on the latent heat because the latent heat has a high store density at a constant temperature. The sensible heat is considered as well in the total stored energy because the sensible heat happens over the melting or freezing temperature range. 


\subsubsection{Specific Heat Capacity}

The specific heat capacity is an important factor in understanding and evaluating a thermal energy storage (TES) system during sensible heating periods (before and after phase change) (Warzoha et al. [2015]).

The specific heat capacities of the PCMs in the solid state or the liquid state can be decided from results of the enthalpy as a function of temperature curves, such as the sensible heat slopes for the solid phase regions or the liquid regions. Tables 3.3 to 3.5 summarize the specific heat capacities, the enthalpies, and the total energy storage (TES) capacities of the PCMs for the endothermic reaction and the exothermic reaction. Specimens 1 to 4 indicate the original PCMs melted at $21^{\circ} \mathrm{C}$, $23^{\circ} \mathrm{C}, 26^{\circ} \mathrm{C}$, and $30^{\circ} \mathrm{C}$, respectively. Specimens 5 and 6 are PCMs made into the liquid state at above room temperature, and these two samples are melted at $21^{\circ} \mathrm{C}$ and $23^{\circ} \mathrm{C}$, respectively. Specimen 7 is the $\mathrm{PCM}$ in the liquid state at room temperature and melted at $23^{\circ} \mathrm{C}$.

The results for the specific heat capacities of the PCMs measured using DSC Q 200 equipment under the endothermic reaction through a temperature range of about $15^{\circ} \mathrm{C}$ are shown in Table 3.3. Also, under the exothermic reaction, the results of PCMs measured using DSC Q 200 equipment through temperature ranges of about $30^{\circ} \mathrm{C}$ in the liquid region and of about $10^{\circ} \mathrm{C}$ in the solid region are indicated in Table 3.4. In Table 3.5, there are the results for the specific heat capacities of the PCMs 
measured using DSC STA 8000 equipment under the endothermic reaction through temperature ranges of about $17^{\circ} \mathrm{C}$. 
Table 3.3: The specific heat capacities, enthalpies, and total energy storage of PCMs for endothermic reaction

\begin{tabular}{|c|c|c|c|c|}
\hline PCM & $\mathrm{C}_{p, \text { solid }}\left(\mathrm{J} / \mathrm{g}{ }^{\circ} \mathrm{C}\right)$ & $\mathrm{C}_{p, \text { liquid }}\left(\mathrm{J} / \mathrm{g}{ }^{\circ} \mathrm{C}\right)$ & Enthalpy $(\mathrm{J} / \mathrm{g})$ & $\mathrm{TES}(\mathrm{J} / \mathrm{g})$ \\
\hline Specimen 1 & 18.3 & 17.67 & 145.8 & 191.97 \\
\hline Specimen 2 & 24.25 & 23.65 & 142.6 & 223.90 \\
\hline Specimen 3 & 29.04 & 28.44 & 143.4 & 200 \\
\hline Specimen 4 & 28.85 & 28.25 & 144.2 & 201.24 \\
\hline Specimen 5 & 29.31 & 27.20 & 162.0 & 218.81 \\
\hline Specimen 6 & 26.01 & 23.41 & 149.8 & 199.82 \\
\hline
\end{tabular}

Table 3.4: The specific heat capacities, enthalpies, and total energy storage of PCMs for exothermic reaction

\begin{tabular}{|c|c|c|c|c|}
\hline PCM & $\mathrm{C}_{p, \text { solid }}\left(\mathrm{J} / \mathrm{g}^{\circ} \mathrm{C}\right)$ & $\mathrm{C}_{p, \text { liquid }}\left(\mathrm{J} / \mathrm{g}{ }^{\circ} \mathrm{C}\right)$ & Enthalpy $(\mathrm{J} / \mathrm{g})$ & $\mathrm{TES}(\mathrm{J} / \mathrm{g})$ \\
\hline Specimen 1 & 79.67 & 75.13 & 131.8 & 288.36 \\
\hline Specimen 2 & 190.08 & 189.48 & 149.4 & 531.9 \\
\hline Specimen 3 & 154.44 & 153.12 & 126.7 & 437.82 \\
\hline \multirow{2}{*}{ Specimen 4 } & - & 6.72 & 32.58 & 60.81 \\
\cline { 2 - 5 } & 117.96 & 116.04 & 105.9 & 401.27 \\
\hline Specimen 5 & 30.86 & 30.72 & 88.0 & 149.61 \\
\hline \multirow{2}{*}{ Specimen 6 } & - & 10.88 & 36.67 & 47.71 \\
\cline { 2 - 5 } & 6.32 & 6.22 & 12.67 & 83.86 \\
\hline
\end{tabular}

Table 3.5: The specific heat capacities, enthalpies, and total energy storage of PCMs for endothermic reaction

\begin{tabular}{|c|c|c|c|c|}
\hline PCM & $\mathrm{C}_{p, \text { solid }}\left(\mathrm{J} / \mathrm{g}^{\circ} \mathrm{C}\right)$ & $\mathrm{C}_{p, \text { liquid }}\left(\mathrm{J} / \mathrm{g}{ }^{\circ} \mathrm{C}\right)$ & Enthalpy $(\mathrm{J} / \mathrm{g})$ & $\mathrm{TES}(\mathrm{J} / \mathrm{g})$ \\
\hline Specimen 1 & 1.0909 & 0.7091 & 7.05 & 8.85 \\
\hline Specimen 2 & 0.7636 & 0.9273 & 6.11 & 7.80 \\
\hline \multirow{2}{*}{ Specimen 3 } & 1.5818 & 0.2182 & 4.23 & 8.42 \\
\cline { 2 - 5 } & - & - & 1.96 & - \\
\hline Specimen 4 & 1.7455 & 1.0364 & 4.11 & 6.89 \\
\hline Specimen 5 & 1.0909 & 0.5455 & 7.84 & 9.45 \\
\hline Specimen 6 & 3.1636 & 1.4182 & 26.36 & 30.94 \\
\hline Specimen 7 & 3.8727 & 1.9636 & 30.10 & 35.90 \\
\hline
\end{tabular}




\subsection{Heat Flow Meter Analysis}

\subsubsection{Thermal Conductivity}

The thermal conductivity of a PCM is an important factor in assessing the thermal performance of PCMs in the solid state or in the liquid state (Mehrali et al. [2013]). In this study, the thermal conductivity was measured by heat flow meter equipment (FOX 314 from TA Instruments). Forms of PCM samples were macro-encapsulated PCMs covered in multilayer polyfilm. The thermal conductivities of the PCMs were evaluated under fully frozen samples (in the solid state before the onset temperature) and fully melted samples (in the liquid state after the melting temperature) in the thermal equilibrium condition, which was already measured using the isothermal DSC mode. The thermal conductivities of five samples were measured at two times per each specimen.

Figure 3.49 shows the thermal conductivities of the PCMs, and specimens 1 to 4 indicate the $\mathrm{PCM}$ melted at $21^{\circ} \mathrm{C}, 23^{\circ} \mathrm{C}, 26^{\circ} \mathrm{C}$, and $30^{\circ} \mathrm{C}$, respectively. Specimens 1 and 2 have the thermal conductivities between 70 to $90 \mathrm{~mW} / \mathrm{mK}$, and specimens 3 and 4 have the thermal conductivities between 100 to $120 \mathrm{~mW} / \mathrm{mK}$. The thermal conductivities of the PCMs in the solid state are higher than those of the PCMs in the liquid state. This phenomenon happens because of the effect of the microstructure changing from the orderly solid structure in the solid state to the disorderly liquid structure in the liquid state (Wang et al. [2010b]. Also, because the distances between 


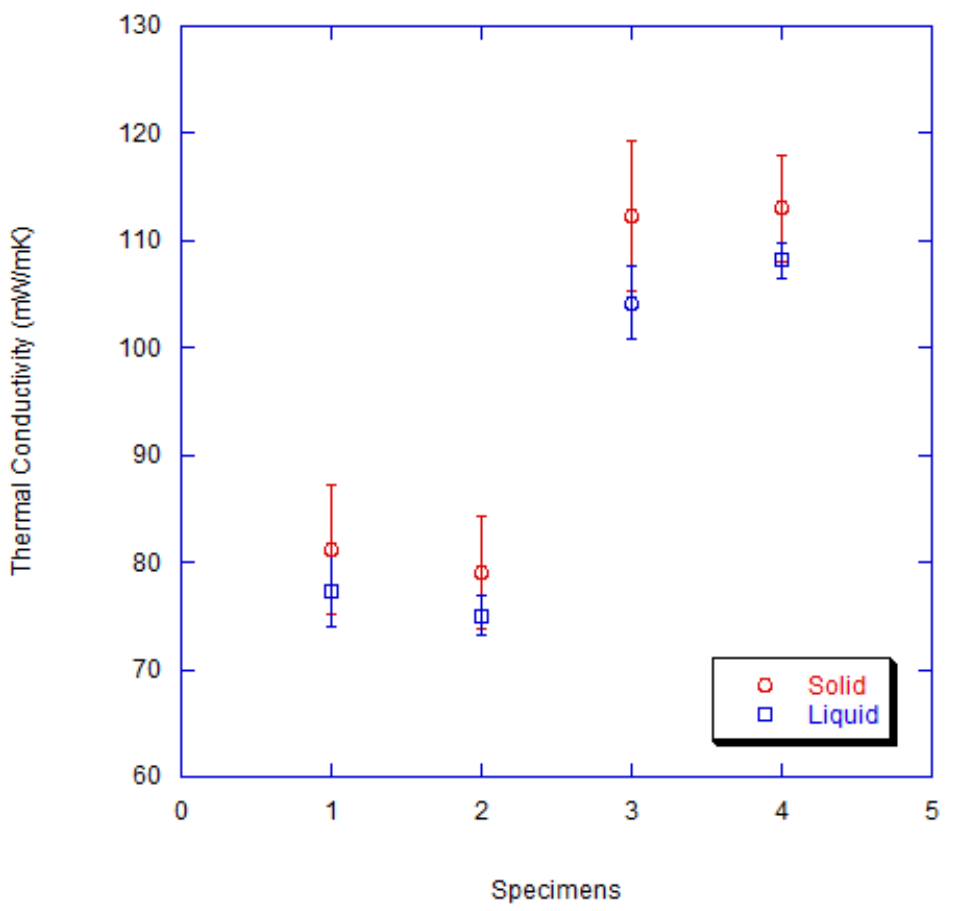

Figure 3.49: The thermal conductivities of the PCMs

molecules in the solid structure are short, the PCMs in the solid state show higher thermal conductivities than those of the PCMs in the liquid state. 


\subsubsection{Volumetric Heat Capacity}

The volumetric heat capacity at a constant pressure is a crucial value, which is evaluated by heat flow meter equipment (FOX 314 heat flow equipment from TA Instruments). In addition, the volumetric heat capacity obtained from using the heat flow meter equipment can be also worked as a result of a Differential Scanning Calorimeter (DSC). In this study, the specific mode in heat flow meter FOX 314 equipment from TA Instruments was conducted to analyze the volumetric heat capacities for all samples under same temperature conditions.

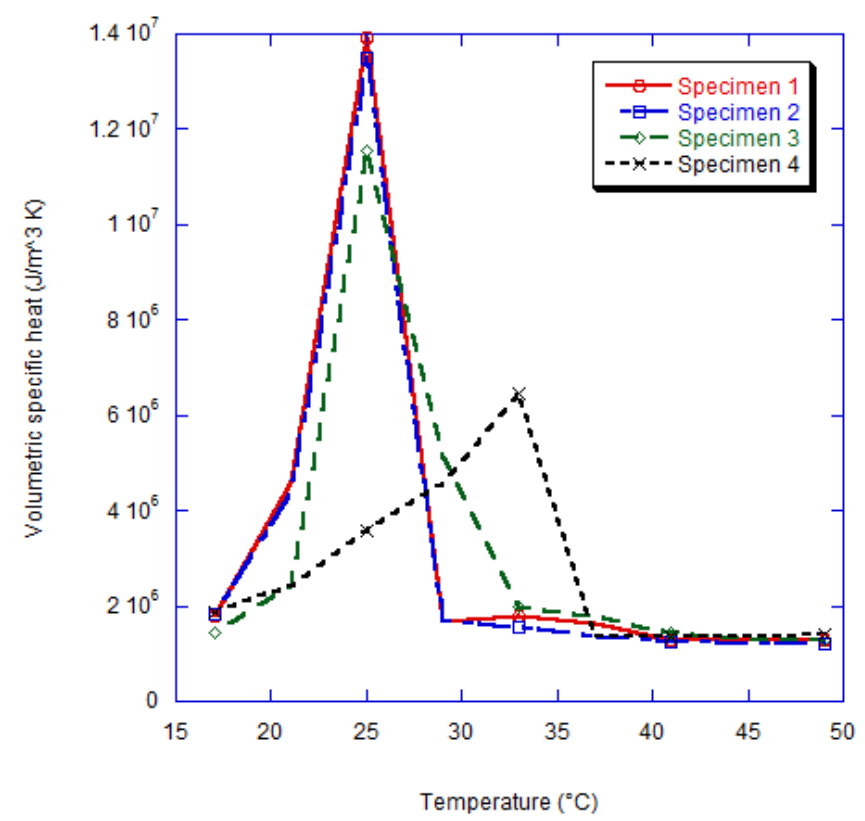

Figure 3.50: Volumetric heat capacities of PCMs measured using heat flow meter FOX 314 equipment 
In Figure 3.50, specimens 1 to 4 indicate the original $\mathrm{PCMs}$ melted at $21^{\circ} \mathrm{C}, 23^{\circ} \mathrm{C}$, $26^{\circ} \mathrm{C}$, and $30^{\circ} \mathrm{C}$, respectively. In Figure 3.50, specimens 1 and 2 show very similar curve shapes. As shown in Figures 3.1 to 3.2 and Figures 3.5 to 3.6, the DSC curves of the PCMs, which melt at $21^{\circ} \mathrm{C}$ and $23^{\circ} \mathrm{C}$, also indicate similar curve shapes and temperatures, such as the onset temperature and the peak temperature.

In the case of specimens 3 and 4 , these results show to be shifted toward high temperatures and to be broaden curves. This is the reason why the thermal gradient is increased within the sample. This characteristic occurs strongly for the PCMs (Günther et al. [2009]; Drissi et al. [2015]). 


\subsubsection{Enthalpy Curves}

A Phase Change Material (PCM) can store and release energy, and it can work as a thermal energy storage material. The precise ability of a thermal energy storage for a PCM can be indicated through the enthalpy curve as a function of temperature. In this study, the enthalpy curves as a function of temperature were measured to analyze the thermal energy storage systems using heat flow meter equipment, FOX 314 equipment from TA Instruments.

Figure 3.51 shows the enthalpy-temperature curves of four kinds of the original

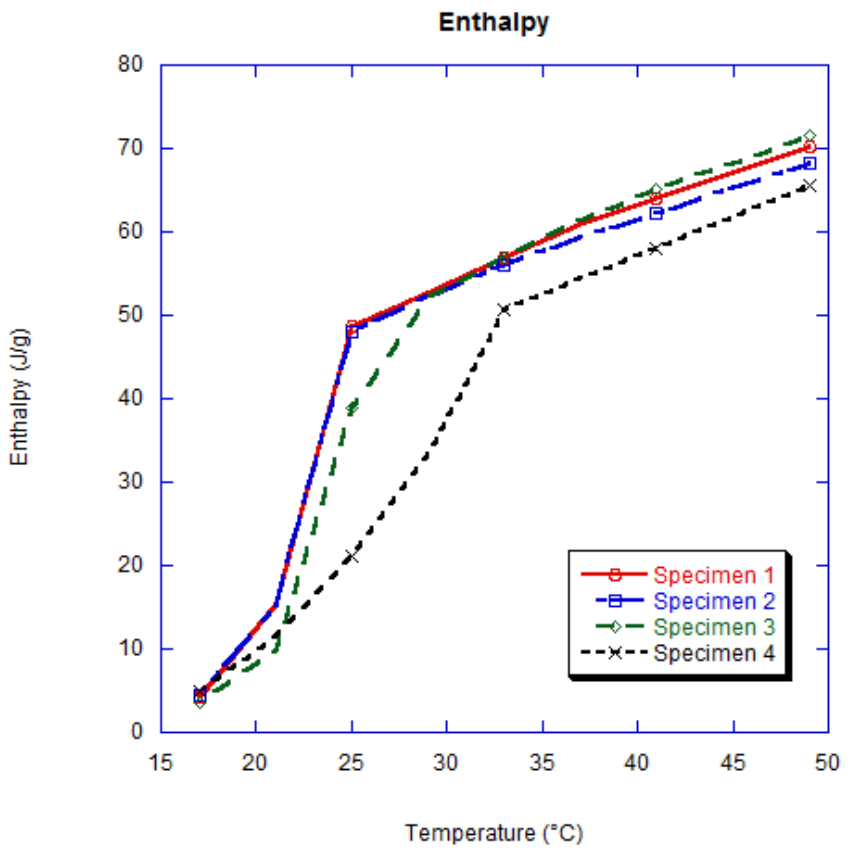

Figure 3.51: Enthalpy curves of PCMs measured using heat flow meter FOX 314 equipment 
PCMs, and specimens 1 to 4 are the kinds of PCMs, which melt at $21^{\circ} \mathrm{C}, 23^{\circ} \mathrm{C}$, $26^{\circ} \mathrm{C}$, and $30^{\circ} \mathrm{C}$, respectively. Measurements of these samples are started under fully freezing conditions.

Basically, the enthalpy curve as a function of temperature (the stored heat curve as a function of temperature) for a PCM has three parts, such as the sensible heat parts of the solid phase region and the liquid phase region and the melting latent heat in the curve. Sensible heat storages store thermal energy by raising the temperature with changing heat capacities when PCMs are in the solid state or the liquid state.

In this study, the enthalpy-temperatures curves, such as the total stored energy curves of the four kinds of PCMs, are meausred during the melting process. Figure 3.58 shows the total stored energy for the Thermal Energy Storage (TES) system between $65.5 \mathrm{~J} / \mathrm{g}$ to $71.5 \mathrm{~J} / \mathrm{g}$ for the temperature range from $17^{\circ} \mathrm{C}$ to $50^{\circ} \mathrm{C}$.

As shown in Figure 3.51, enthalpy curves for all PCMs have three parts, such as the sensible parts and the latent part. Specimens 3 and 4 show that the enthalpytemperature curves are shifted toward high temperatures. A broadened temperature range is a very important part due to the relation to the sensible heat, which is reliant on the heat capacity of the solid region or the liquid region. Therefore, because a broadened temperature range is used to calculate the heat capacity, the more the temperature range broadens, the more the sensible heat part is increased, and the more the enthalpy curve is also shifted toward high temperatures.

The total stored energy values for TES systems measured from heat flow meter 
FOX 314 equipment are presented about 2.5 times smaller than those values measured by DSC Q 200 equipment with the dynamic measurement method as shown in Figures 3.36 to 3.39 or Table 3.3. However, sometimes the results from the DSC method are uncertain regarding the enthalpy-temperature relationships of PCMs. The enthalpy curves measured using the DSC method can be shifted to higher/lower temperatures. Shifting the temperature depends on the heat capacity, the thermal conductivity, the sample size, and the heating/cooling rates. These four factors lead to a temperature gradient in the PCM and the heat flux signal shifting toward a higher temperature (Castellǿn et al. [2008]). Therefore, due to these heat transfer limitations, the enthalpy curve as a function of temperature measured by DSC equipment is not consistent and indicates uncertain result, so the enthalpy-temperature curves measured by heat flow meter equipment show more accurate results than those from the DSC method. 


\subsection{Thermal Diffusivity}

The thermal diffusivities of the PCMs in the solid state and the liquid state can be calculated by the thermal conductivities, the densities, and the specific heat capacities of the PCMs in the solid state and the liquid state. In this study, the thermal diffusivity of a PCM is evaluated by using equation 2.55. In order to calculate the thermal diffusivities, the results of Tables 3.3 to 3.5 were used. The results of Tables 3.3 and 3.4 were calculated using DSC Q 200 equipment (TA Instruments), and the results of Table 3.5 were calculated using DSC STA 8000 equipment (Perkin Elmer Company). In this study, the thermal diffusivities of the PCMs in the solid state and the liquid state were directly measured because the thermal conductivities and the specific heat capacities of the PCMs were already measured experimentally by heat flow equipment and DSC equipment, respectively.

As shown in all three Tables, specimens 1 to 4 indicate the PCMs melted at $21^{\circ} \mathrm{C}$, $23^{\circ} \mathrm{C}, 26^{\circ} \mathrm{C}$, and $30^{\circ} \mathrm{C}$, respectively. Tables 3.6 and 3.7 are the thermal diffusivities of the PCMs under the endothermic reaction and the exothermic reaction using DSC Q 200 equipment, and Table 3.8 is the thermal diffusivities of the PCMs under the endothermic reaction using DSC STA 8000 equipment.

The thermal diffusivity is defined by the speed of heat conduction while the temperature of a PCM is changed. Therefore, the higher the value of the thermal diffusivity, the faster the speed of the heat. 
Table 3.6: Thermal diffusivity of PCMs under endothermic reaction

\begin{tabular}{|c|c|c|}
\hline PCM & $\alpha_{\text {solid }}\left(\mathrm{mm}^{2} / \mathrm{s}\right)$ & $\alpha_{\text {liquid }}\left(\mathrm{mm}^{2} / \mathrm{s}\right)$ \\
\hline Specimen 1 & 0.00297 & 0.00292 \\
\hline Specimen 2 & 0.00219 & 0.00213 \\
\hline Specimen 3 & 0.00256 & 0.00243 \\
\hline Specimen 4 & 0.00262 & 0.00255 \\
\hline
\end{tabular}

Table 3.7: Thermal diffusivity of PCMs under exothermic reaction

\begin{tabular}{|c|c|c|}
\hline PCM & $\alpha_{\text {solid }}\left(\mathrm{mm}^{2} / \mathrm{s}\right)$ & $\alpha_{\text {liquid }}\left(\mathrm{mm}^{2} / \mathrm{s}\right)$ \\
\hline Specimen 1 & 0.000682 & 0.000687 \\
\hline Specimen 2 & 0.000280 & 0.000266 \\
\hline Specimen 3 & 0.000481 & 0.000452 \\
\hline Specimen 4 & 0.000640 & 0.000595 \\
\hline
\end{tabular}

Table 3.8: Thermal diffusivity of PCMs under endothermic reaction

\begin{tabular}{|c|c|c|}
\hline PCM & $\alpha_{\text {solid }}\left(\mathrm{mm}^{2} / \mathrm{s}\right)$ & $\alpha_{\text {liquid }}\left(\mathrm{mm}^{2} / \mathrm{s}\right)$ \\
\hline Specimen 1 & 0.0498 & 0.0728 \\
\hline Specimen 2 & 0.0697 & 0.0543 \\
\hline Specimen 3 & 0.0470 & 0.211 \\
\hline Specimen 4 & 0.0432 & 0.0694 \\
\hline
\end{tabular}

Tables 3.6 to 3.8 indicate the speed of the thermal diffusivities of the PCMs in the solid phase and the liquid phase are almost similar. 


\subsection{Numerical Simulation}

\subsubsection{Verification Study}

In this study, verification studies were designed and conducted to check the accuracy of the result obtained by using ABAQUS.

Figures 3.52, 3.54, and 3.56 show the temperature change in an Al structure with the temperature initial condition and the boundary conditions, such as the temperature boundary conditions and the convection boundary condition. All results are tabulated in Table 3.9. In verification studies, the analytic results and the numerical Finite Element Analysis (FEA) results are compared with the various initial and boundary conditions in the $\mathrm{Al}$ model. Figures 3.52 and 3.53 are the results from the first verification study, Figures 3.54 and 3.55 are the results from the second verification, and Figures 3.56 and 3.56 are the results from the third verification study.

Figure 3.53 shows the temperature curve as a fucntion of time as $\mathrm{x}$ is $0.025 \mathrm{~m}$ and $0.2 \mathrm{~m}$, respectively. As shown in Figure 3.53 , when $\mathrm{x}$ is $0.025 \mathrm{~m}$ or $0.2 \mathrm{~m}$, the temperature of each node achieves a steady-state condition. When $\mathrm{x}$ is $0.025 \mathrm{~m}$, the steady-state condition is achieved at $24.2^{\circ} \mathrm{C}$ after $872 \mathrm{~s}$ from the FEA result, and the steady-state condition is achieved after 234 s from the analytic result.

To compare the analytic and FEA results with their respective times and temperatures, when the equilibrium time in the analytic result is $234 \mathrm{~s}$, the temperature is $23.1^{\circ} \mathrm{C}$ in the ABAQUS result, and the temperature difference is $\pm 1.1^{\circ} \mathrm{C}$ for the 
equilibrium between the analytic and FEA results. When $\mathrm{x}$ is $0.2 \mathrm{~m}$, the existence of the equilibrium indicates after 268s from the analytic result, and in the ABAQUS result the steady-state conditions is achieved at $33.1^{\circ} \mathrm{C}$ after $880 \mathrm{~s}$. When the time, the equilibrium time in the analytic result, is $268 \mathrm{~s}$, the temperature from the ABAQUS result is $31.7^{\circ} \mathrm{C}$. The temperature difference is $\pm 1.4^{\circ} \mathrm{C}$ for the equilibrium between the analytic and FEA results.

As shown in Figure 3.55, the temperature curves as a function of time show as $\mathrm{x}$ is $0.025 \mathrm{~m}$ and $0.2 \mathrm{~m}$, respectively. The results of the second verification study are also reached in the steady-state conditions. When $\mathrm{x}$ is $0.025 \mathrm{~m}$, the analytic result shows to achieve in the steady-state condition after $856 \mathrm{~s}$. When the time, the equilibrium time in the analytic result, is $856 \mathrm{~s}$, the temperature in the FEA result is $30^{\circ} \mathrm{C}$. In terms of the FEA result, the steady-state is achieved at $34.8^{\circ} \mathrm{C}$ after $38 \mathrm{~min}(2280 \mathrm{~s})$. When $\mathrm{x}$ is $0.2 \mathrm{~m}$, the equilibrium time from the analytic result is $420 \mathrm{~s}$. Also, as the quillibrium time from the analytical result is 420 s, the temperature from the FEA result is $30^{\circ} \mathrm{C}$. The temperature difference between the results of analytic and FEA is $\pm 2.4^{\circ} \mathrm{C}$.

Figure 3.57 also shows the temperature curve as a function of time but the results of the third verification study do not show an achieved the steady-state conditions. Not only the analytic result but also the FEA result do not achieve the steady-state conditions. 
Table 3.9: Test conditions and results for verification studies

\begin{tabular}{|c|c|c|c|c|c|}
\hline \multirow{2}{*}{ Materials } & \multirow{2}{*}{ Conditions } & \multicolumn{2}{|c|}{ Boundary Conditions } & \multicolumn{2}{|c|}{ Results } \\
\hline & & Temp. & Convection & Analytic & ABAQUS \\
\hline \multirow[t]{2}{*}{$\mathrm{Al}$} & \multirow{2}{*}{$\begin{array}{c}\text { 1. Initial } \\
\text { Condition } \\
23^{\circ} \mathrm{C} \\
\text { 2. Boundary } \\
\text { Conditions } \\
\text { 3. } \mathrm{L}=0.225 \mathrm{~m} \\
4 . \\
x_{1}=0.025 \mathrm{~m} \\
x_{2}=0.2 \mathrm{~m}\end{array}$} & \multirow[t]{2}{*}{$\begin{array}{c}T_{1}=23 \\
T_{2}=35\end{array}$} & \multirow[t]{2}{*}{$\begin{array}{c}\text { Convection= } \\
-35 \mathrm{~W} / \mathrm{m}^{2}\end{array}$} & $\begin{array}{c}x_{1}=0.025 \mathrm{~m} \\
\mathrm{t}=234.28 \mathrm{~s}=3.9 \\
\min \end{array}$ & $\begin{array}{c}\text { At } \mathrm{t}=234.28 \mathrm{~s}, \\
\mathrm{~T}=23.1^{\circ} \mathrm{C} \\
\text { Stable: } \\
\mathrm{T}=24.2^{\circ} \mathrm{C} \\
\text { after } 872 \mathrm{~s}\end{array}$ \\
\hline & & & & $\begin{array}{c}x_{2}=0.2 m \\
\mathrm{t}=268.5 \mathrm{~s}=4.5 \\
\min \end{array}$ & $\begin{array}{c}\text { At } \mathrm{t}=268.5 \mathrm{~s} \\
\mathrm{~T}=31.7^{\circ} \mathrm{C} \\
\text { Stable: } \\
\mathrm{T}=33.1^{\circ} \mathrm{C} \\
\text { after } 880 \mathrm{~s}\end{array}$ \\
\hline \multirow[t]{2}{*}{$\mathrm{Al}$} & \multirow{2}{*}{$\begin{array}{c}\text { 1. Initial } \\
\text { Condition } \\
23^{\circ} \mathrm{C} \\
\text { 2. Boundary } \\
\text { Conditions } \\
\text { 3. } \mathrm{L}=0.225 \mathrm{~m} \\
4 . \\
x_{1}=0.025 \mathrm{~m} \\
x_{2}=0.2 \mathrm{~m}\end{array}$} & \multirow[t]{2}{*}{$\begin{array}{l}T_{1}=0 \\
T_{2}=35\end{array}$} & \multirow[t]{2}{*}{$\begin{array}{c}\text { Convection= } \\
-35 \mathrm{~W} / \mathrm{m}^{2}\end{array}$} & $\begin{array}{c}x_{1}=0.025 m \\
\mathrm{t}=856 \mathrm{~s}=14 \\
\min \end{array}$ & $\begin{array}{c}\text { At } \mathrm{t}=856 \mathrm{~s} \\
\mathrm{~T}=30^{\circ} \mathrm{C} \\
\text { Stable: } \\
\mathrm{T}=34.8^{\circ} \mathrm{C} \\
\text { after } 38 \mathrm{~min}\end{array}$ \\
\hline & & & & $\begin{array}{c}x_{2}=0.2 \mathrm{~m} \\
\mathrm{t}=420 \mathrm{~s}=7 \mathrm{~min}\end{array}$ & $\begin{array}{c}\text { At } \mathrm{t}=420 \mathrm{~s} \\
\mathrm{~T}=32.4^{\circ} \mathrm{C} \\
\text { Stable: } \\
\mathrm{T}=34.8^{\circ} \mathrm{C} \\
\text { after } 25 \mathrm{~min}\end{array}$ \\
\hline $\mathrm{Al}$ & $\begin{array}{c}\text { 1. Initial } \\
\text { Condition } \\
23^{\circ} \mathrm{C} \\
\text { 2. Boundary } \\
\text { Conditions } \\
\text { 3. } \mathrm{L}=0.225 \mathrm{~m} \\
4 . \\
x_{1}=0.025 \mathrm{~m} \\
x_{2}=0.2 \mathrm{~m}\end{array}$ & $\begin{array}{l}T_{1}=0 \\
T_{2}=0\end{array}$ & $\begin{array}{l}\text { Convection= } \\
-35 \mathrm{~W} / \mathrm{m}^{2}\end{array}$ & $\begin{array}{c}\mathrm{U}(\mathrm{x})=\mathrm{C} 2: \text { No } \\
\text { equilbrium } \\
u(x)= \\
\frac{1}{L} \int f(x) d x\end{array}$ & $\begin{array}{c}x_{1}=0.025 \mathrm{~m}, \\
\text { at } 4000 \mathrm{~s} \\
(66 \mathrm{~min}), \\
\mathrm{T}=0.65^{\circ} \mathrm{C} \\
x_{2}=0.2 \mathrm{~m}, \text { at } \\
4000 \mathrm{~s}(66 \mathrm{~min}), \\
\mathrm{T}=0.72^{\circ} \mathrm{C}\end{array}$ \\
\hline
\end{tabular}




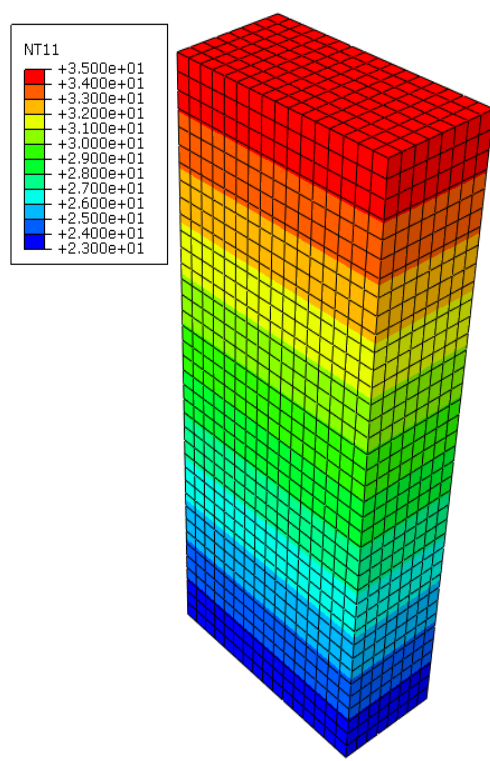

Figure 3.52: FEA result of the first verification

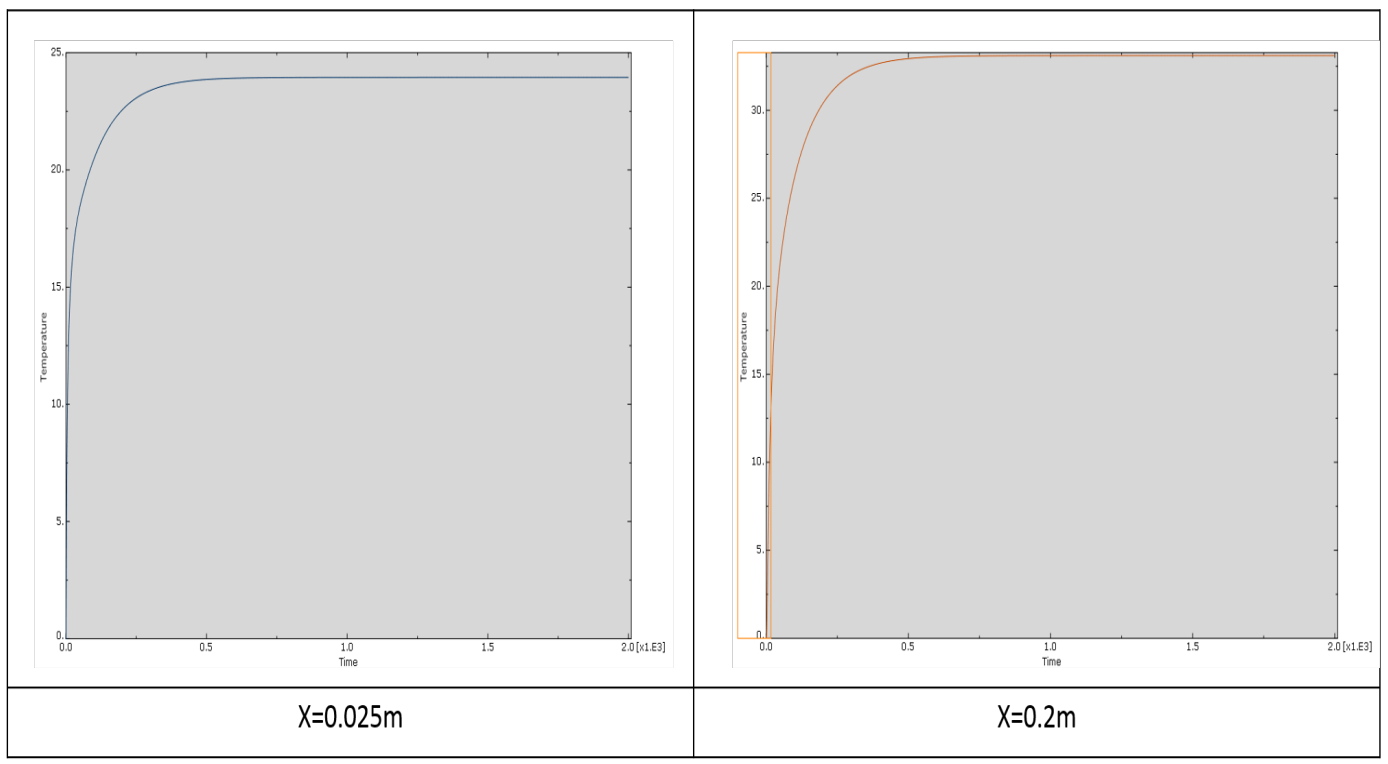

Figure 3.53: Temperature curves as a function of time from FEA results of the first verification study 

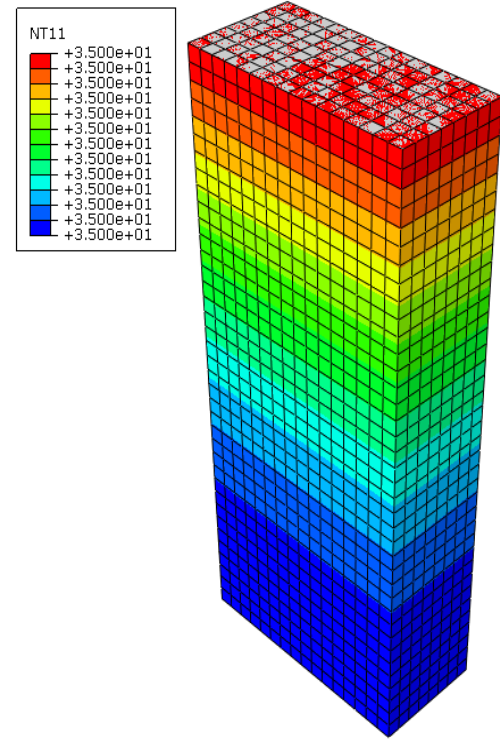

Figure 3.54: FEA result of the second verification

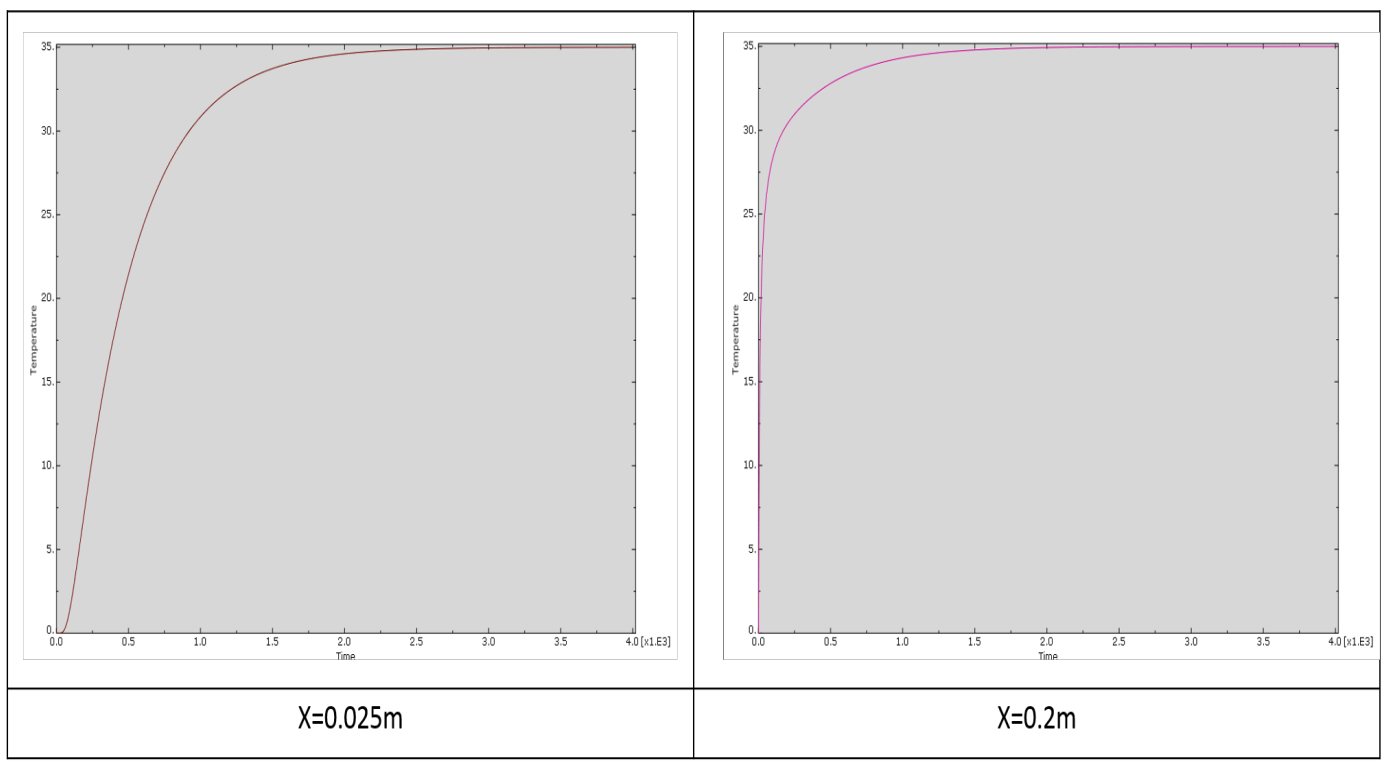

Figure 3.55: Temperature curves as a function of time from FEA results of the second verification study 


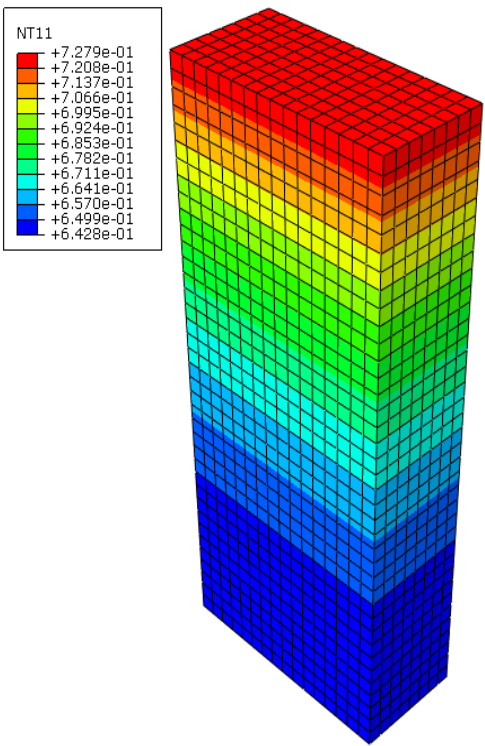

Figure 3.56: FEA result of the third verification

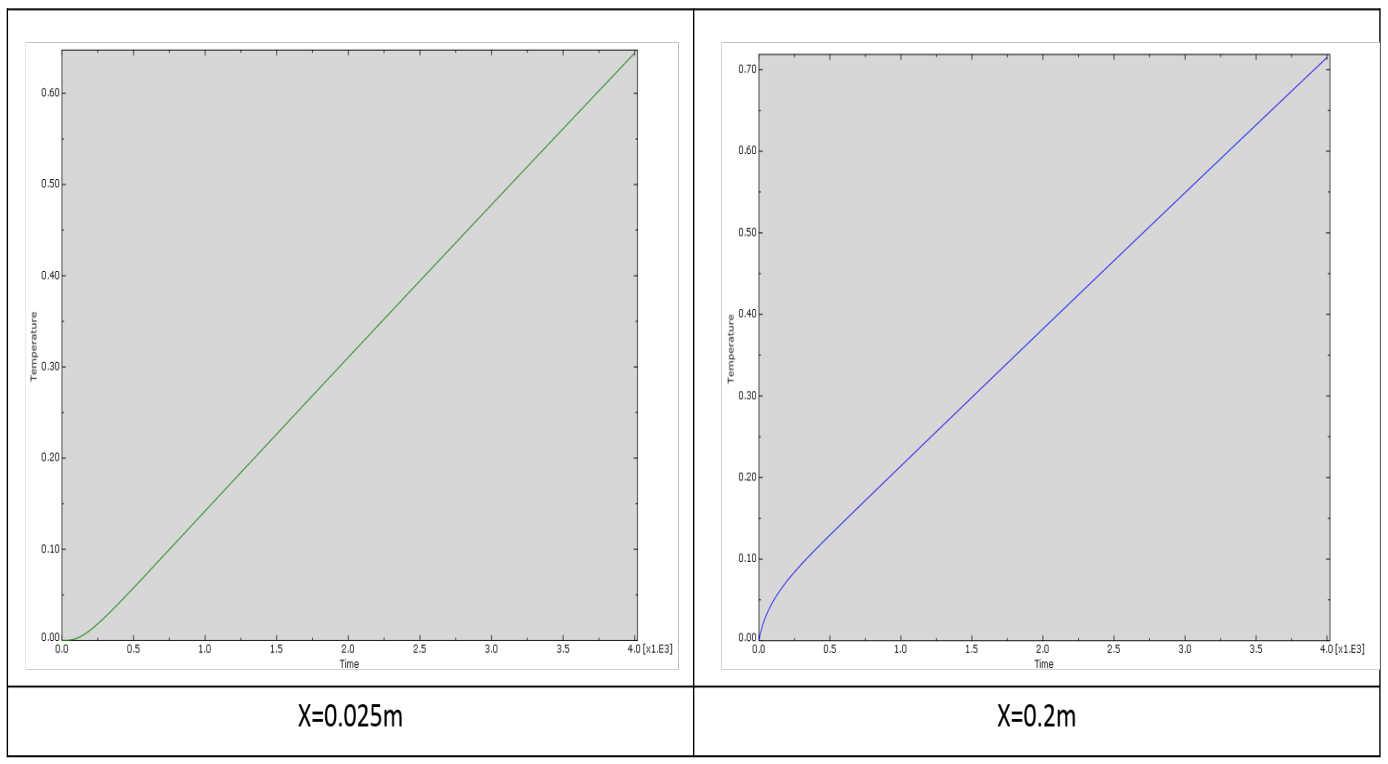

Figure 3.57: Temperature curves as a function of time from FEA results of the third verification study 


\subsubsection{Case Study}

In this study, the thermal performance of a building roof with the PCM plate was simulated to investigate potential for energy savings with the PCMs incorporated in a building. In order to evaluate the thermal performace of a roof with the PCM plate, various factors, such as the specific heat capacity, the heat of fusion, the phase change temperature, and the thermal conductivity of the PCM, were considered in the numerical Finite Element Analysis (FEA). Figures 3.58 to 3.61 reveal the temperature variations as a function of time, and Figure 3.62 shows those graphs for the roof systems with the PCMs. As shown in Figures 3.58 to 3.61, the left figures are measured under step 1, and the right figures are also measured under step 2.

As shown in the left figures measured under step 1 (the daytime) of Figures 3.58 to 3.61 , the temperature variations from the outdoor to the indoor are revealed by thermal radiation and convection. During the daytime, it is observed from the figures that the outdoor temperature is higher than the indoor temperature. This is because of the low thermal conductivity of the PCM in the liquid state. The low thermal conductivity of the PCM reduces the heat transmission to the indoor that in turn increases the outdoor temperature. During the nighttime, the results from the figures reveal the outdoor and the indoor temperatures are almost the same. This is the reason why the heat transmission speed of the PCM in the solid state to the indoor is faster than that of the PCM in the liquid state, because the thermal conductivity 
of the PCM in the solid state is higher than that of the PCM in the liquid state.

Figure 3.62 shows the effects of the PCMs on the temperature distribution when the four types of PCMs are taken into account, and Table 3.10 lists time and temperature until the steady-state conditions are achieved from the FEA results.

As shown in Figure 3.62, it is found that there is no noticeable tendency between the PCMs. The reason is speculated due to the use of the dynamic DSC results, which have margins of error. From the dynamic DSC results, the melting temperatures of the PCMs measured using DSC equipment exceed their own temperature, such as the theoretical melting temperatures. However, as the theoretical melting temperatures of the PCMs increase, the experimental melting temperatures of the PCMs are not
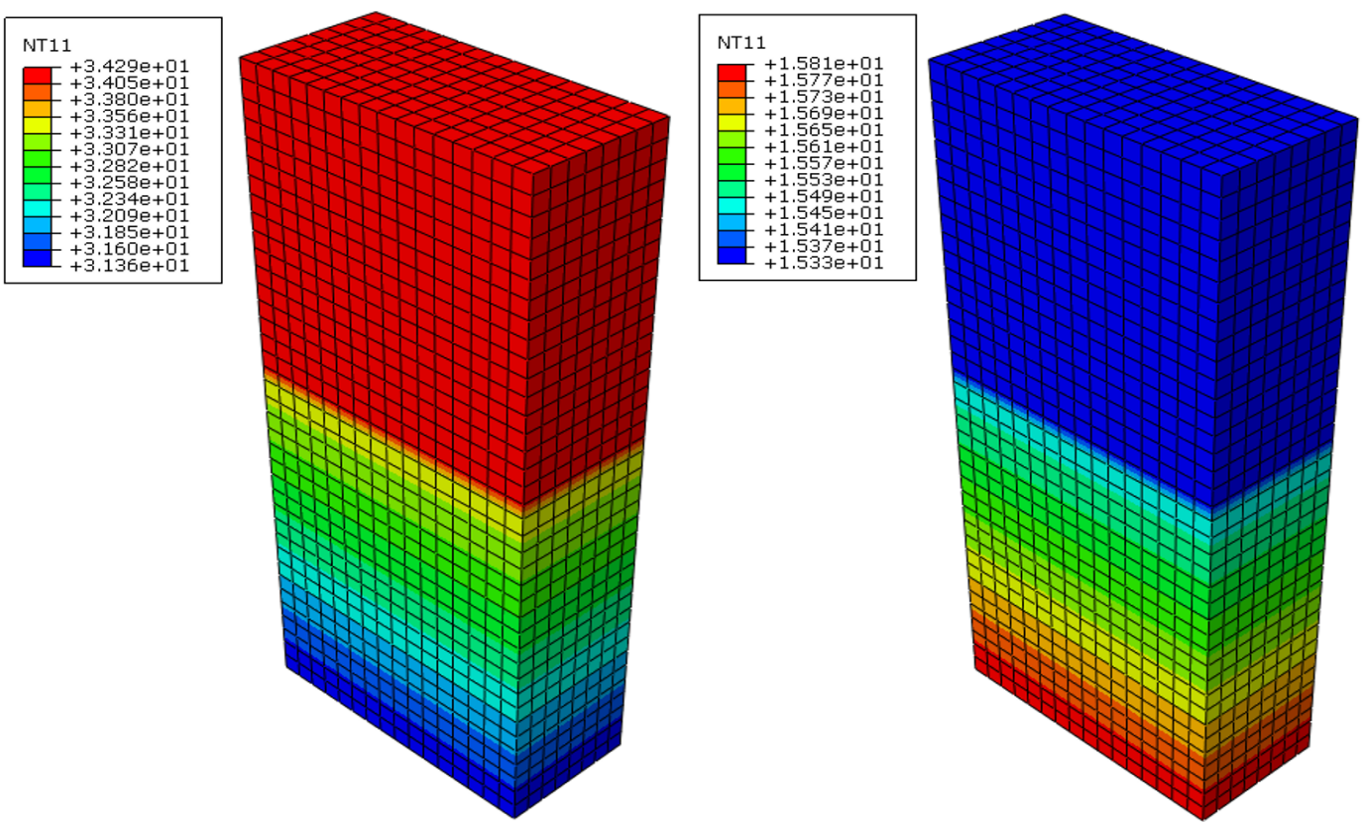

Figure 3.58: FEA results for the building roof incorporating PCM melted at $21^{\circ} \mathrm{C}$ 

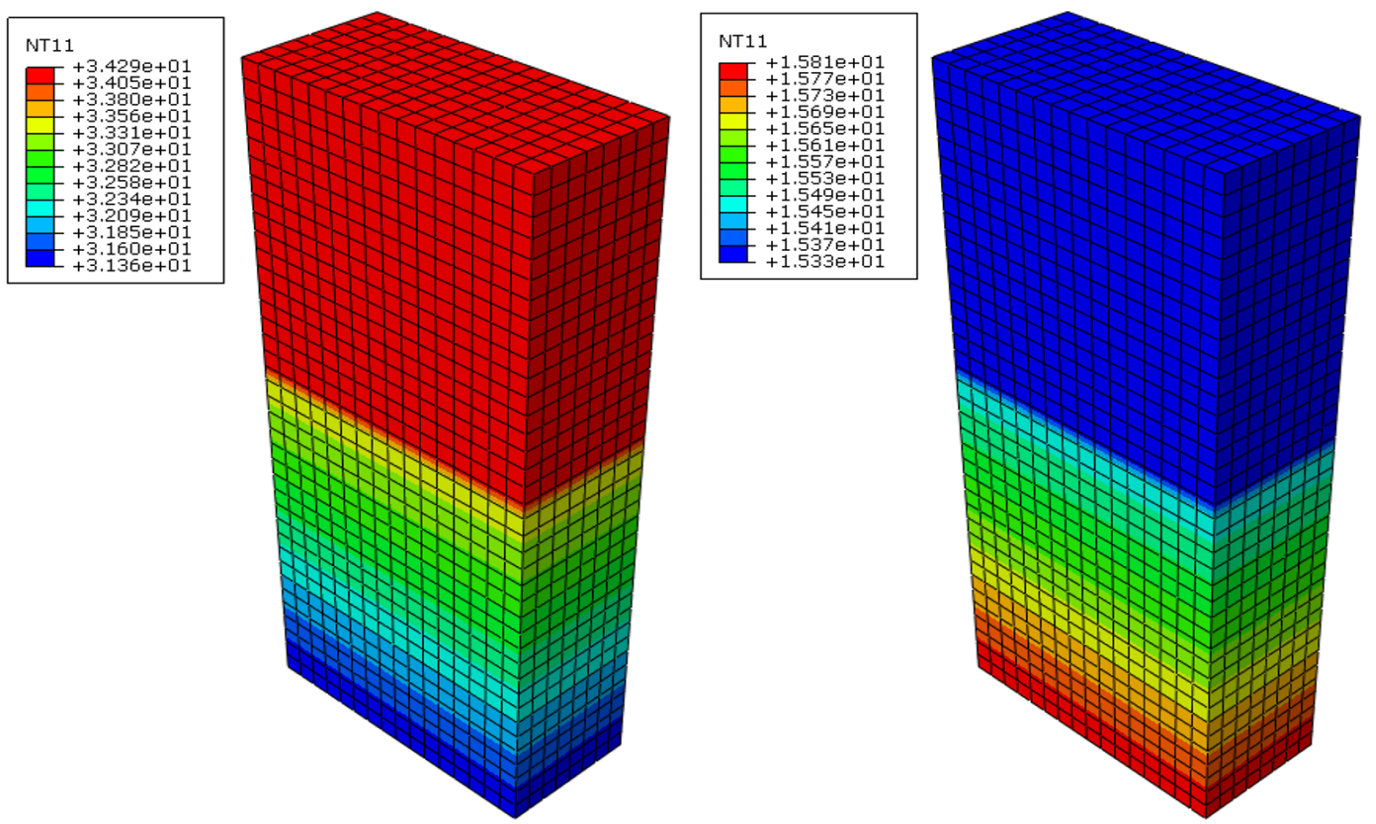

Figure 3.59: FEA results for the building roof incorporating PCM melted at $23^{\circ} \mathrm{C}$
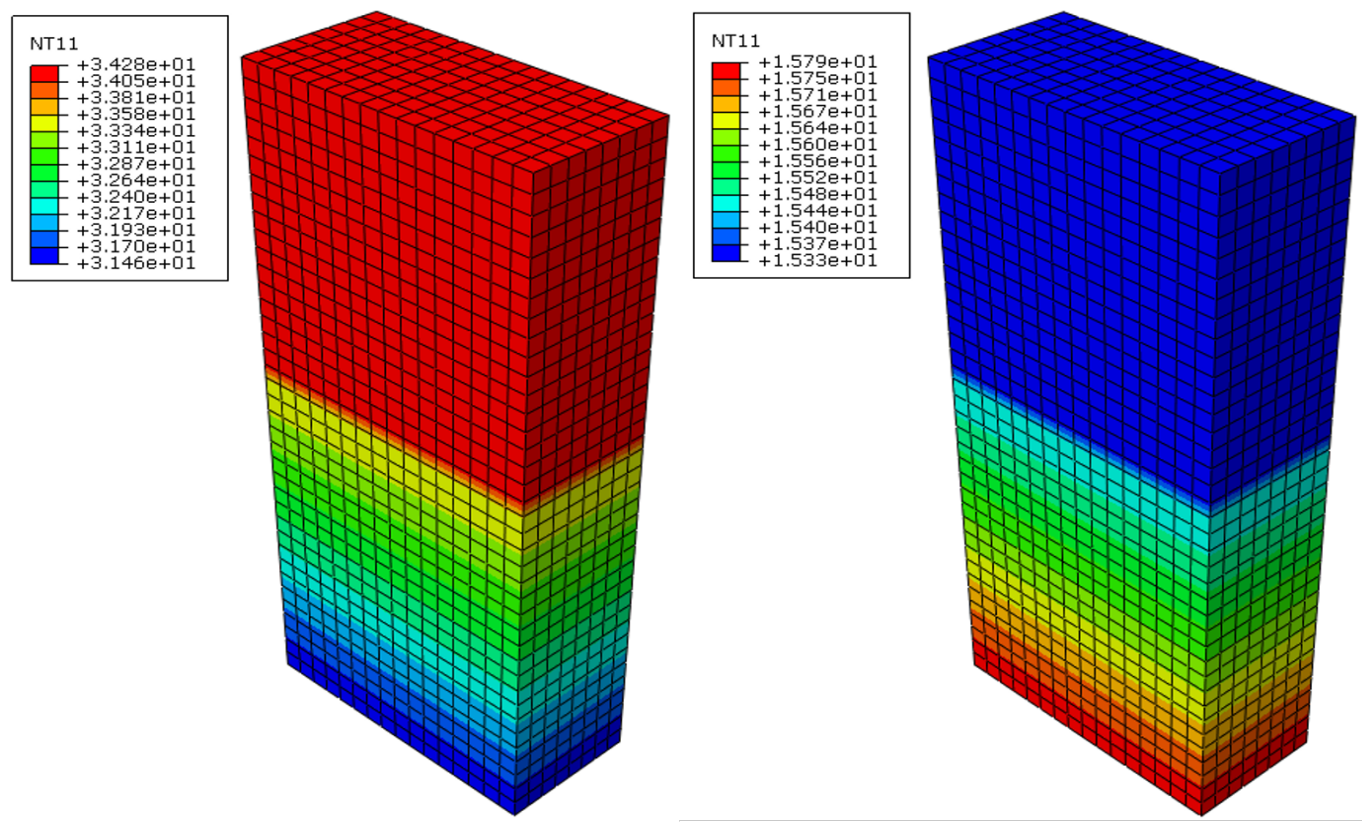

Figure 3.60: FEA results for the building roof incorporating PCM melted at $26^{\circ} \mathrm{C}$ 

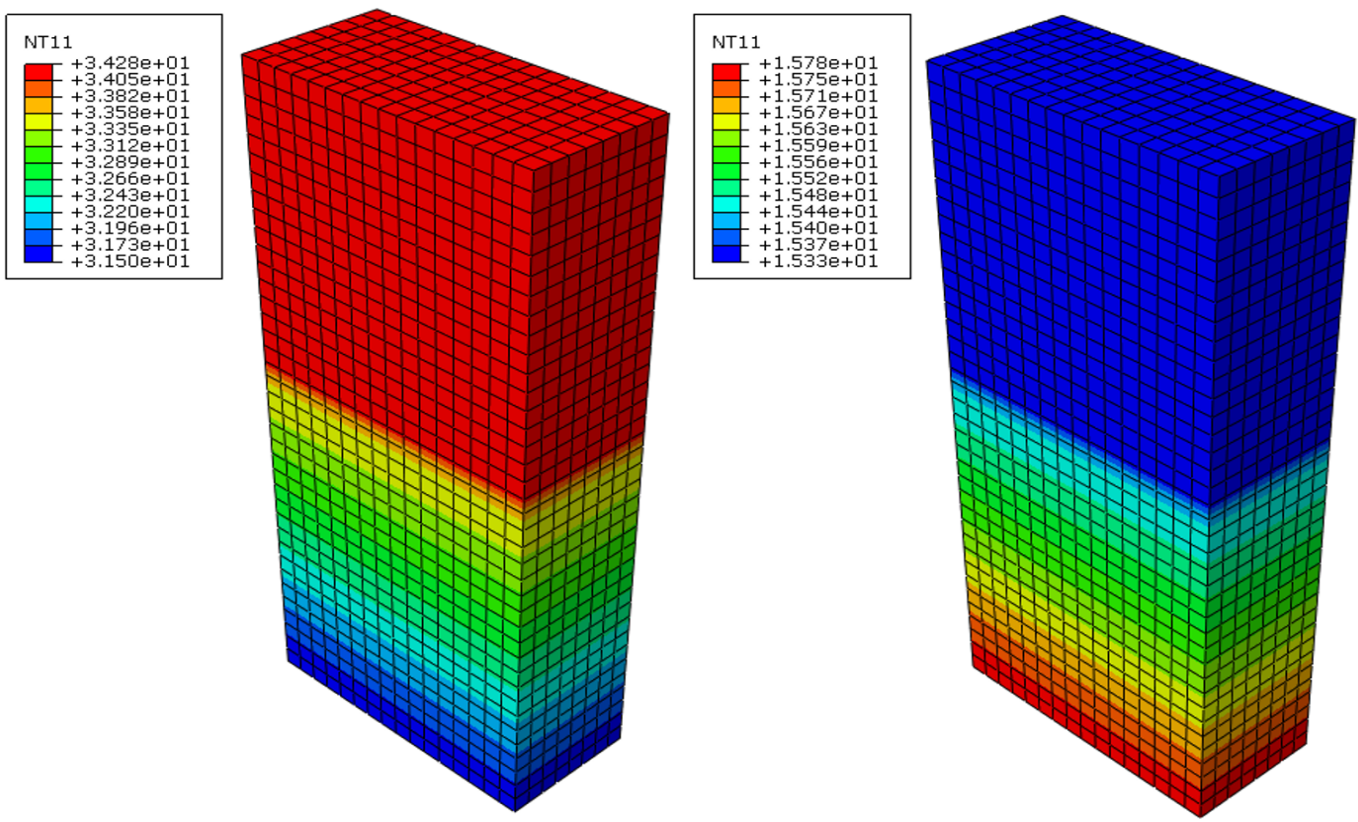

Figure 3.61: FEA results for the building roof incorporating $\mathrm{PCM}$ melted at $30^{\circ} \mathrm{C}$

increased consistently. The phenomenon is speculated to be a phase segregation in the solid state or a mixing problem of the macro-encapsulated PCM samples, so the dynamic DSC results show the margins of error. In this study, because the dynamic DSC results should be applied to the simulations of the roof systems incorporating the PCMs, FEA results also have the margins of error.

Figure 3.62 and Table 3.10 reveal that the indoor temperatures for the four types of the roof systems are reached in about $530 \mathrm{sec}$ to $570 \mathrm{sec}$ during the day and in about $320 \mathrm{sec}$ to $350 \mathrm{sec}$ during the night. Therefore, these results show the roof systems incorporating the PCMs can maintain stable temperatures and reach the steady-state condition in a short time. 


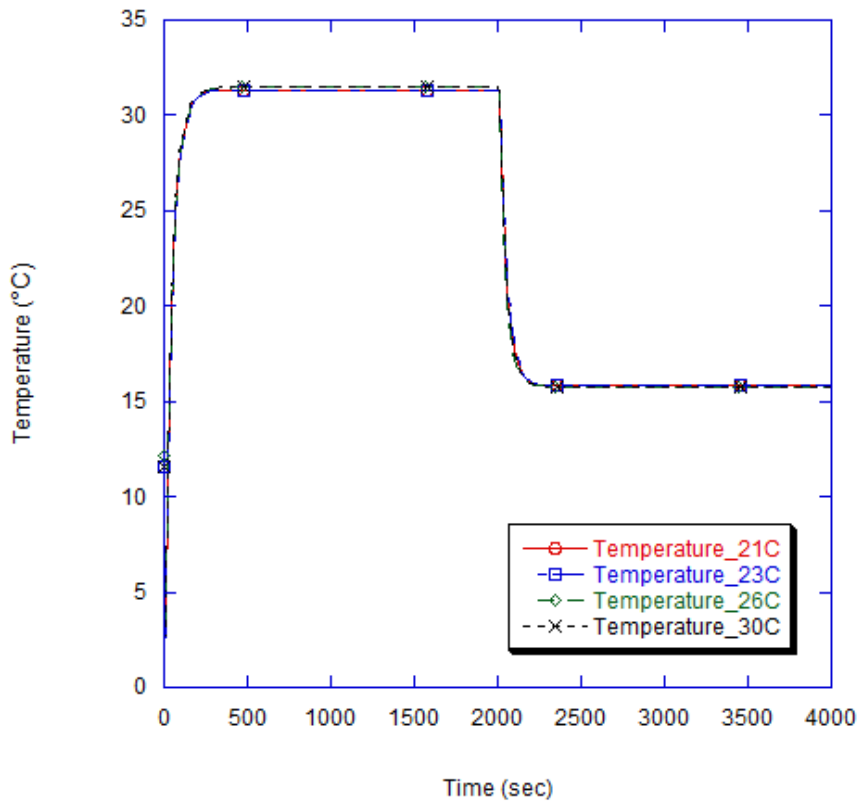

Figure 3.62: Temperature variations as a function of time graphs of the building roofs incorporating PCMs

Table 3.10: Time and temperature until steady-state conditions are achieved

\begin{tabular}{|c|c|c|c|}
\hline PCMs & Step & Time $(\mathrm{sec})$ & Temperature $\left({ }^{\circ} \mathrm{C}\right)$ \\
\hline \multirow{2}{*}{ Specimen 1 } & Daytime & 530 & 31.36 \\
\cline { 2 - 4 } & Night & 320 & 15.81 \\
\hline \multirow{2}{*}{ Specimen 2 } & Daytime & 540 & 31.36 \\
\cline { 2 - 4 } & Night & 330 & 15.81 \\
\hline \multirow{2}{*}{ Specimen 3 } & Daytime & 550 & 31.46 \\
\cline { 2 - 4 } & Night & 320 & 15.79 \\
\hline \multirow{2}{*}{ Specimen 4 } & Daytime & 570 & 31.5 \\
\cline { 2 - 4 } & Night & 350 & 15.78 \\
\hline
\end{tabular}




\section{Chapter 4}

\section{Conclusions}

The objective of this study was to develop a methodology and procedure to accurately determine the characterizations of Phase Change Materials (PCMs) based on salt hydrates. The characterizations of the PCMs were presented by various methods, such as DSC method and heat flow method. In order to determine and assess the TES system of the PCMs over a temperature range, the results, such as the dynam-

ic/isothermal DSC results, the thermal conductivities, and the enthalpy changes of the PCMs, were compared and analyzed. In addition, this study demonstrated how to design roofs with the PCMs. Therefore, this study proposed the developed methodology such as using heat flow method to analyze accurately the characterizations of the PCMs. The developed methodology can be used to analyze accurately the thermal energy storage systems of PCMs. The results obtained by the methodology can then be used to form a database, which can offer important and valuable information for a wide range of TES applications.

In this study, four kinds of Phase Change Materials (PCMs), which melted at 
$21^{\circ} \mathrm{C}, 23^{\circ} \mathrm{C}, 26^{\circ} \mathrm{C}$, and $30^{\circ} \mathrm{C}$, respectively, were selected for measuring the thermophysical properties for Thermal Energy Storage (TES) systems. The measured properties were the temperature properties, the sensible heats, the latent heats, and thermal conductivities of the PCMs. A Differential Scanning Calorimetry (DSC) was used to analyze characteristics of the PCMs and to determine the thermophysical properties, such as the temperature properties, the latent heat of fusions, the specific heat capacities, the enthalpy curves as a function of temperature, and the total TES capacities of the PCMs. In addition, the thermal conductivities, the volumetric heat capacities, and the more precise enthalpy curves than those measured by DSC equipment were measured using heat flow meter equipment.

In order to determine the thermophysical properties of the PCMs, two types of DSC equipment were used, and unexpected phenomena of the thermal characterizations of the PCMs were revealed from the results of dynamic DSC curves by using DSC Q 200 equipment (TA Instruments). The unexpected phenomena included several energy peaks, which happened below the freezing temperature of the PCM during the freezing process. These phenomena were speculated due to the supercooling problem.

From the results of the temperature properties using DSC Q 200 equipment from TA Instruments, a noticeable temperature tendency was not shown, but the experimental melting temperatures of the PCMs exceeded their own melting temperatures, which were known theoretically. From the result of the temperature properties using DSC STA 8000 equipment (Perkin Elmer Company), as the melting temperatures of 
the PCMs were increased, the PCMs showed to have low enthalpies and high heat capacities.

In this study, the temperature properties and the enthalpies of the original PCMs and the PCMs made into the liquid state were compared. In terms of the PCM melted at $21^{\circ} \mathrm{C}$ for the endothermic reaction (both results from Q 200 equipment and STA 8000 equipment), the temperature properties and enthalpies of the original PCM and the PCM made into the liquid state indicated similar results, respectively. However, for the exothermic reaction, the original PCM had a higher freezing temperature and the enthalpy than those of the PCM made into the liquid state. It was speculated that phase segregation happened during the solidification at room temperature for the original PCM. Also, the PCM made into the liquid state seemed to solve the problem of phase segregation during the melting process. Also, in the case of the PCM melted at $23^{\circ} \mathrm{C}$ (results from DSC Q 200 equipment), the temperature properties for the endothermic reaction were similar, but for the exothermic reaction the PCM made into the liquid state indicated to have two peaks. The primary peak under the exothermic curve seemed to be an exothermic change of phase of the PCM as solidification, and the secondary peak was the freezing of the solution of salt hydrate present in the PCM sample.

In terms of the PCM melted at $23^{\circ} \mathrm{C}$ (results from DSC STA 8000 equipment), the temperature properties and the enthalpies of the original PCM, the PCM made into the liquid state, and the PCM in the liquid state were compared. The PCM made 
into the liquid state and the PCM in the liquid state showed similar results. These two PCMs had a larger temperature range and a higher heat flow than those of the original PCM. It was assumed that there was a mixing problem or phase separation could happen during the solidification of the original PCM.

To evaluate the total TES capacity, the total stored energy considered not only the latent heat but also the sensible heat contributions, such as the specific heat capacities of the solid and the liquid phase regions of the PCMs. According to the enthalpy curves, the energy was increased with the temperature increase during the phase change. It was speculated that the energy was applied to loosen or break apart the molecular or atomic bond structures of the PCMs by the latent heat. This meant that energy was not used to increase the temperature, but most of the energy was being absorbed into the molecular or atomic bond structures of the PCMs. In this study, the sharp peak (the heat flow peak) happened at a narrow temperature range. Because the PCMs released much more energy than they absorbed during the phase change, the high sensible heats in the exothermic reaction were recorded. Therefore, in this study, much more energy was calculated than the actual energy released. This was because supercooling happened during the solidification, so this result was not exactly correct.

This study experimentally investigated the thermal conductivities of the PCMs thorough heat flow meter equipment. The thermal conductivities of the PCMs were evaluated under a fully frozen and fully melted state in the thermal equilibrium 
condition, which was already measured using the isothermal DSC mode. As a result, the thermal conductivities of the PCMs in the solid state were higher than those of the PCMs in the liquid state. This phenomenon happened because of the effect of the microstructure changing from the orderly solid structure in the solid state to the disorderly liquid structure in the liquid state.

In order to more precisely analyze the total TES capacity, heat flow meter equipment was used in this study. The volumetric heat capacity at a constant pressure and the enthalpy curve as a function of temperature were examined. The PCMs melted at $26^{\circ} \mathrm{C}$ and $30^{\circ} \mathrm{C}$, respectivley, and they indicated a shift toward high temperatures, and enthalpy curves broadened in the results of the volumetric heat capacities. This was the reason why the thermal gradient was increased within the sample. The total stored energy values for TES systems measured from heat flow meter equipment were presented 2.5 times smaller than those values measured by DSC equipment with the dynamic measurement method. However, the results from the DSC method were often uncertain about the enthalpy-temperature relationships of PCMs. The enthalpy curves measured with the DSC method could be shifted to higher/lower temperatures. Shifting the temperatures depended on the heat capacity, the thermal conductivity, the sample size, and the heating/cooling rates. These four factors led to a temperature gradient in the PCM and a heat flux signal shifting temperature. Therefore, due to these heat transfer limitations, the enthalpy-temperature curves measured by DSC equipment were not consistent and indicated uncertain results. 
In this study, the numerical Finite Element Analysis (FEA) was considered to investigate potential for energy savings with incorporating the PCMs in a building. In order to assess potential for energy savings, the thermal performances of the buildings applying the PCM plates were simulated by using ABAQUS. First of all, verification studies were designed and conducted to check the accuracy of the result obtained using ABAQUS. Three conditions with the various initial and boundary conditions were considered for verification studies. In the verification studies, the analytic results and the FEA results were compared with the various initial and boundary conditions in an $\mathrm{Al}$ structure. For the first verification study, the initial condition and the boundary conditions, such as the temperature boundary condition on the indoor and the outdoor and the convection boundary condition on only the outdoor, were applied into an $\mathrm{Al}$ sample. For the second and third verification studies, no initial condition was applied, but the convection boundary condition on the outdoor was applied. The temperature boundary conditions were considered as $T_{1}=0$ and $T_{2}=35$ for the second study and $T_{1}=0$ and $T_{2}=0$ for the third study.

The FEA results showed the temperature curves as a function of time as $\mathrm{x}$ is $0.025 \mathrm{~m}$ and $0.2 \mathrm{~m}$, respectively. The first and second verification studies reached the steady-state conditions as shown in both of the FEA and analytical results, but in the case of the third verification study, not only the analytic result but also the FEA result did not achieve steady-state conditions.

In this study, the numerical FEA was conducted to evaluate the thermal perfor- 
mance of a roof with the PCM plate with various factors, such as the specific heat capacity, the heat of fusion, the phase change temperature, and the thermal conductivity of the PCM. The Finite Element Analysis (FEA) corresponded to a transient heat transfer analysis with the initial and boundary conditions. The roof structure incorporating the PCM consisted of a three-layer assembly, such as the roof, the $\mathrm{PCM}$, and the slab. The initial conditions were $35^{\circ} \mathrm{C}$ on the outdoor and $25^{\circ} \mathrm{C}$ on the indoor at $\mathrm{t}=0$ sec. All FEA results were run for a total of 4000 seconds for two steps (the daytime and the nighttime). The results, such as the temperature variations from the outdoor to the indoor measured under step 1 condition (the daytime), were observed that the outdoor temperatures were higher than the indoor temperatures. This was due to the low thermal conductivity of the PCM in the liquid state. The low thermal conductivity of the PCM reduced the heat transmission to the indoor, which in turn increased the outdoor temperature. During the nighttime, the results showed that the outdoor and indoor temperatures were almost the same. This was because the heat transmission speed of the PCM in the solid state was faster than that of the $\mathrm{PCM}$ in the liquid state. Also, as shown in the temperature curves as a function of time, a noticeable tendency between the PCMs was not discovered. The reason was speculated due to the use of the dynamic DSC results, which had margins of error. In the dynamic DSC result, the experimental melting temperatures of the PCMs were not increased consistently due to phase segregation in the solid state or a mixing problem of the macro-encapsulated salt hydrate PCM samples, so the dy- 
namic DSC results had margins of error. In FEA results, because the dynamic DSC results should be applied to the FEA, the FEA result also contained margins of error. 


\section{Bibliography}

Infinity R Corporation, 2017a. URL http://www.insolcorp.com.

Archtecture and Design Powered by Infolink, $2015 . \quad$ URL http://www . architectureanddesign.com.au/features/features-articles.

Dupont. Energy saving thermal mass systems. 2012.

K. Lin, Y. Zhang, H. Di, and R. Yang. Study of an electrical heating system with ductless air supply and shape stabilized pcm for thermal storage. Energy Conversion and Management, 48:2016-2024, 2007.

NetGreen Solar Ltd. 2017. URL http://www .netgreensolar.com/page2.html.

X. Wang and J. Niu. Performance of cooled ceiling operating with mpcm slurry. Energy Conversion and Management, 50:583-591, 2009.

J. R. Turnpenny, D. W. Etheridge, and D. A. Reay. Novel ventilation cooling system for reducing air conditioning in buildings: Part 1: Testing and theoretical modelling. Applied Thermal Engineering, 20:1019-1037, 2000. 
P. Moreno, A. Castell, C. Sol' ${ }^{\prime}$, G. Zsembinszki, and L. F. Cabeza. Pcm thermal energy storage tanks in heat pump system for space cooling. Energy and Buildings, 82:399-405, 2014.

L. G. Socaciu. Thermal energy storage with phase change material. Leonardo Electronic Journal of Practices and Technologiest, 20:75-78, 2012a.

A. Pasupathy, L. Athanasius, R. Velraj, and R. V. Seeniraj. Experimental investigation and numerical simulation analysis on the thermal performance of a building roof incorporating phase change material for thermal management. Applied Thermal Engineering, 28:556-565, 2008.

K. Biswas, S. Kriner, W. Miller, and G. Y. Manlove. A study of the energy-saving potential of metal roofs incorporating dynamic insultion systems. Conference on Thermal Performance of the Exterior Envelopes of Whole Buildings XII, 2013.

J. Prakash, H. P. Garg, and G. Datta. A solar water heater with a built-in latent heat storage. Energy Conversion and Management, 25:51-56, 1985.

A. A. Ghoneim. Comparison of theoretical models of phase change and sensible heat storage for air and water-based solar heating systems. Solar Energy, 42:209-220, 1989.

J. J. Jurinak and S. I. Abdel-Khalik. On the performance of air-based solar heating systems utilizing phase change energy storage. Energy, 4:503-522, 1979. 
G. Zhou, Y. Zhang, Q. Zhang, K. Lin, and H. Di. Performance of a hybrid heating system with thermal storage using shape-stabilized phase change material plated. Appled Energy, 84:1068-1077, 2007.

H. Tan, Y. Li, H. Tuo, M. Zhou, and B. Tian. Experimental study on liquid/solid phase change for cold energy storage of liquefied natural gas (lng) refrigerated vehicle. Energy, 35:1927-1935, 2010.

S. Mondal. Phase change materials for smart textiles-an overview. Applied Thermal Engineering, 28:1536-1550, 2008.

R. Kandasamy, X. Q. Wang, and A. S. Mujumdar. Transient cooling of electronics using phase change material (pcm)-based heat sinks. Applied Thermal Engineering, 28:1047-1057, 2008

H. Cui, X. Yuan, and X. Hou. Thermal performance analysis for a heat receiver using multiple phase change materials. Applied Thermal Engineering, 23:23532361, 2003.

M. Reading and D. Q. Craig. Principles of differential scanning calorimetryt. Thermal analysis of pharmaceuticals, 1:1-22, 2006.

E. Günther, S. Hiebler, and R. Redlich. Enthalpy of phase change materials as a function of temperature: Required accuracy and suitable measurement methods. International Journal of Thermophysics, 30:1257-1269, 2009. 
Infinity R Corporation, 2017b. URL http://www. phasechangetechnologies.com/.

The U.S. Energy Information Administration. Annual energy outlook. 2016.

The United Kingdom's Government Department. 2016. URL https://www.gov.uk/government/statistical-data-sets/.

A. H. Abedin and M. A. Rosen. A critical review of thermochemical energy storage systems. The Open Renewable Energy Journal, 4:42-46, 2011.

B. Zalba, J. M. Marín, L. F. Cabeza, and H. Mehling. Review on thermal energy storage with phase change: Materials, heat transfer analysis and applications. Applied Thermal Engineering, 23:251-283, 2003.

K. Pielichowska and K. Pielichowski. Phase change materials for thermal energy storage. Progress in Materials Science, 65:67-123, 2014.

A. Sharma, V. V. Tyagi, C. R. Chen, and D. Buddhi. Review on thermal energy storage with phase change materials and application. Renewable and Sustainable Energy Reviews, 13:318-345, 2009.

Y. B. Tao, C. H. Lin, and Y. L. He. Preparation and thermal properties characterization of carbonate salt/carbon nanomaterial composite phase change material. Energy Conversion and Management, 97:103-110, 2015. 
D. W. Hawer, D. Feldman, and D. Banu. Latent heat storage in building materials. Energy and Buildings, 20:77-86, 1993.

A. M. Khudhair and M. M. Farid. A review on energy conservation in building applications with thermal storage by latent heat using phase change materials. Energy Conservation and Management, 45:263-275, 2004.

V. V. Tyagi and D. Buddhi. Pcm thermal storage in buildings: A state of art. Renewable and Sustainable Energy Reviews, 11:1146-1166, 2007a.

M. M. Kenisarin. High temperature phase change materials for thermal energy storage. Renewable and Sustainable Energy Reviews, 14:955-970, 2010.

E. Subramanian. Integrating phase change materials in building materials: Experimentation, characterization and numerical simulation. 2011.

D. Banu, D. Feldman, F. Haghighat, J. Paris, and D. Hawes. Energy storing wallboard: Flammability tests. Journal of Materials in Civil Engineering, 10:98-105, 1998.

S. Furbo. Heat storage units using a salt hydrate as storage medium based on the extra water principle. 1983.

H. Y. Chan, S. B. Riffat, and J. Zhu. Review of passive solar heating and cooling technologies. Renewable and Sustainable Energy Reviews, 14:781-789, 2010. 
V. V. Tyagi and D. Buddhi. Pcm thermal storage in buildings: A state of art. Renewable and Sustainable Energy Reviews, 11:1146-1166, 2007b.

Microtek. 2017. URL http://www.microteklabs.com.

S. Cao. State of the art thermal energy storage solutions for high performance buildings. 2010 .

Dupont. 2017. URL http://www.dupont.co.uk/.

A. A. Ghoneim, S. A. Klein, and J. A. Duffie. Analysis of collector-storage building walls using phase change materials. Solar Energy, 47:237-242, 1991.

C. Benard, Y. Body, and A. Zanoli. Experimental comparison of latent and sensible heat thermal walls. Solar Energy, 34:475-487, 1985.

C. J. Swet. Phase change storage in passive solar architecture. Proc. Annu. Meet. Am. Sect. Int. Sol. Energy Soc, 5.1:282-286, 1980.

S. Chandra, R. Kumar, S. Kaushik, and S. Kaul. Thermal performance of a non air conditioned building with pccm thermal storage wall. Energy Conversion and Management, 25:15-20, 1985.

F. Kuznik and J. Virgone. Experimental assessment of a phase change material for wall building use. Applied Energy, 86:2038-2046, 2009. 
I. O. Salyer and A. K. Sircar. Phase change materials for heating and cooling of residential buildings and other applications. Energy Conversion Engineering Conference, 4:236-241, 1990.

D. Feldman, D. Banu, D. Hawes, and E. Ghanbari. Obtaining an energy storing building material by direct incorporation of an organic phase change material in gypsum wallboard. Solar Energy Materials, 22:231-242, 1991.

D. A. Neeper. Thermal dynamics of wallboard with latent heat storage. Solar Energy, 68:393-403, 2000.

M. Kalousck and J. Hirs. Simulation of the summer indoor thermal comfort by using wallboard with phase change material. Eurosun, Bolobna, 19:263-270, 2002.

M. Ahmad, A. Bontemps, H. Sall'e, and D. Quenard. Thermal testing and numerical simulation of a prototype cell using light wallboards coupling vacuum isolation panels and phase change material. Energy and Buildings, 38:673-681, 2006.

H. Liu and H. B. Awbi. Performance of phase change material boards under natural convection. Building and Environment, 44:1788-1793, 2009.

P. Schossig, H. M. Henning, S. Gschwander, and T. Haussmann. Micro encapsulated phase change materials integrated into construction materials. Solar Energy Materials and Solar Cells, 89:297-306, 2005. 
A. K. Athienitis and Y. Chen. The effect of solar radiation on dynamic thermal performance of floor heating systems. Solar Energy, 69:229-237, 2000.

K. Lin, Y. Zhang, X. Xu, H. Di, R. Yang, and P. Qin. Modeling and simulation of under-floor electric heating systeme with shape stabilized pcm plates. Building and Environment, 39:1427-1434, 2004.

N. K. Bansal and D. Buddhi. An analytical study of a latent heat storage system in a cylinder. Energy Conversion and Management, 33:235-242, 1992.

G. Bajnǿczy, E. G. P’lffy, E. Pr’postffy, and A. Z'øld. Heat storage by two-grade phase change material. Periodica Polytechnica. Chemical Engineering, 43:137, 1999.

K. Kaygusuz. Experimental and theoretical investigation of latent heat storage for water based solar heating systems. Energy Conversion and Management, 36:315323, 1995 .

Y. Rabin, I. Bar-Niv, E. Korin, and B. Mikic. Integrated solar collector storage system based on a saly-hydrate phase change material. Solar Energy, 55:435-444, 1995.

E. B. S. Mettawee and G. M. Assassa. Experimental study of a compact pcm solar collector. Energy, 31:2958-2968, 2006. 
D. J. Morrison and S. I. Abdel-Khalik. Effects of phase change energy storage on the performance of air-based and liquid-based solar heating systems. Solar Energy, 20: $57-67,1978$.

A. A. Ghoneim and S. A. Klein. The effect of phase change material properties on the performance of solar air-based heating systems. Solar Energy, 42:441-447, 1989.

S. O. Enibe. Performance of a natural circulation solarair heating system with phase change material energy storage. Reneable Energy, 27:69-86, 2002.

E. Orǿ, A. De Gracia, A. Castell, M. M. Farid, and L. F. Cabeza. Review on phase change materials (pcms) for cold thermal energy storage applications. Appled Energy, 99:513-533, 2012.

Sofrigam. 2017. URL http://www.sofrigam.com.

PCM Thermal Solution. 2017. URL http://www.pcm-solutions.com./.

PCM Products. 2017. URL http://www.pcmproducts.net./.

Rubitherm. 2017. URL https://www.rubitherm.eu/en/applications.html.

L. Melone, L. Altomare, A. Cigada, and L. De Nardo. Phase change material cellulosic composites for the cold storage of perishable products: From material preparation to computational evaluation. Appled Energy, 89:339-346, 2012. 
K. Azzouz, D. Leducq, and D. Gobin. Performance enhancement of a household refrigerators by addition of latent heat storage. International Journal of Refrigeration, 31:892-901, 2008.

K. Azzouz, D. Leducq, and D. Gobin. Enhancing the performance of household refrigerators with latent heat storage: An experimental investigation. International Journal of Refrigeration, 32:1634-1644, 2009.

B. Gin, M. M. Farid, and P. K. Bansal. Effect of door opening and defrost cycle on a freezer with phase change panels. Energy Conversion and Management, 51: 2698-2706, 2010.

T. L. Vigo and C. E. Frost. Temperature-sensitive hollow fibers containing phase change materials salts. Textile Research Journal, 52:633-637, 1982.

T. L. Vigo and C. M. Frost. Temperature adaptable hollow fibers containing polyethylene glycols. Journal of Coated Fabrics, 12:243-252, 1983.

T. L. Vigo. Intelligent fibrous substrates with thermal and dimensional memories. Polymers for Advanced Technologies, 8:281-288, 1997.

Y. Shin, D. I. Yoo, and K. Son. Development of thermoregulating textile materials with microencapsulated phase change materials $(\mathrm{pcm})$. ii. preparation and application of pcm microcapsules. Journal of Applied Polymer Science, 96:2005-2010, 2005a. 
Y. Shin, D. I. Yoo, and K. Son. Development of thermoregulating textile materials with microencapsulated phase change materials ( $\mathrm{pcm}$ ). iv. performance properties and hnd of fabrics treated with pcm microcapsules. Journal of Applied Polymer Science, 97:910-915, 2005b.

K. Koo, Y. Park, J. Choe, and E. Kim. The application of microencapsulated phasechange materials to nylon fabric using direct dual coating method. Journal of Applied Polymer Science, 108:2337-2344, 2008.

C. Chen, L. Wang, and Y. Huang. Electrospinning of thermo-regulating ultrafine fibers based on polyethylene glycol/cellulose acetate composite. Polymer, 48:52025207, 2007.

E. Onder, N. Sarier, and E. Cimen. Encapsulation of phase change materials by complex coacervation to improve thermal performances of woven fabricse. Thermochimica Acta, 467:63-72, 2008.

M. Rothmaier, M. Weder, A. Meyer-Heim, and J. Kesselring. Design and performance of personal cooling garments based on three-layer laminates. Medical and Biological Engineering and Computing, 46:825-832, 2008.

S. X. Wang, Y. Li, H. Tokura, and Q. W. Song. Effect of phase-change material on energy consumption of intelligent thermal-protective clothing. Polymer Testing, 25:580-587, 2006. 
X. Zhang. Heat-Storage and Thermo-Regulated Textiles and Clothing. Woodhead Publishing Limited Cambridge England, 2001.

D. Mondieig, F. Rajabalee, A. Laprie, H. A. Oonk, T. Calvet, and M. A. CuevasDiarte. Protection of temperature sensitive biomedical products using molecular alloys as phase change material. Transfusion and Apheresis Science, 28:143-148, 2003

Y. Lv, Y. Zou, and L. Yang. Feasibility study for thermal protection by microencapsulated phase change micro/nanoparticles during cryosurgery. Chemical Engineering Science, 66:3491-3953, 2011.

C. Wang, M. Hossain, L. Ma, Z. Ma, J. J. Hickman, and M. Su. Highly sensitive thermal detection of thrombin using aptamer-functionalized phase change nanoparticles. Biosensors and Bioelectronics, 26:437-443, 2010a.

A. Alrashdan, A. T. Mayyas, and S. Al-Hallaj. Thermo-mechanical behaviors of the expanded graphite-phase change material matrix used for thermal management of li-ion battery packs. Journal of Materials Processing Technology, 210:174-179, 2010 .

R. Kandasamy, X. Q. Wang, and A. S. Mujumda. Application of phase change materials in thermal management of electronics. Applied Thermal Engineering, 27: $2822-2832,2007$. 
H. Yin, X. Gao, J. Ding, and Z. Zhang. Experimental research on heat transfer mechanism of heat sink with composite phase change materials. Energy Conversion and Management, 49:1740-1746, 2008.

H. Yin, X. Gao, J. Ding, Z. Zhang, and Y. Fang. Thermal management of electronic components with thermal adaptation composite material. Applied Energy, 87:37843791, 2010.

S. Krishnan, S. V. Garimella, and S. S. Kang. A novel hybrid heat sink using phase change materials for transient thermal management of electronics. IEEE Transactions on Components and Packaging Technologies, 28:281-289, 2005.

F. L. Tan and C. P. Tso. Cooling of mobile electronic devices using phase change materials. Applied Thermal Engineering, 24:159-169, 2004.

S. D. Burch, M. A. Keyser, C. P. Colucci, T. F. Potter, D. K. Benson, and J. P. Biel. Applications and benefits of catalytic converter thermal management. 1996.

S. D. Burch, T. F. Potter, M. A. Keyser, M. J. Brady, and K. F. Michaels. Reducing cold-start emissions by catalytic converter thermal management. 1995 .

K. B. Kim, K. W. Choi, Y. J. Kim, K. H. Lee, and K. S. Lee. Feasibility study on a novel cooling technique using a phase change material in an automotive engine. Energy, 35:478-484, 2010. 
B. Yimer and M. Adami. Parametric study of phase change thermal energy storage systems for space application. Energy Conversion and Management, 38:253-262, 1997.

H. Cui, Y. Xing, Y. Guo, Z. Wang, H. Cui, and X. Yuan. Numerical simulation and experiment investigation on unit heat exchange tube for solar heat receiver. Solar Energy, 82:1229-1234, 2008.

W. F. Wu, N. Liu, W. L. Cheng, and Y. Liu. Study on the effect of shape-stabilized phase change materials on spacecraft thermal control in extreme thermal environment. Energy Conversion and Management, 69:174-180, 2013.

D. Q. Craig and M. Reading. Thermal analysis of pharmaceuticals. 2006.

$\mathrm{X}$. Jin, X. Xu, X. Zhang, and Y. Yin. Determination of the pcm melting temperature range using dsc. Thermochimica Acta, 595:17-21, 2014.

Particle Analytical. 2017. URL http://particle.dk/.

J. D. Menczel, L. Judovits, R. B. Prime, H. E. Bair, M. Reading, and S. Swier. Differential scanning calorimetry (dsc), in thermal analysis of polymers: Fundamentals and applications. pages 7-239, 2009.

R. M. R. Saeed. Thermal characterization of phase change materials for thermal energy storage. pages 1-121, 2016. 
J. M. Marin, B. Zalba, L. F. Cabeza, and H. Mehling. Determination of enthalpy-temperature curves of phase change materials with the temperature-history method: Improvement to temperature dependent properties. Measurement science and Technology, 14:184-189, 2003.

TA Instruments. Fox instruments manual. pages 1-29, 2016.

Hani A. El Husayni. Heat flow meter instruments. pages 1-21, 1999.

A. Tleoubaev. Measurements of the volumetric specific heat $\mathrm{cp}$ and enthalpy of the phase-change materials (pcm) using the fox heat flow meter instrumentss. pages $1-5,2007$.

A. Tleoubaev and A. Brzezinski. Thermal diffusivity and volumetric specific heat measurements using heat flow meter instruments. Thermal Conductivity, 29:1-9, 2007.

J. L. McNaughton and C. T. Mortimer. Differential scanning calorimetry. pages 1-44, 1975.

M. Koschenz and B. Lehmann. Development of a thermally activated ceiling panel with pcm for application in lightweight and retrofitted buildings. Energy and Buildings, 36:567-578, 2004.

A. Elgafy and K. Lafdi. Effect of carbon nanofiber additives on thermal behavior of phase change materials. Carbon, 43:3067-3074, 2005. 
L. Hembade, N. Neithalath, and S. D. Rajan. Understanding the energy implications of phase-change materials in concrete walls through finite-element analysis. Journal of Energy Engineering, 140:04013009, 2013.

L. G. Socaciu. Thermal energy storage with phase change material. Leonardo Electronic Journal of Practices and Technologies, 20:75-98, 2012b.

ASTM International. Standard test method for using a heat flow meter apparatus for measuring thermal storage properties of phase change materials and products. pages $1-17,2016$.

E. Or'ø, A. De Gracia, A. Castell, M. M. Farid, and L. F. Cabeza. Review on phase change materials (pcms) for cold thermal energy storage applications. Applied Energy, 99:513-533, 2012.

R. J. Warzoha, R. M. Weigand, and A. S. Fleischer. Temperature-dependent thermal properties of a paraffin phase change material embedded with herringbone style graphite nanofibers. Applied Energy, 137:716-725, 2015.

M. Mehrali, S. T. Latibari, M. Mehrali, H. S. C. Metselaar, and M. Silakhori. Shapestabilized phase change materials with high thermal conductivity based on paraffin/graphene oxide composite. Energy Conversion and Management, 67:275-282, 2013 
J. Wang, H. Xie, Z. Xin, Y. Li, and L. Chen. Enhancing thermal conductivity of palmitic acid based phase change materials with carbon nanotubes as fillers. Solar Energy, 84:339-344, 2010b.

S. Drissi, A. Eddhahak ans S. Car', and J. Nejj. Thermal analysis by dsc of phase change materials, study of the damage effect. Journal of Building Engineering, 1: 13-19, 2015.

C. Castellǿn, E. G’`nther, H. Mehling, S. Hiebler, and L. F. Cabeza. Determination of the enthalpy of pcm as a function of temperature using a heat-flux dsc - a study of different measurement procedures and their accuracy. International Journal of Energy Research, 32:1258-1265, 2008. 